\title{
Scoping Workshop on Research for Enhancing Survival of Threatened, Endangered, and Sensitive (TES) Plant Species on Military Lands
}

edited by

Dr. Alison Hill and Patricia M. Kirby

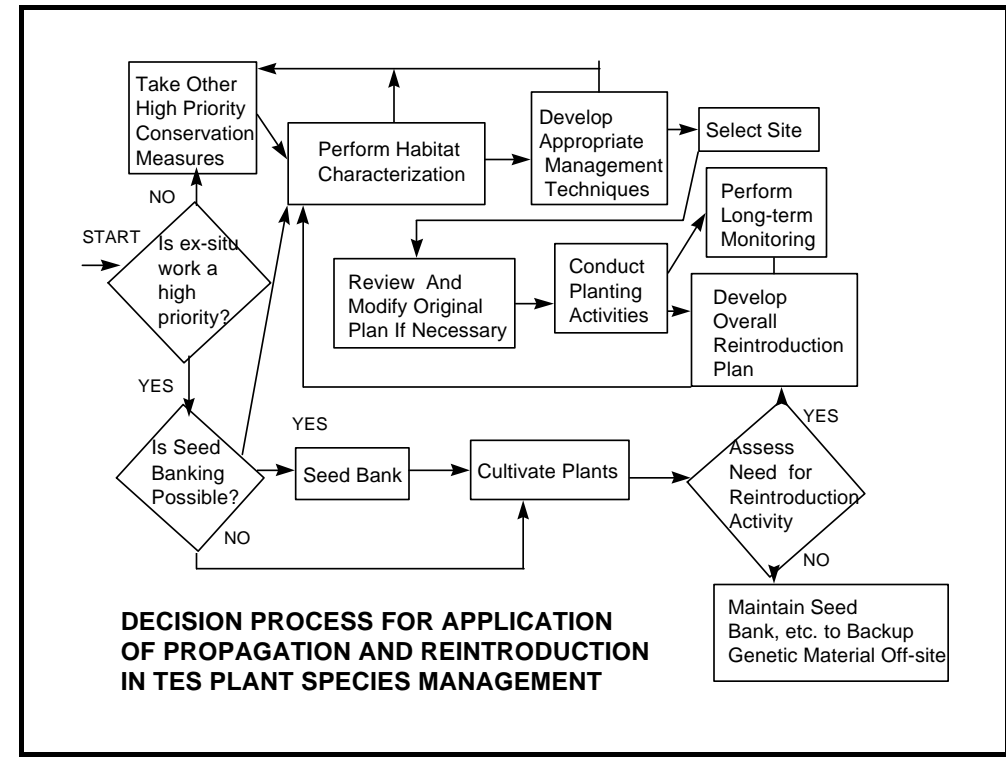

This report provides the proceedings of the scoping workshop held 29 November - 2 December 1994 in Albuquerque, NM. The workshop was co-sponsored by the U.S. Army Construction Engineering Research Laboratories (USACERL) and the U.S. Fish and Wildlife Service (USFWS), Region 2. Workshop participants included TES researchers, regulators, and managers from numerous military services and organizations, the U.S. Fish and Wildlife Service, other Federal agencies, private sector organizations, and universities.
The workshop addressed propagation and translocation (P\&T) of TES plant species on military lands within the broad context of management options for enhancing the survival of TES plants. Workshop participants explored issues associated with P\&T and discussed a wide range of military needs for management activities and research to enhance survival of TES plants.

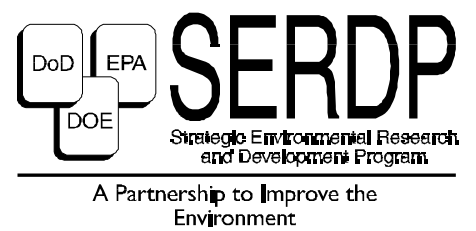


SF 298 


\section{Foreword}

These proceedings were prepared with funding by the Strategic Environmental Research and Development Program (SERDP) under the Threatened and Endangered Species (TES) Program, Thrust Area: Enhancing the Recovery of TES Plants, Work I tem CS-507. Public Law 101-510 established SERDP as a multiagency program to identify, develop, and demonstrate technologies in the areas of pollution prevention and cleanup, energy and resource conservation, and global environmental change. SERDP responds to the environmental requirements of the Department of Defense (DOD) and is undertaken in cooperation with DOD, the Department of Energy, and the Environmental Protection Agency. Dr. Femi Ayorinde is the technical monitor; Bradley P. Smith is Executive Director, SERDP.

The work was performed by the Natural Resource Assessment and Management Division (LL-N) of the Land Management Laboratory (LL), U.S. Army Construction Engineering Research Laboratories (USACERL). The USACERL principal investigator was Dr. Alison Hill. The work was performed on contract by Stephanie Weisband and Gordon Venable, Advanced Sciences I ncorporated (ASI ), 1525 Wilson Blvd., Suite 1200, Arlington, VA 22209. Dr. William D. Severinghaus is Operations Chief, CECER-LL; and William D. Goran is the responsible Technical Director, CECER-LL. The USACERL technical editor was Linda L. Wheatley, Technical Information Team.

COL J ames A. Walter is Commander of USACERL, and Dr. Michael J . O'Connor is Director. 


\section{Contents}

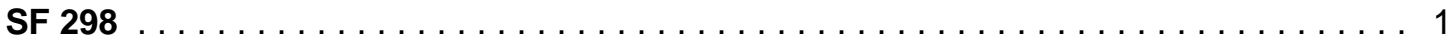

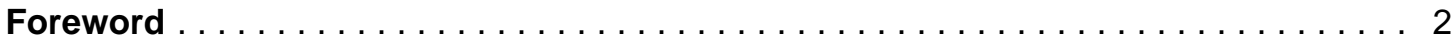

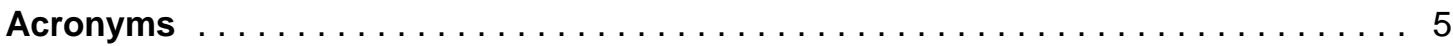

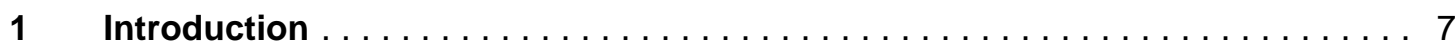

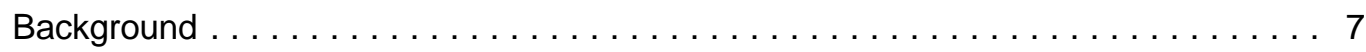

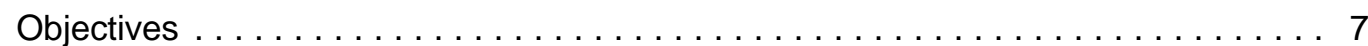

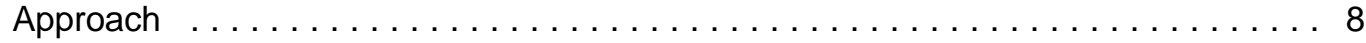

2 Military Missions and Installation Requirements $\ldots \ldots \ldots \ldots \ldots \ldots \ldots$

3 Regulatory and Policy Requirements/Constraints $\ldots \ldots \ldots \ldots \ldots \ldots \ldots$

Overview of USFWS Policies and Regulatory Compliance Requirements

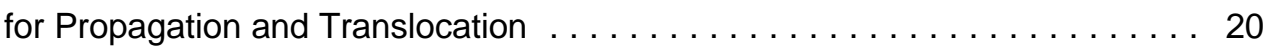

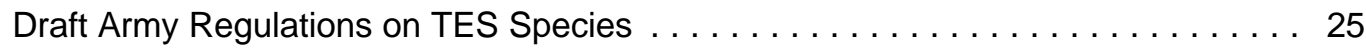

4 Case Studies of Projects Involving Introduction, Reintroduction, and Recovery of TES Plants $\ldots \ldots \ldots \ldots \ldots \ldots \ldots \ldots \ldots \ldots \ldots \ldots \ldots \ldots \ldots \ldots \ldots \ldots$

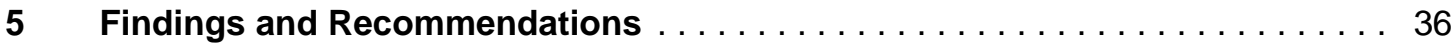

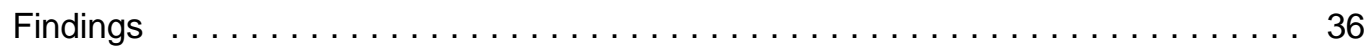

Recommendations . . . . . . . . . . . . . . . . . . . . . . . . 37

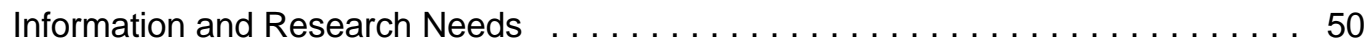

Research Issues and Approaches for Enhancement of TES Species . . . . . . . . . 53

Appendix A: List of Participants - USACERL/USFWS Scoping Workshop on TES

Research, 29 November - 2 December $1994 \ldots \ldots \ldots \ldots \ldots$

Appendix B: Baseline References, Workbook Materials, and Technical References Provided

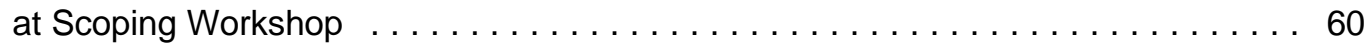

Appendix C: Draft USFWS Policy on TES Propagation $\ldots \ldots \ldots \ldots \ldots \ldots \ldots \ldots$

Appendix D: The Endangered Species Act — Regulatory and Policy Implications for Plant

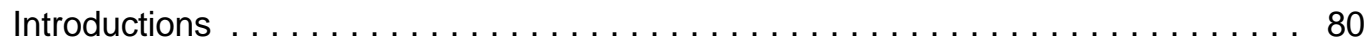


Appendix E: Regulatory Overview and Commentary on Chapter 11, AR 420-74: DRAFT; "Endangered/Threatened Species Guidance" . . . . . . . . . . . . . . . . . . 94

Distribution 


\title{
Acronyms
}

\author{
AAZPA - American Association of Zoological Parks and Aquaria (also AZA) \\ ACSIM - Assistant Chief of Staff for Installation Management \\ AMC - U.S. Army Materiel Command \\ AR - - Army Regulation \\ ASI - Advanced Sciences, Inc. \\ BLM - U.S. Bureau of Land Management \\ BoR - Bureau of Reclamation \\ BRAC - Base Realignment and Closure \\ $\mathrm{C} 1, \mathrm{C} 2$ - Category 1 or Category 2 Species \\ CERCLA - Comprehensive Environmental Response, Compensation and \\ Liability Act (of 1980) \\ CFR - Code of Federal Regulations \\ CITES - Convention on International Trade in Endangered Species \\ of Wild Fauna and Flora \\ CPC - Center for Plant Conservation \\ DA - Department of the Army \\ DAIM-ED - Office of the Director of Environmental Programs \\ DAJ A-EL - J udge Advocate General, Environmental Laboratories \\ DAMO-TRS - Office of the Deputy Chief of Staff for Operations and Plans, \\ Training Simulations Division \\ DCSOPS - Deputy Chief of Staff for Operations and Plans \\ DOD - Department of Defense \\ EA - Environmental Assessment \\ EIS - Environmental Impact Statement \\ EO - Element Occurrence \\ EPA - Environmental Protection Agency \\ EQCC - Environmental Quality Control Committee \\ ESA $\quad-\quad$ Endangered Species Act \\ ESMG - Endangered Species Management Guidelines \\ ESMP - Endangered Species Management Plan \\ FORSCOM - U.S. Army Forces Command \\ GIS - Geographic Information System \\ HAFB - Holloman Air Force Base \\ HQDA - Headquarters, Department of the Army
}


ISIS - IUCN International Species I nformation Systems

ITAM - Integrated Training Area Management

IUCN - International Union for the Conservation of Nature

LCTA - Land Condition Trend Analysis

MACOM - Major Army Command

NEPA - National Environmental Policy Act

NMFS - National Marine Fisheries Service

P\&T - Propagation and Translocation

PTR - Propagation, Translocation, and Restoration

QA/QC - Quality Assurance/Quality Control

QA/RA - Quality Assurance/Regulatory Assurance

ROD - Record of Decision

RPMP - Real Property Master Plan

RTD\&E - Research, Testing, Development, and Evaluation

SSP - Species Survival Program

T\&E $\quad-\quad$ Threatened and Endangered

TES - Threatened, Endangered, and Sensitive

TJ AG - The J udge Advocate General

TRADOC - U.S. Army Training and Doctrine Command

UCMJ - Uniform Code of Military J ustice

UNM - University of New Mexico

USACERL - U.S. Army Construction Engineering Research Laboratories

USFWS - U.S. Fish and Wildlife Service

WSMR - White Sands Missile Range, Department of the Army 


\section{Introduction}

\section{Background}

A fundamental function of the Endangered Species Act (ESA) is the comprehensive responsibility imposed on all Federal agencies for the conservation of protected species, critical habitat and, ultimately, theecosystems in which theseareensconced. In the United States, military lands (most importantly those of the Army and Air Force) have come to be important refuges not only for rare and isolated species but for entirefloristic communities and, perhaps, entireecosystems. In a major evolution of its efforts to meet these objectives, the U.S. Army has proposed extensive new regulations and major regulatory revisions-and has al ready promulgated them as Army policy-for many of its environmental responsibilities, including particularly compliance with the broad duties under theESA. TheU.S. Fish and Wild ife Service (USFWS), the implementing agency for the ESA, both in terms of rule-making and enforcement on one hand and cooperative guidance and interagency support on the other, is likewise moving forward to more effectively pursue and achieve the wider, ecosystem-level mandates of the ESA. In this regard, both the Army and USFWS have recognized the long-term benefits of early, regular, and continuing cooperation in meeting the mandates and mission requirements of both agencies, while minimizing or entirely avoiding serious conflicts between their respective primary functions. To this end, the joint sponsorship of workshops such as this has been determined to be in the common interests of the agencies, their missions, and the species and ecosystems which may depend for their ultimate survival on the wisdom that these organizations invest in these efforts. Through this and future workshops and interagency conferences, an increased familiarity with thetechnical issuesfacing both agencies will be achieved, and an increasing level of cooperative, effective, working interaction between them will germinate and grow into a mutualistic, perhaps symbiotic, successful, long-term implementation program toward theESA's fullest goals on Army and other military lands.

\section{Objectives}

The initial, primary objectives of the workshop were to: (1) scope the legal framework for propagation, translocation, and restoration (PTR) projects involving 
threatened, endangered, and sensitive (TES) plant species on military lands, (2) educate military users on USFWS policy regarding PTR work, (3) obtain consensus to move forward on developing researchable PTR topics, (4) review military needs and case studies involving PTR projects, and (5) use the forum to scope partnership activities and cost sharing opportunities.

Through facilitated discussions and group consensus, the workshop objectives were modified to address propagation and translocation (P\&T) in a broader context of management options for enhancing the survival of TES plants. As a result, the workshop explored issues associated with $\mathrm{P} \& \mathrm{~T}$, but also covered a wider range of military needs for management activities and research to enhance survival of TES plants.

\section{Approach}

Workshop participants were selected through an interview process based on their interest and expertise. A diverse group of participants was assembled, representing a broad range of expertise pertinent to the workshop scope. Participants included representatives from Major Army Commands (MACOMs), selected military installations, and U.S. Army Corps of Engineers laboratories; the USFWS and other Federal agencies; private sector organizations; and universities. Participants are listed in Appendix A.

Before the workshop, participants were surveyed to elicit ideas for agenda topics. Interviews and survey responses identified legal and technical issues, research approaches, references, and recommendations for possible study sites and species of interest. Responses to the pre-workshop surveys were used to identify the background and interests of individual participants, and to determine issues and approaches for workshop sessions and follow-on scoping activities. Each participant received a preliminary agenda and baseline reference materials for review prior to the meeting.

The workshop consisted of several facilitated working sessions on agenda topics. Session formats included presentations, group discussions, and breakout groups. A workbook containing presentations and reference materials was distributed to each participant. Through a consensus-driven process, participants identified issues, findings, and recommendations based on the objectives for each session.

On the first day of the workshop, presentations addressed $F$ ederal and Army policies and regulations pertaining to TES plant species. Each of the MACOMs was invited 
to present an overview of its mission and natural resources management programs, and to discuss the MACOM's needs, problems, and desires involving the management of TES plant species. On day two, military requirements at the installation level were discussed and case studies of $P \& T$ projects were presented. For the remainder of the workshop, breakout groups were assembled to further define management issues and research needs. The third day of the workshop included presentations by each breakout group and consensus discussions on management and research priorities. On the last day of the workshop, flow diagrams were generated to show the processes and decision criteria involved in managing TES plants and conducting P\&T projects. Workshop findings and recommendations were summarized through facilitated group discussions.

In addition to the workshop sessions, the meeting also provided an excellent forum for technical exchange. To facilitate this process, individuals were encouraged to bring technical publications and other reference materials to the meeting. Copies of these materials were displayed on a reference table, and made available to participants on request. Appendix $B$ contains a list of references provided at and subsequent to the workshop. 


\section{Military Missions and Installation Requirements}

Following is a summary of presentations by each of the MACOMs and selected military installations. These presentations provide an overview of military missions and requirements. They also offer insight into opportunities and constraints for $P \& T$ projects and other activities associated with managing TES plants on military lands.

\section{U.S. Army Forces Command (FORSCOM)}

Albert Bivings, Natural Resources Program Manager, HQ FORSCOM

FORSCOM provides the Army's military combat forces. The primary mission activity is military training. This training is conducted to ensure that soldiers attain proficiency in military tasks with the best available weapons and equipment, to maintain readiness, and minimize the likelihood of casualties and reversals on the battlefield.

FORSCOM installations comprise approximately four million acres of land. Land use requirements are dictated, in large part, by the FORSCOM training mission. These requirements for training lands are impacted by the use of new weapons technologies that have produced higher speed vehicles and weapons systems with longer range capabilities. The Army downsizing has also had an impact on land use. Troop density mobility has increased due to base realignments and closures. FORSCOM is now required to support a higher number of people per base and to conduct more training on this smaller land base. FORSCOM is also responsible for protecting Threatened and Endangered (T\&E) plant species and other natural resources on its installations. If FORSCOM cannot train, its land is of no value to the military mission. Consequently, my goal is to mesh military training and the management of $T \& E$ species by optimizing land use for both.

Funding within FORSCOM is typically compliance-driven. Projects needed to comply with biological opinions or other Federal or Army regulations receive a higher priority for funding than those not required for compliance. The most 
serious problems involving TES have occurred when managers haven't followed requirements specified in the National Environmental Policy Act (NEPA).

Areas of Interest: FORSCOM is interested in finding ways to manage T\&E plants to avoid adverse impact by the training mission. FORSCOM is also interested in ecosystems management; however, biological opinions under ESA tend to be single species-oriented. Because there is no specific regulatory requirement for ecosystems management, these types of projects often go unfunded.

Impact areas on Army installations may contain unknown populations of T\&E plants. Impact areas are defined geographic areas that contain high explosive ammunition including duds and unexploded ordnance from military training and testing activities. These munitions sometimes detonate due to high temperatures, vibrations, or other causes, often causing a chain reaction of multiple detonations. For this reason, access to impact areas is determined by ordnance specialists, and, in most cases, is highly restricted. Surface danger zones located outside the dudded impact areas are also subject to limited access. It is assumed that TES species exist-and perhaps thrive-in impact areas and surface danger zones because of the frequent fire disturbance regimes that occur in these areas and/or because of the limited human activities. There is some interest within the Army and the USFWS in conducting inventories of T\&E plants in these areas so that populations are considered in conservation and recovery goals for species of concern. Although the Army is exploring the possibility of using remote sensing techniques to survey impact areas and surface danger zones, the risk of human danger is likely to significantly restrict inventory projects and preclude any active management of TES species in these areas.

\section{U.S. Army Materiel Command (AMC)}

Tom Vorac, Forester/Environmental Protection Specialist, HQ AM CCOM

The AMC's primary mission involves chemical and munitions manufacturing and storage, as well as research, testing, development, and evaluation (RTD\&E) activities. AMC has 71 installations covering more than five million acres of land. These installations are located in 38 states and three foreign countries, and range in size from seven acres to more than two million acres. The AMC requires large buffer zones around explosive operations and storage sites, and large land expanses for testing at its proving grounds and missile ranges. Unlike other MACOMs, AMC does not support ground troops and military training; therefore, ground disturbance is minimal. Currently, 76 F ederally-listed plant species and 
204 state-listed plant species are found on AMC acreage. Fifteen installations have completed inventories of TES species.

Areas of Interest: AMC offers a number of opportunities for management and research activities involving TES plants. There are no plans for new construction, and installations have land available that can be devoted to natural resources management. AMC funding for natural resources management is not limited to those projects needed for compliance. With no major mitigation problems, current funds are being spent on inventory and restoration projects. Species of interest include Tennessee yellow-eyed grass (Xyris tennesseensis) at Anniston, Agalinis scutellaria, and the prairie bush clover (Lespedeza leptostachya) in Wisconsin. Firedependent habitat is also of interest to AMC.

\section{U.S. Army Training and Doctrine Command (TRADOC)}

Robert Anderson, Environmental/Natural Resources Specialist, HQ TRADOC

The primary mission of TRADOC is to devel op war-fighting technologies and associated military training. TRADOC has 17 installations. Environmental activities within TRADOC are organized according to the four pillars of the Army's environmental program: (1) compliance, which is rule-based and involves enforcement actions and fines, (2) restoration, which involves clean-up of previous environmental contamination, (3) pollution prevention, which is focused on reengineering processes and procedures to reduce or eliminate waste and environmental hazards, and (4) conservation, which includes efforts to preserve and maintain natural resources.

All proposed "must-fund" environmental projects at TRADOC undergo legal review and are assigned funding priorities based on compliance requirements. Natural resources management projects typically receive low priority. These projects accounted for only 2.2 percent of the Army's environmental budget last year. The Sikes Act and Army Regulation 200-3 require integrated natural resources management plans, but since mandatory deadlines are not specified, associated projects are assigned a low priority for funding. Approximately 60 percent of TRADOC installations have completed surveys for TES species. A potential source of funding and technical support is the Legacy Program, which was allocated $\$ 50$ million in FY 1994 for projects not related to compliance. TRADOC has experienced some difficulties in obtaining outside contractors to perform environmental work due to contracting and procurement constraints. 
Areas of Interest: Based on input from TRADOC installations, the following recommendations were presented for possible management and research projects involving TES plants:

- Fort McClellan, AL, has a population of the endangered Tennessee yelloweyed grass, and is interested in possible translocation to non-Federal property. Also present is the threatened Mohr's Barbara's Buttons (Marshallia mohrii). The Tennessee yellow-eyed grass is not in imminent danger at Fort McClellan. Translocation would ease the pressure on the installation of having one of the two known Federal populations of this species.

- $\quad$ F ort Sill, OK, apparently has no listed plants. The installation has recently converted hundreds of acres back to native prairie grasses in keeping with a White House memorandum on Federal landscaping.

- $\quad$ Fort Benning, GA, has one known endangered plant, Relict Trillium (Trillium reliquum), plus state-listed buckthorn, needle palm, sweet pitcher plant, and Pickering's morning glory. These species are not adversely impacting training.

- $\quad$ Fort Huachuca, AZ, has an extensive population of agave (Agave palmeri), a nonlisted species which is a food source for the endangered lesser long-nosed bat. The installation may want to move or grow agave in new locations less prone to damage. More information on the impacts of fire on agaves is desired relative to their distribution and demographics. In grasslands, more knowledge of the fire ecology of the golden aster (Heterotheca rutteri), a Category 2 (C2) species, is needed. The species has a puzzling patchy distribution compared with the weedy habit of related species. In riparian habitat, the Huachuca water umbel (Lilaeopsis scaffneriana recurva) is a Category 1 (C1) species overdue for listing. Knowledge of its distribution relative to successional stages of emergents and degree of flood scouring is needed. Also a riparian, the Lemmon lily (Lillium parryi) is a C2 species with very specialized requirements. Further knowledge of these requirements would indicate when human intervention is necessary for survival.

- $\quad$ Although closing, Fort Ord, CA, has significant requirements under its closure Environmental I mpact Statement (EIS) multi-species Habitat Management Plan. Maritime chaparral is scheduled for limited burns to allow for unexploded ordnance removal over a 10-year period with concurrent listed and candidate plant management. Controlled burns will comprise the mitigation because natural fires are responsible for the diversity of plant species present 
in the maritime chaparral. Monitoring of burned areas will be done for five years to ensure recovery of plant communities. Problems may occur during this time due to the invasive nature of exotic plants.

Species involved are the endangered sand gilia (Gilia tenuiflora arenaria), threatened Monterey spineflower (Chorizanthe pungens pungens), seaside bird's-beak (Cordylanthus rigidus littoral is, C1), Yadon's piperia (Piperia yadoni, C1), Toro manzanita (Arctostaphylos montereyensis, C2), Sandmat manzanita (Arctostaphylos pumila, C2), Monterey ceanothus (Ceanothus rigidus, C2), Eastwood's ericameria (E ricameria fasciculata, C2), coast wallflower (Erysimum ammophilum, C2), and Hooker's manzanita (Arctostaphylos hookeri). Additionally, seacliff buckwheat and coast buckwheat, both unlisted, are the only sources of food and oviposition for the endangered Smith's blue butterfly.

Headquarters for F ort Ord is now the nearby Presidio of Monterey. It contains the candidate Monterey pine whose genetic integrity is threatened by ornamental Monterey pines from New Zealand. This problem has been researched by the California Forest Germ Plasm Research Project at the University of California-Berkeley, but funding has been sporadic.

- $\quad$ Fort Bliss, TX, is under extensive pressure from training. The only known endangered plant is the Sneed pincushion cactus (Coryphantha sneedii sneedii). A more extensive survey is needed in the Organ Mountains. Also on the installation are a number of state rare species including Organ Mountain pincushion cactus (Coryphantha organensis), button cactus, Neolloyda intertextus, sand prickly pear, desert night-blooming cereus, Alamo beard tongue, nodding cliff daisy, and grama grass cactus. An ability to propagate these species would greatly ease pressure on training missions. Though not listed, two species of grama grass are impacted by training, and propagation/ seeding of this species would help mitigate impacts.

- $\quad$ Fort Gordon, GA, has two F ederal candidate species, Pickering's morning glory and Indian olive. Three state-listed species are also present, Atlantic white cedar, pink lady's slipper, and sweet pitcher plant. These species are not impacting training adversely.

- $\quad$ F ort J ackson, SC, has two endangered plants, smooth coneflower (Echinacea laevigata), and rough-leaved loosestrife (Lysimachia asperulaefolia). Candidate species present are crested fringed orchid (Pteroglossaspis ecristata, C2), piedmont milfoil (Myriophyllum laxum, C2), nestronia (Nestronia umbellula, 
C3), and Sarvis holly (Ilex amelanchier, C3). State-listed species are pale beak rush (Rhynchospora pallida), beak rush (R. stenophylla), and cottongrass.

These species do not appear to be impacted at this time.

- $\quad$ Fort Rucker, AL, is not currently being impacted. Possibly present there, are several Federal candidates, incised gravel bur (Agrimonia incisa), Flyer's nemesis (Brickellia cordifolia), Baltzell's sedge (Carex baltzelii), and Alabama anglepod (Matelea alabamensis). In addition, 10 state-listed plants are known or suspected to be present at this location.

In discussion following the MACOM presentations, it was noted that 80 percent of the upcoming listed species will be plants. There was general agreement that the Army should devel op a strategy now since compliance problems may become a future issue as more plants are listed. All three MACOMs expressed interest in pursuing work with candidate plants.

To augment the MACOM presentations, representatives from various military installations were asked to discuss their needs, problems, and recommendations related to TES plants on their sites. Presentations from each installation are summarized below.

\section{Department of the Army, Fort Bliss, TX}

Raphael Corral, Endangered Species Biologist, Fort Bliss

Fort Bliss is the largest TRADOC installation. At 1.2 million acres, it comprises approximately 58 percent of the land that TRADOC controls. Fort Bliss has one endangered plant, the Sneed pincushion cactus (Coryphantha sneedii sneedii), which is located in a protected area on the installation. There are also nine candidates, three state-listed, and two sensitive species of plants onsite. Only one candidate is located on a firing range and another is subject to some disturbance from grazing. Historically, Fort Bliss has only one person responsible for natural resources management. That number is going to change to seven permanent personnel in 1995. Problems include lack of baseline information on the species present. The installation biologists are interested in determining what percent onsite populations represent relative to all known populations of the species.

Fort Bliss views $P \& T$ as a potential tool for mitigation. I nitially, the installation could collect and bank seeds since this activity does not require a lot of personnel or 
funding. The seeds could be used in the future if a plant population is destroyed or adversely impacted. There is also a need to monitor existing populations, which may reveal other possible uses for $P \& T$.

\title{
Department of the Army, Fort Pickett, VA
}

\author{
Alan Dyck, Wildlife Administrator, HQ USAG F ort Pickett
}

Fort Pickett, located in the southern Virginia piedmont area, has a large population of one endangered plant, the Michauxii sumac (Rhus Michauxii). The population, discovered in 1993, contains 40,000 plants including some introgressions. The species is also found on Fort Bragg in North Carolina.

Fort Pickett has obtained Legacy funds to conduct P\&T work on the species including a seed viability study. The installation is looking for non-invasive techniques for this effort. Fort Pickett's work with the Michauxii sumac has been incorporated in the site endangered species management plan. The installation has consulted with the USFWS and obtained a permit to collect seeds and plant material. Distribution work is currently underway, and monitoring plots have been established. The installation is also studying species management requirements and fire regimes. There is interest in possibly obtaining an experimental population status and using a fire box to study fire effects on the plants.

If the project is successful, Fort Pickett would like to use P\&T to augment plant populations when a new range is constructed in the future. The installation may also want to relocate plants, possibly to offsite lands managed by The Nature Conservancy or the State of Virginia.

\section{Department of the Army, White Sands Missile Range, NM}

\section{Gretchen Norman, Environmental Scientist, Cortez III Service Corporation}

The White Sands Missile Range (WSMR), located in southern New Mexico, is a large, ecologically diverse installation that covers 110 miles north to south and 40 miles east to west. Both Federally-listed and state-listed plant species are found onsite. WSMR is currently surveying TES plants and producing a vegetation map for the range. The installation is using a Geographic I nformation System (GIS) containing soil, vegetation, topographic, and geological data layers to identify 
potential habitat for the Todson's pennyroyal (Hedeoma todsenii). This approach has not been applied to other listed species, but plans to do so are being developed.

$P \& T$ techniques are viewed as potential tools for mitigation and recovery. WSMR has moved four Sheer's pincushion cactus (Coryphantha sheeri; var. valida) within the same population to avoid adverse impact from construction. WSMR has experienced some problems with ground squirrels uprooting transplants. Also, limited funding is often a constraint for $\mathrm{P} \& \mathrm{~T}$ projects.

\section{U.S. Air Force, Holloman Air Force Base, NM}

Hildy Reiser, Wildlife Biologist/Natural Resources Manager, Holloman AFB

Like the Army, the Air Force is a large and diverse organization. Its installations support a variety of mission activities, and range in size from 2,000 acres to 3 million acres. Funding for environmental projects within the Air Force is compliance-driven; the A-106 budgeting process is used to assign priorities to those projects needed for compliance. The DOD Legacy Resource Management Program is an additional source of funding for land stewardship projects that are not required for compliance. In performing environmental work, the Air Force frequently coordinates with other Federal agencies and conducts offsite projects where fly-overs occur.

Holloman Air Force Base (HAFB), located in New Mexico, consists of 60,000 acres. The installation does not have any listed plant species; however, more than 12 candidate species potentially occur onsite. HAFB does have some unique endemic populations of animals, which it treats as listed species. Although legally not required, HAFB has informally involved the USFWS and implemented cooperative agreements for these species. The installation is currently setting up mitigationrelated transplanting experiments with the grama grass cactus. Other ongoing work at the base includes a habitat modeling project supported by Colorado State University and USACERL, and a plant survey that is being performed by the New Mexico Natural Heritage Program.

HAFB represents an excellent opportunity for ecosystem management applications. HAFB is located in the Chihuahuan Desert. Over 3 million acres of Federal land are located within this ecosystem. The installation would like to see a Chihuahuan Desert/Tulorosa Basin I nitiative similar to other regional ecosystem projects like the Mojave Desert I nitiative. Other needs and desires for research at HAFB include desert grassland ecological studies and impact studies on plants in a 
more natural setting. The installation would also like to perform some transplant projects. P\&T techniques would be potentially useful for ecosystem restoration, population augmentation, and mitigation activities. The Dare County Air F orce Range in North Carolina may also be interested in P\&T techniques to address problems with regeneration of the endangered white cedar.

\section{Department of the Army, Fort Bragg, NC}

J anet Shipley, Botanist, F ort Bragg

Fort Bragg covers approximately 155,000 acres and supports the largest concentration of rare plants in the state. The installation is comprised of a longleaf/wiregrass ecosystem, supporting three F ederally-listed species onsite: Michaux's sumac (Rhus michauxii), rough-leaved loosestrife (Lysi machia asperulaefolia), and American chaffseed (Schwalbea americana), 31 potential natural areas to be state registered, and numerous Federal candidate and statelisted species. Some of these species are narrow endemics.

Due to compliance problems with the red-cockaded woodpecker, work with TES plants has received a lower priority for funding. The first botanist at Fort Bragg was hired in 1990. Since that time, the installation has marked all Federallyprotected plant sites and now wants to map communities and establish a biological monitoring program.

There have been some conflicts between training requirements and the location of TES species at Fort Bragg. Translocation could possibly be used to mitigate some of these problems in the future, though it should be considered as a last resort.

\section{Department of the Army, Fort Stewart, GA}

\section{Linton Swindell, Natural Resources Specialist, Fort Stewart}

Fort Stewart consists of 280,000 acres of land. More than 1,000 plant taxa have been identified at this location. None of these plants is Federally-listed; however, several are candidates and some are state-listed. The installation contains 96,000 acres of wetlands, and approximately half of the state-listed and candidate species are wetlands species. F ort Stewart emphasized the need to coordinate management of TES plants, including $P \& T$ activities, with military training and mission plans. Fort Stewart is interested in possibly using $P \& T$ on wetlands 
banking areas at the installation. This approach might provide an incentive to work with candidate species by combining management areas and protected wetlands. Also, P\&T projects are likely to generate basic information on species biology and habitat management that can be used in the integrated natural resources management plans. 


\section{Regulatory and Policy Requirements/Constraints}

One of the primary workshop objectives was to scope the legal framework for P\&T projects and determine the policy and regulatory requirements applicable to TES plant species on military lands. Presentations on this topicaddressed USFWS policies on propagation, ESA requirements pertaining to $P \& T$ projects, and draft Army regulations on TES species. These presentations are summarized below.

\section{Overview of USFWS Policies and Regulatory Compliance Requirements for Propagation and Translocation}

\section{Charlie McDonald, Botanist, U.S. Fish and Wildlife Service, Region 2}

The USFWS has responsibility for administration of the Endangered Species Act as it applies to terrestrial and freshwater species. The USFWS issues policies and regulations governing the management of TES species, including P\&T activities.

USF WS Policies on P\&T. A USFWS memorandum dated 1981 states that listed species will not be relocated or transplanted outside their historic range without specific case-by-case approval from the Director. Historic range is defined as the range generally known to scientists through research or literature searches. The purpose of the ESA is to conserve ecosystems upon which T\&E species depend. Transplanting populations outside their historic range is inconsistent with ecosystem preservation. The biological considerations for the policy include: (1) the doubtful survival of transplanted populations outside natural range limits and (2) the potential for altering gene pools, i.e., unnaturally disturbing gene pools of other varieties in the locale where the population is transplanted.

In accordance with its policy, the USFWS generally opposes the relocation of entire populations even if within historic range. From a management perspective, it is more practical and appropriate to maintain and restore existing species and ecosystems rather than recreate populations and develop new ecosystems through plant introductions. There has been marginal success on P\&T projects. 
In the next month or so, the USFWS and the National Marine Fisheries Service (NMFS) expect to publish draft policy on controlled propagation of T\&E species. (See Appendix C for a draft copy of this policy.) Controlled propagation is recognized in certain situations as an essential tool for the conservation and recovery of listed species. The proposed policy sanctions controlled propagation of listed species when recommended in an approved recovery plan and supported by an approved genetics management plan. Consent may also be granted when controlled propagation is used to conduct recovery-related research, to maintain refugia populations, and to rescue species or population segments at risk of imminent extinction or extirpation in order to prevent the loss of essential genetic viability.

The proposed policy states that controlled propagation of T\&E species:

1. Will be used only after higher priority recovery measures have failed or are likely to fail (last resort)

2. Will be based on tasks identified as necessary for recovery in an approved USFWS recovery plan (should be identified in the recovery plan in advance)

3. Will consider ecological and genetic effects on wild populations of removal of individuals for propagation

4. Will be based on sound genetic principles to preserve genetic variability found in wild populations

5. Will be preceded by the development of a genetics management plan (Note that the Center for Plant Conservation has written guidelines on preparing genetics management plans)

6. Will be done in a way that minimizes introduction of disease into controlled or wild habitats (more an issue with animals but could also apply to plants)

7. Will be done in a way that prevents escape of captive stock outside its historic range

8. Will be conducted at multiple locations if feasible in order to reduce the potential for catastrophic loss at a single site 
9. Will be coordinated, as appropriate, with organizations both internal and external to the USFWS and the NMFS

10. Will be conducted in a manner consistent with the information needs of the USFWS and other organizations (requires coordination of information, record-keeping, and databases)

11. With limited exceptions, will be implemented only after funding is secured following approval of final recovery plans and genetics management plans

12. Will, prior to releases of propagated individuals, require development of a controlled propagation/reintroduction plan that identifies objectives, milestones, protocols for health management, monitoring, data collection, and record-keeping among other requirements

13. Will be conducted in accordance with regulations implementing ESA, Marine Mammal Protection Act, Animal Welfare Act, Lacey Act, Fish and Wildlife Act, and procedures required by NEPA.

Requirements Under the ESA. The ESA specifies a number of requirements for protection and management of TES species by Federal agencies. ESA requirements pertaining to $P \& T$ projects are discussed below.

(Also see Appendix D for a paper by Charlie McDonald, USFWS, entitled, The Endangered Species Act: Regulatory and Policy Implications for Plant Introductions. This paper addresses ESA requirements and also covers the draft policy on propagation. Discussion is based on an earlier draft of the policy which is slightly different than the version contained in these proceedings.)

Recovery plans. Recovery plans identify the steps needed for recovery of T\&E species. These plans consist of three parts: (1) an introduction and background information on the species, (2) objectives and quantifiable criteria which must be satisfied in order to downlist or remove plants from listed status, and (3) an outline of planned recovery actions including an implementation schedule, task priorities, identification of responsible parties, and a cost estimate.

All new and revised recovery plans undergo technical and agency review, and are also announced in the Federal Register to invite public review and comment. Although recovery plans are not binding, policies issued by the Army and/or MACOMs may require adherence to the plans. Also, the USFWS Ecological Field Offices use recovery plans in developing biological opinions which are binding. 
Recovery plans are not set in stone; they are to be updated as needed, and revised as dictated by new findings, changes in species status, and the completion of recovery tasks. The USFWS reviews agency proposals involving management and recovery of TES plants, including $P \& T$ activities, on a case-by-case basis.

Approximately 25 percent of the existing recovery plans prescribe propagation and/or translocation activities, in most cases for narrow endemics. The USFWS has accepted or recommended the use of P\&T in biological opinions, including jeopardy opinions requiring mitigation actions.

One such case involved an aqueduct project within the Bureau of Reclamation (BoR) where there was no way to alter the proposed project to avoid adverse impact on the Tumamoc globeberry. The impacted population represented half of the known plants within this species. Under a jeopardy opinion issued by the USFWS, BoR was asked to conduct surveys for the species in Mexico, conduct research on translocating the plants, purchase parcels of land along the project area to set aside as habitat, and transplant salvaged plants to a safe area. Another example involved a consultation with the Environmental Protection Agency (EPA) regarding a water discharge permit for a coal-fired electric plant in Texas. The proposed impact area contained five to ten percent of the total population of Navasota ladies tresses, and it was not possible to alter the project to avoid impact. USFWS issued a jeopardy opinion and required EPA to perform surveys, set aside major populations, and conduct salvage and transplant activities. In this case, EPA was not asked to conduct P\&T research, but was asked to perform monitoring and ensure that a qualified botanist performed the work.

Because of their low success rates, $P \& T$ projects should be designed and conducted as experiments until proven methodologies are established. Common problems include inadequate commitment to the longevity of these projects (three to five years is not long enough), abysmal baseline data collection, and projects with poor experimental design including those performed too quickly or with little peer review.

Permits. USFWS permits are required only if a proposed action is prohibited by the ESA. Permits are not required for candidate species although agencies are encouraged to coordinate with the USFWS in these instances. Also, USFWS permits are not required for actions affecting species on private, non-Federal lands or species subject to state law. 
Section 10(a)(1)(A) of the ESA authorizes the issuance of permits for actions prohibited by Section 9 when T\&E species are used for scientific purposes or to enhance propagation or survival of the affected species. The USFWS recommends that each agency combine proposed actions such as seed acquisition and propagation into one permit application where possible. The permit process is being decentralized, and will be handled by USFWS regional offices. Many permits are now issued for three years; however, an annual report is required. Before obtaining permit applications, agencies are encouraged to call the USFWS to discuss requirements. Permit applications must be published in the Federal Register, for species listed as endangered only, and provide for a 30-day public comment period. Agencies should submit their applications well in advance of their proposed projects, allowing three to four months for processing time. As a general rule, consultants and contractors require their own permits unless they are included as sub-permittees on Federal agency applications.

Experimental populations. Under ESA Section 10(j), the USFWS can designate experimental status for reintroduced populations of T\&E species. Proposals for experimental population status are announced in the Federal Register, providing an opportunity for public review and comment. Proposals must identify specific locations and boundaries for the experimental populations, and also designate them as either essential or non-essential. A population is considered essential if it is deemed necessary for the continued existence of the species.

Experimental, non-essential populations are subject to less stringent regulatory requirements than would otherwise apply. Under ESA Section 7, these populations are treated as proposed species and critical habitat does not have to be specified. Special rules for the experimental populations can also be devel oped, resulting in additional management flexibility. Experimental, non-essential populations do not count toward recovery goals for the species. To date, the experimental population rules have only been applied to animal species. Based on the management and regulatory advantages this status affords, Federal agencies may want to consider using this approach on proposed P\&T projects involving plants.

In the question and answer period following the presentation, several participants commented that the USFWS regions vary in their interpretations of the regulations and are not al ways consistent from one region to another. It was al so noted that rules for TES species on private lands are different than those for public lands. Another comment pertained to the issue of historic range. Sometimes little information is known about the historic range of TES species, or a species has only recently been 
discovered in a particular site or state. In a strict ruling, P\&T cannot be used if a TES plant species is limited to a single population. Agencies need to be prudent and use the best available scientific expertise in addressing historic range questions. The USFWS policy on hybrids was also reviewed. Basically, individuals with characteristics most like pure species are treated as pure species with respect to their protective status, and those with significant differences are not protected.

\section{Draft Army Regulations on TES Species}

Gordon Venable, J .D., Sr. Regulatory Compliance Specialist, Advanced Sciences, Inc.

(F or more detailed recommendations on compliance strategies, refer to Appendix $E$, Regulatory Overview and Commentary on Chapter 11, AR 420-74: DRAFT; "Endangered/ Threatened Species Guidance." * The material below is a summary of that commentary.)

The Army has issued draft regulations on TES species in "DRAFT AR 420-74, Chapter 11, Endangered/Threatened Species Guidance." Each of the Army MACOMs has directed the implementation of these draft regulations as interim policy, pending issuance as final regulation. The Chapter 11 regulations reflect the Army's commitment to leadership in natural resources management. Long-term planning and effective management are identified as key methods for balancing mission requirements and the conservation of listed species. The draft regulations establish requirements for long-term cooperation and informal consultation with regulatory agencies (NMFS and USFWS). Chapter 11 also requires conservation of biological diversity on Army lands through ecosystem and community management, establishing standards well beyond minimal compliance with the ESA.

The regulations include important interactive requirements for ESA and NEPA compliance. Section 11-2 sets out a synopsis of ESA requirements including conservation of listed species, interpreted in the Army's proposed regulations/ interim policy standards as necessitating affirmative efforts to improve the status of listed species and critical habitat. The prohibition against jeopardizing listed species, and requirements to consult and confer with the USFWS or NMFS when ongoing or proposed actions may affect a listed species or critical habitat, are also reviewed. Section 11-2.d requires the Army to conduct a biological assessment for

\footnotetext{
* Army Regulation (AR) 200-3, Natural Resources C Land, Forest and Wildlife Management, 28 February 1995, supersedes AR 420-74, 1 July 1977 and AR 210-9, 1 July 1978.
} 
any action which triggers the NEPA analysis requirement, if T\&E species are located in the area affected by the proposed action. A prohibition against taking, removing, or destroying listed species is included in Section 11-2.e.

It is extremely important to note that the draft regulations also require consideration of candidate and state-listed species and habitats, as well as associated planning and coordination activities for these species, in order to avoid actions which would result in deterioration of these species and consequent adverse changes in their Federal listing status.

Section 11-5 addresses the development of Endangered Species Management Plans (ESMPS). These plans are required for listed and proposed species and critical habitat present on Army lands. Installation commanders must approve the ESMPS within one year following the discovery of a listed/proposed species or the proposal for listing a species or designating critical habitat, whichever occurs first. Installations are encouraged to coordinate the development of ESMPs with other Federal, state, and private landowners; conservation organizations; and regulatory agencies.

Integrated planning and coordination of ESA and NEPA (through the ESMP and ESA recovery plan processes especially) are strongly encouraged. The ESMP provisions require development of detailed compliance checklists as integral parts of each ESMP; these become part of the ESMP audit process, and also become the primary auditing tool for internal and external audits of ESA and NEPA compliance under the proposed regulations. To assist in the audit process, each installation should integrate the preparation of its NEPA checklist at the time the ESMP is devel oped. The NEPA compliance requirements, as described in several sections (Section 11-6.f in particular), apply to species and critical habitats that are Federally-listed, state-listed, or proposed for listing at the Federal or state level.

The development of a standardized, uniform ESMP/NEPA/ESA compliance checklist(s) would be a major step in streamlining Army ESA and NEPA compliance systems and the environmental compliance audit system. This would result in lower compliance costs, faster development and implementation efforts, increased efficiency, and substantially enhanced scientific and legal defensibility.

Section 11-7 of the draft regulations outlines requirements for formal consultation and conference procedures. A formal consultation under ESA Section 7(a)(2) is required if a proposed action "may affect" a listed species or critical habitat. The installation must confer with USFWS or NMFS if an action is "likely to jeopardize" a proposed species or a proposed critical habitat. Recovery plans developed by 
USFWS or NMFS are used in consultations under Section 7 of ESA. Army participation in development of these recovery plans will allow long-range Army needs and plans to be considered in the plan development, minimizing potential mission and ESA conflicts, while creating opportunities for the Army to conserve and enhance listed and proposed species and habitats.

Requirements for identifying and documenting the location of listed, proposed, and candidate species on an installation are specified in Section 11-11 of the draft Army regulations. Section 11-14 states that the Army will support the reintroduction and introduction of Federal and state listed, proposed, and candidate species on Army lands unless these actions will have a significant impact on the present or future ability of the Army to meet its mission requirements. Proposals for reintroduction/introduction on Army lands are approved or disapproved following a thorough assessment of impact on the environment and mission requirements, as well as the potential benefits of reintroduction/introduction.

A greatly improved flow diagram on the ESA decision process was presented to the workshop participants. The improved flow diagram, depicted in Figure 1, was finalized based on comments, revisions, and major supplemental contributions from Charlie McDonald, USFWS. 


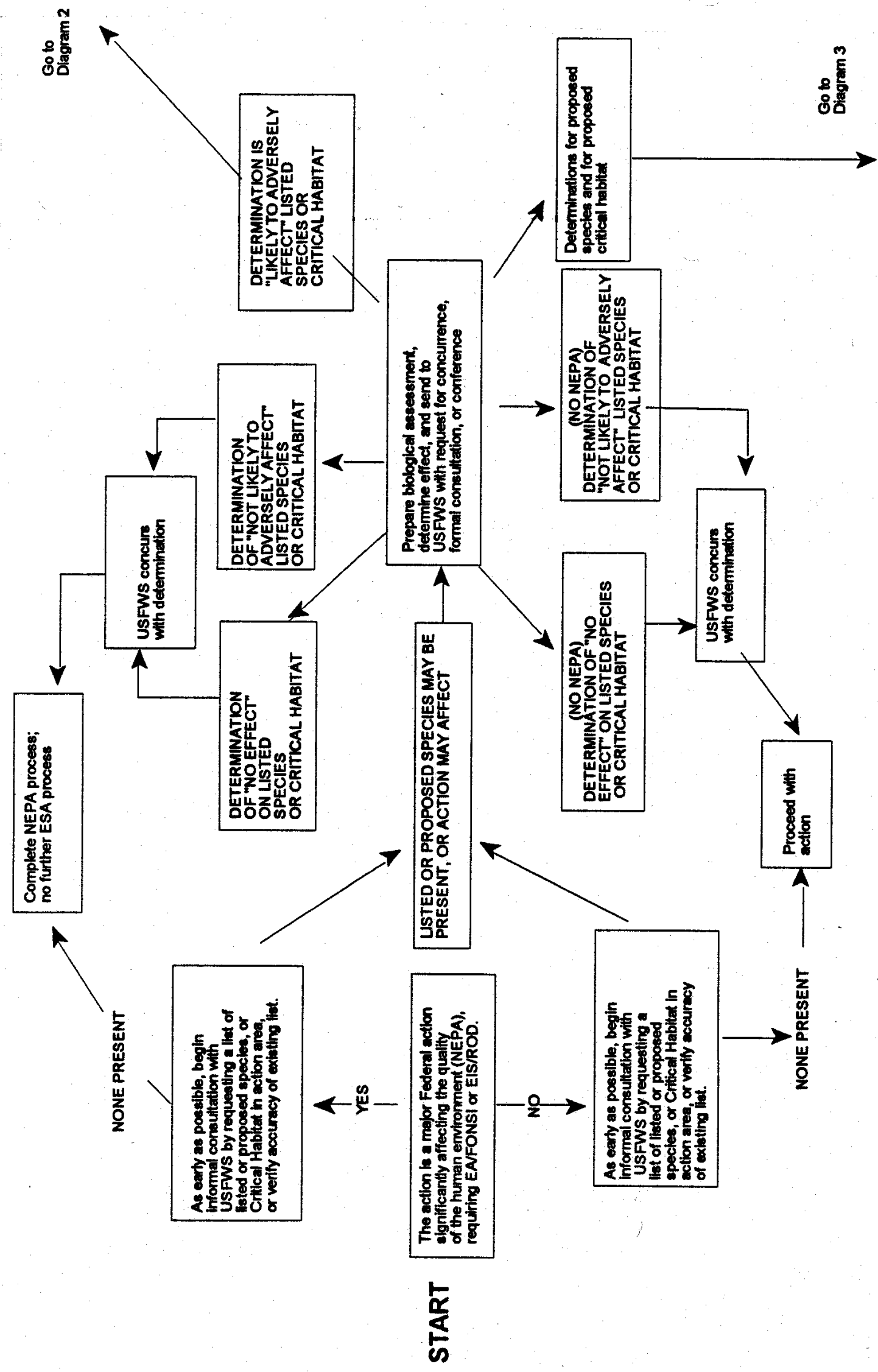

$\frac{5}{8}$

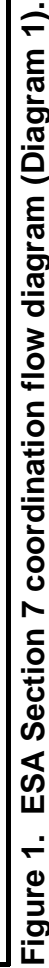




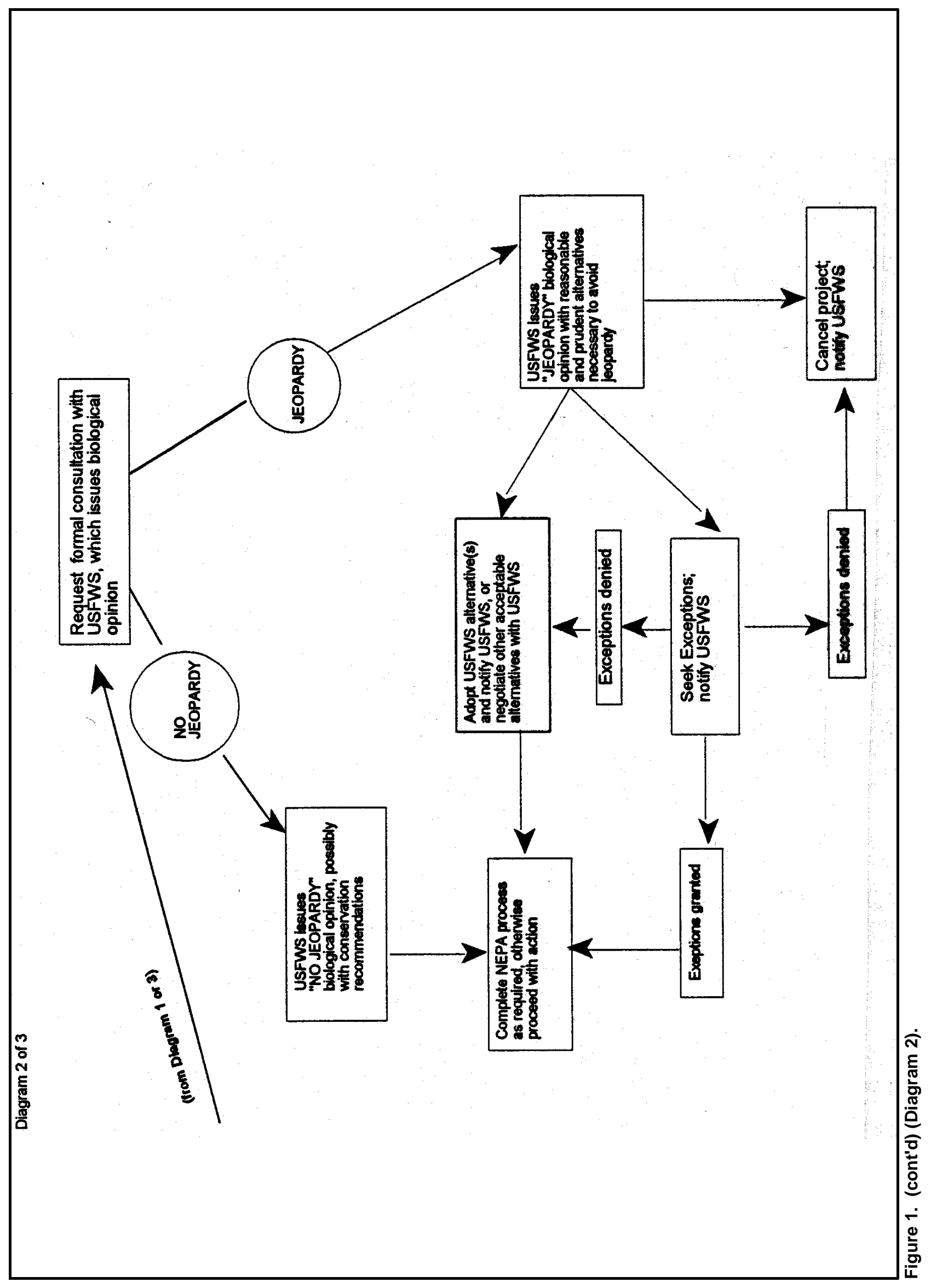




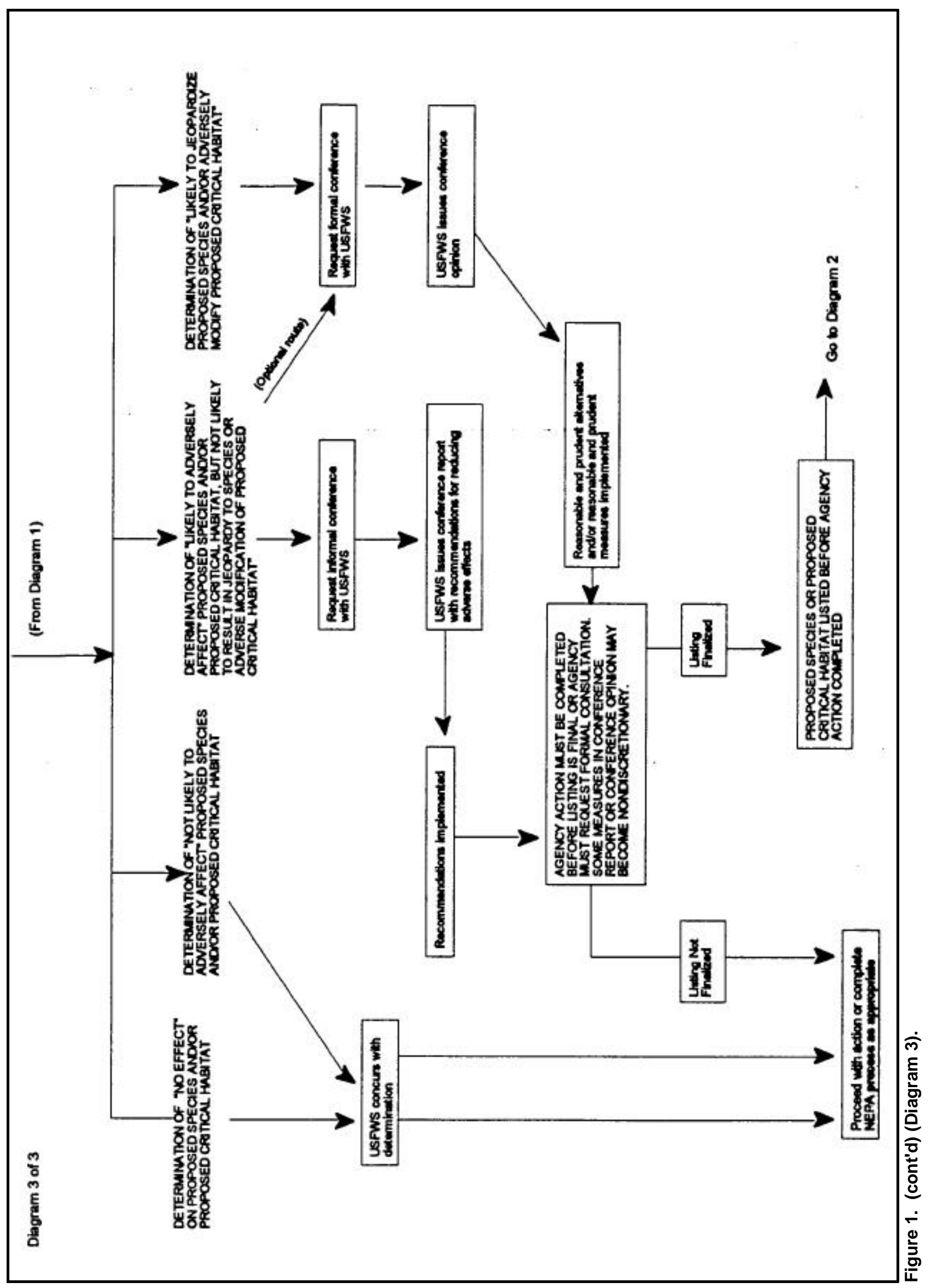




\section{Case Studies of Projects Involving Introduction, Reintroduction, and Recovery of TES Plants}

Representatives from selected nonmilitary organizations were invited to present case studies on their experience involving the propagation or translocation of TES plants. Presentations are summarized below.

\section{The Morton Arboretum, Lisle, I L}

Marlin Bowles, Research Associate

Two projects were discussed where $P \& T$ techniques are being used for recovery of plants that are Federally-listed as threatened. The first example pertained to the Pitcher's dune thistle (Cirsium pitcheri), a monocarpic plant that grows five to ten years. This plant is extinct in Illinois and is currently restricted to the shoreline of Lake Michigan. Research indicates the plant has very specific habitat requirements and will grow only in areas with more than 60 percent sand. The Federal recovery plan for the species calls for the reestablishment of a certain number of populations and experimental restoration in Illinois.

Under the research project, the plant's distribution has been mapped and thoroughly studied. The species occupies a dynamic habitat within the shoreline ecosystem. Its primary habitat is located on the outer dunes. The species is incompatible with anthropogenic disturbance regimes at this location which include shoreline stabilization activities, construction, and recreational access by the public. Secondary dunes within the area serve as the plant's secondary habitat, and were selected as the site for the P\&T project. The effort began by collecting seeds under permit at several sites, propagating the seeds in a greenhouse, and planting seedlings once a year for four years. The seedlings were placed along transects in the field in both fenced and unfenced plots. Extensive data has been collected to determine habitat requirements and other factors affecting survivorship. Approximately one to five percent of the seeds germinated and the overall rate of survival has been 30 percent. Plants from Wisconsin have 
not adapted well to the Illinois lake shore. Studies on allozyme frequencies indicate the plant is genetically uniform, but planting success shows ecotypic differentiation. Results also show a need for age-structured populations as the plant blooms once and then dies. There have been some problems with deer and rabbits eating the leaves of the plants prior to the flowering stage. However, two plants that did flower produced over 1,000 seeds, which are being maintained in cold storage.

The second project involved the Mead's milkweed (Asclepias meadii), a perennial plant that is found from Kansas to Illinois in undisturbed dry-mesic prairie. It is almost extirpated from the eastern part of its range. In the prairie ecosystem where the plants occur, active burning regimes have not been maintained and some habitats have been destroyed by herbicides. In the west, where more plants occur, most populations do not reproduce because annual hay-mowing removes the immature seeds. Small populations appear to be genetically uniform and incapable of outcrossing, which is needed for seed production.

Restoration is needed to create new genetically diverse populations, and to restore reproduction in hay meadow populations. Tissue culture of plants is problematic because such clones would be genetically uniform, and because the procedure is not fully understood. As a result, restoration requires garden-propagated seedlings from wild collected seeds or from nurseries. Garden propagation must avoid selection for cultivars. Experimental restorations were initiated in 1994. After planting, a leaf area index was used to compare plants from different restoration areas. The study has shown that different habitats and seed sources affect survival.

P\&T projects entail a lengthy, detailed, and expensive process. It is important to have a large sample size, replicate field sites, and use experienced researchers when conducting these types of projects.

\section{University of New Mexico (UNM)}

Timothy Lowrey, Associate Professor, Department of Biology, UNM

Dr. Lowrey discussed his work with the Tetramolopium arenarium at the Pohakuloa Army Training Area, a dry forest in Hawaii. This area has been heavily used for tank maneuvers, artillery practice, bombing runs, and other military training activities. In this example, TES plants were a "show stopper." Following a lawsuit on environmental impact, the Army was required to cease operations at the new 
$\$ 30$ million motorized target facility constructed at this site. A biological survey of the training area located plant species previously thought to be extinct as well as new populations of other listed species.

Research on the Tetramolopium arenarium has involved measuring the genetic relatedness of congeneric species as well as measuring the amount of genetic variation at the population level. Only one population of the species was found, and the plants were for the most part genetically identical. Plants with genetic similarities were interbred and grown successfully in the greenhouse. However, when transplanted to the field, the plants experienced a mortality rate of more than 90 percent.

\section{New Mexico Forestry and Resources Conservation Division}

\section{Robert Sivinski, Botanist, NM Forestry and Resources Conservation Division}

Mr. Sivinski described his experience with several projects involving P\&T. One project pertained to Knowlton's cactus, an endangered species known from one small population on a reserve managed by The Nature Conservancy. The recovery plan for the species required dispersing plants to other remote locations in its historic range. Cloning was the selected method of propagation since the population is small and clones from a few dozen individuals could easily contain most genetic variation. Stem cuttings were taken from the caudex, dipped in rootone, dried for a couple of days, then potted in a greenhouse. The cuttings developed roots in approximately three months and were then transplanted to the field. Of the first 150 cacti set out, 97 percent survived the first year and 65 percent have survived the last eight years. Although these plants have flowered and produced fruit, no new seedlings have occurred at the transplant site. The project cannot be considered successful until there is natural reproduction.

Seed plots were also established for the Knowlton's cactus. Wire field fence was nailed horizontally to the ground and seed planted in each cell. This process was used to help locate and count seedlings in subsequent years. Less than two percent of seeds planted have germinated over a period of six years.

Translocation projects have had a much lower success rate. On one project involving grama grass cactus, only 25 percent of attempts were successful. New transplants were often destroyed by predation from rabbits and other rodents. Failure to establish micorrhizal relationships may have also contributed to the low survival rate. Another project involved moving a Mesa Verde cactus from a site on 
a Navaho reservation. In this case, the transplant was not marked, and seedlings could not be found for several years. In another example, the Bureau of Land Management asked an oil/gas company to transplant Gilia formosa, a candidate plant. The plant was moved to a greenhouse for one year and then transplanted in the field. Only 12 percent of the plants survived. Agencies should generally avoid transplanting for mitigation purposes since these projects rarely succeed.

Mr. Sivinski recommended that agencies focus on candidate species. The USF WS is under a law suit to either list or delist $401 \mathrm{C} 1$ candidate species by September 30,1996 . If installations have $\mathrm{C} 1$ species onsite, now is the time to be proactive. Agencies should explore the possibility of obtaining funding through ESA Section 6. Under this program, the USFWS covers 75 percent of approved project costs, and the state pays 25 percent.

\section{U.S. Bureau of Land Management (BLM)}

Ken Berg, National Botanist, BLM

Mr. Berg summarized case studies of mitigation-related projects involving the translocation, relocation, and reintroduction of TES plants in California. The source of this data is a 1991 publication by Peggy L. Fielder entitled, Mitigationrelated transplantation, relocation and reintroduction projects involving endangered and threatened, and rare plant species in California. Final report to California Department of Fish and Game, Sacramento, CA.

The case studies were devel oped from responses to questionnaires mailed to 377 individuals, agencies, and institutions. Of those questionnaires sent, 168 were returned by 24 agencies and individuals involved with T\&P projects in California. Files from the California Department of Fish and Game provided supplemental data.

Questionnaire responses contained information on 46 different projects involving 41 translocations, nine reintroductions, two restorations, and one other. The case studies represented a total of 40 plant species in 21 families. Most of the projects had been implemented, with only 10 in the planning stages. Notably, only onethird of the projects had explicitly defined success criteria, and according to evaluations by the individual project proponents, eight attempts (15 percent) were fully successful and nine attempts (17 percent) were partially successful. 
The following conclusions were drawn from the case studies:

- Individual plants should be removed with as little physical disturbance as possible, and at a phenologically appropriate time of the year, e.g., when plants are dormant or photosynthetically inactive.

- The receptor site should be of the same habitat quality, especially soil and physical characteristics. Weeding, watering during drought, and fencing and other forms of site protection may be needed.

- Knowledge of the biology of the species is essential to developing appropriate horticultural techniques. This knowledge is usually lacking.

- Because of low success rates, translocation, relocation, reintroduction should be used to mitigate adverse impacts to endangered, threatened, and rare plant species only when impacts cannot be avoided and there is no demonstrated practicable alternative. 


\section{Findings and Recommendations}

In a panel discussion and small group sessions, participants were asked to identify management issues and research priorities, focusing on the decision process and tools needed to enhance survival of TES plants on military lands.

Based on small group presentations and facilitated discussions, thefol lowing findings and recommendations were generated.

\section{Findings}

- The USFWS considers controlled propagation an essential tool for the conservation and recovery of listed species in certain circumstances. In general, applications of $\mathrm{P} \& \mathrm{~T}$ for mitigation purposes have had a low success rate, and should be considered only as a last resort. When used as a tool for enhancement, recovery, or reintroduction of TES species, P\&T may be considered a higher priority.

- $\quad P \& T$ projects entail a lengthy, detailed, and expensive process. Failure to plan properly, conduct essential preliminary research, and commit adequateresources for the necessary duration are the primary causes of low success rates on these projects. P\&T activities need to be conducted as well-designed research experiments with provisions and commitments for data gathering and monitoring over a long-term period.

- Military installations require additional information and research on methods to enhance survival of TES plants. Many of these requirements can be met, or strongly supported, by information transfer activities that provide access to relevant literature (including "gray literature") and sources of expertise. Research activities at the national or regional level can address broad military needs. Well-coordinated, additional research is required at the installation level to address issues that are highly specific to the site and species of concern. 


\section{Recommendations}

In addition to the group's general recommendations below, recommendations were developed into programmatic statements in two primary areas: (1) the decision process for managing TES species and (2) guidelines for appropriate use of P\&T. Information and research needs were also formulated. First, the workshop group's general recommendations are presented below, followed by the programmatic statements.

\section{General Recommendations}

- With limited research funds, USACERL should support high priority information transfer and research activities that address broad military requirements. Specific attention should focus on:

- Methodologies for data collection and analysis to support inventory, impact assessment, land use planning, and monitoring activities

- Approaches and techniques for biodiversity and ecosystems management, including cooperativeresearch with other Federal land management agencies that are already pursuing such initiatives (e.g., U.S. Forest Service, BLM, National Park Service, National Biological Service)

- Mechanisms to identify, assemble, and transfer information on available literature and sources of expertise on TES species

- Management information and guidelines including regulatory compliance/ planning tools, and decision process models for enhancing survival of TES species (this material should address a full range of strategies and tools, including conservation techniques, interagency coordination protocols, and P\&T methods).

- USACERL should conduct a series of regional workshops to further assess military needs at the regional and local installation levels, and to facilitate regional communication on pivotal TES and biodiversity management problems.

- USACERL should support on-the-ground research initiatives that focus on specific species, ecosystems, mission impact assessment issues, and/or problem areas that are common to several military installations. Criteria for determining research priorities include:

- Military installations that contain a significant portion of the range of species and communities of concern 
- Military installations with high intensity land useand potential conflicts with long-term conservation requirements (unless such long-term conservation and mission planning is well-integrated)

- Keystone species and TES species located in ecosystems that, themsel ves are rare, unique, or threatened

- Species and/or types of impacts that occur on a number of installations

- Installations where TES management may be adversely affected by Base Realignment and Closure (BRAC) dynamics

- Military installations that have missions and land use practices that enhance the occurrence and survival of TES species

- Installations that have al ready developed a good biological base.

- Research on particular sites and species of concern should focus on:

- Comprehensive study of ecological relationships and requirements of TES species, including applied genetics, in-depth habitat characterization, historical distribution, and community and ecosystem processes

- Impacts of military mission activities and disturbance regimes on TES species and habitats

- Management strategies and approaches to meet the biodiversity mandate, recovery goals, and conservation agreements.

Relative importance of these research topics will be species specific.

\section{Programmatic Statements}

\section{Management Process for TES Species}

The following guidelines represent a synthesis of breakout group presentations and subsequent commentary provided by Ed Guerrant, Conservation Director, Center for Plant Conservation (CPC). Breakout groups were asked to address the process for determining management and research requirements to enhance survival of TES plants.

The management process for TES plants involves the identification and ranking of needs at the installation level. The goal is to facilitate the coexistence on military installations of the military mission and plant taxa of concern. To achieve this balance, installations need to collect and analyze data on the plant communities present, factor in requirements and plans for mission activities, and determine impacts of these mission activities on species of concern. Throughout the management process, the installation should identify linkages with both internal and 
external organizations to identify requirements, constraints, and opportunities for enhancing survival of the TES plants found onsite. By following this process, the installations can determine the best strategies for managing and protecting TES species. The activities involved in this process are summarized below. Although presented in linear order, these activities are not necessarily performed in strict linear fashion. New information may be added to any step at any time, and many of the activities represent parts of functional loops. The management decision process entails the following key activities:

1. Conduct Inventory of Plant Populations. The first step in the process is to conduct background research into what species of concern are known or suspected to occur on a particular installation. There is no need to reinvent the wheel; considerable work has been done in this regard which is readily available. Begin by contacting agencies or organizations, all of which have prioritized lists:

- $\quad$ The USFWS has lists of threatened and endangered species, and of taxa that are candidates for listing. Installations should note that C2 species are not necessarily less rare or threatened than C1 species which the USFWS considers worthy of listing as threatened or endangered. Listing of C2 species is often precluded for practical reasons, in order to focus limited resources on higher priority taxa. C2 taxa are those for which insufficient information exists at this time to make a judgment. Many C2 plants are extremely rare and perhaps highly threatened.

- In many states, there is a specific state agency that is charged with protecting $T \& E$ species. These agencies should be contacted for pertinent information.

- Natural Heritage Programs which may be associated with the state or The Nature Conservancy should also be contacted. These programs are perhaps the best source of site-specific information at the population level. Given the difficulty of defining populations, the Natural Heritage Programs designate and follow sites as "element occurrences" (EOs). Their databases have precise site locality information that, in many cases, can probably be entered directly into the installation's existing GIS. The taxa have all been placed in a Global Ranking scheme, which can aid in prioritizing taxa.

2. Conduct Survey of Plant Populations. This step in the process involves onthe-ground surveys of plant populations as a supplement to the inventory work described above. 
3. Evaluate Biological Resources in Context. Given the information obtained above (i.e., site-specific locations and rough estimates of size of all known occurrences of F ederal and state-listed species and candidate taxa), the biological resources of each installation can be evaluated within a variety of relevant contexts. Putting all of this information in one or more layers of a computer-based GIS is ideal, but paper maps will suffice if GIS capability is not available. Contexts involved in the evaluation include, but are not necessarily limited to:

- Military land use: historical, current, and future

- How do an installation's populations fit into the context of the full geographical range occupied by each taxon? (Does a base have $1 \%, 10 \%$, or $100 \%$ of the known occurrences? Are other populations on F ederal or state land, or are all on privateland?)

- $\quad$ Plant communities and their conditions should also be induded as a layer in the GIS. Many Heritage Programs also have community ranking schemes.

4. Identify Conflicts, Threats, and Opportunities. The objective of this step is to identify conflicts and opportunities associated with land use for mission activities and the protection of TES species and critical habitats. This step and the evaluation step described in item 3 are not really that different. Only when sitespecific information on all known occurrences of listed and candidate species is in a form where it can be viewed in context can informed decisions be made. Installations can use the Land Condition Trend Analysis (LCTA) system and other modules in the Army's I ntegrated Training Area Management (ITAM) system to perform evaluations required under this step.

The military needs an ability to plan and manage land use to support mission requirements while protecting natural resources. In order to accomplish this, installations need tools to determine the significance of varying levels of impact on TES species and the ecosystems on which they depend. The installations also need to understand and recognize the importance of ecosystem processes. Guidelines on ecosystem management are currently being developed by Brian Fisher, National Research Council, Biology Group.

5. Coordinate with Regulatory Agencies. Installations should review pertinent regulations (e.g., NEPA, ESA, Section 404, Army Regulation (AR)-420-74 Chapter 11, etc.) and develop compliance strategies and plans. It is important to establish and maintain successful relations with regulators throughout the process. Coordination with regulatory agencies should begin early on, and continue on a 
frequent and ongoing basis. After having made initial contact with the USFWS and other appropriate state and F ederal agencies to obtain initial lists, go back to them with the full range of information that has been collected, and begin working out installation-specific strategies about how to best deal with any potential conflicts, and how to exploit any opportunities that can be envisioned.

6. Establish Initial Priorities. Rank taxa and populations from highest to lowest concern, and allocate resources accordingly. Species priorities may differ from USFWS rankings depending on installation-specific demands; for instance, the installation may consider candidate species a priority.

For taxa of highest concern, the following steps are necessary.

7. Conduct Site Evaluations. Detailed site evaluations should be coordinated with the USFWS. Kathryn Kennedy, USFWS Austin Field Office, has a protocol for conducting such site evaluations.

8. Develop Baseline Biological Information. Necessary information includes but is not necessarily limited to:

- The taxon itself: life history (habit, perennial, annual, monocarpic, polycarpic?); breeding system (sexual, asexual, mixed); symbionts (pollinators, seed dispersers, mycorrhizae); seed dormancy (Does it exist; How is it broken?)

- Its habitat: What is the type and condition of habitat? What are the habitat requirements and competitive interactions?

9. Establish Monitoring Program. A sound monitoring program will allow managers to detect biologically significant changes in the size or condition of populations whether or not they are being actively managed. Sound monitoring practices are necessary to properly evaluate the effects of management techniques.

Monitoring procedures have undergone a revolution in the last few years, and many groups (e.g., The Nature Conservancy, BLM, and the U.S. Forest Service) have devoted considerable thought and resources to developing statistically sound monitoring strategies for a wide range of situations.

Ed Guerrant, CPC, provided selected references on monitoring to the workshop facilitator subsequent to the workshop. These references are cited in the last section of Appendix B, $\mathrm{p} 63$. 
10. Develop Action Plan for Species of Concern. The installation should evaluate the situation of taxa of highest concern (step 6) in light of specific information gathered in steps 7, 8, and 9. With this sort of information, the installation will be in a position to define the issues of concern, evaluate research needs that have emerged, and clearly outline the universe of management options.

\title{
Guidelines for the Use of Propagation and Reintroduction Techniques in Endangered Plant Recovery Programs
}

\author{
Kathryn Kennedy, Botanist \\ USFWS Ecological Services Field Office, Austin, TX
}

Dr. Kennedy presented the following criteria for deciding on the advisability of using off-site propagation and reintroduction techniques in devising a conservation strategy for a species. Dr. Kennedy also discussed guidance for proceeding with planning and preparations. These steps have been recommended in recovery plans for species where it is felt that achieving full recovery will involve some of these techniques. Conditions leading to such recommendations arise only under circumstances of extreme vulnerability involving low numbers of populations and individuals, with severe risks of catastrophic loss, as discussed below. A process diagram developed by Dr. Kennedy is depicted in Figure 2.

This presentation was directed at providing some general guidance for the proper evaluation and use of propagation and reintroduction techniques in the context of an overall conservation strategy for a species. It should be clearly understood that USFWS policy does not permit "introduction" of T\&E species into habitat outside of known historic range. Additionally, the Service discourages transplantation of individuals, let alone populations, from one wild site to another; this presentation was not intended to provide guidance for transplantation from one wild locality to another in a "rescue" scenario. Given the failure of most of these attempts, this is seldom recommended.

Decisions to pursue propagation and translocation activities require thorough analysis and coordination with the USFWS and other sources of expertise. These decisions are highly specific to the particular site and species of concern. In general, propagation and reintroduction actions are recommended as recovery or conservation measures for TES plants ONLY when there is a low number of populations AND a low number of individuals (often with insufficient reproduction rates) AND the plants are vulnerable to catastrophic loss. 


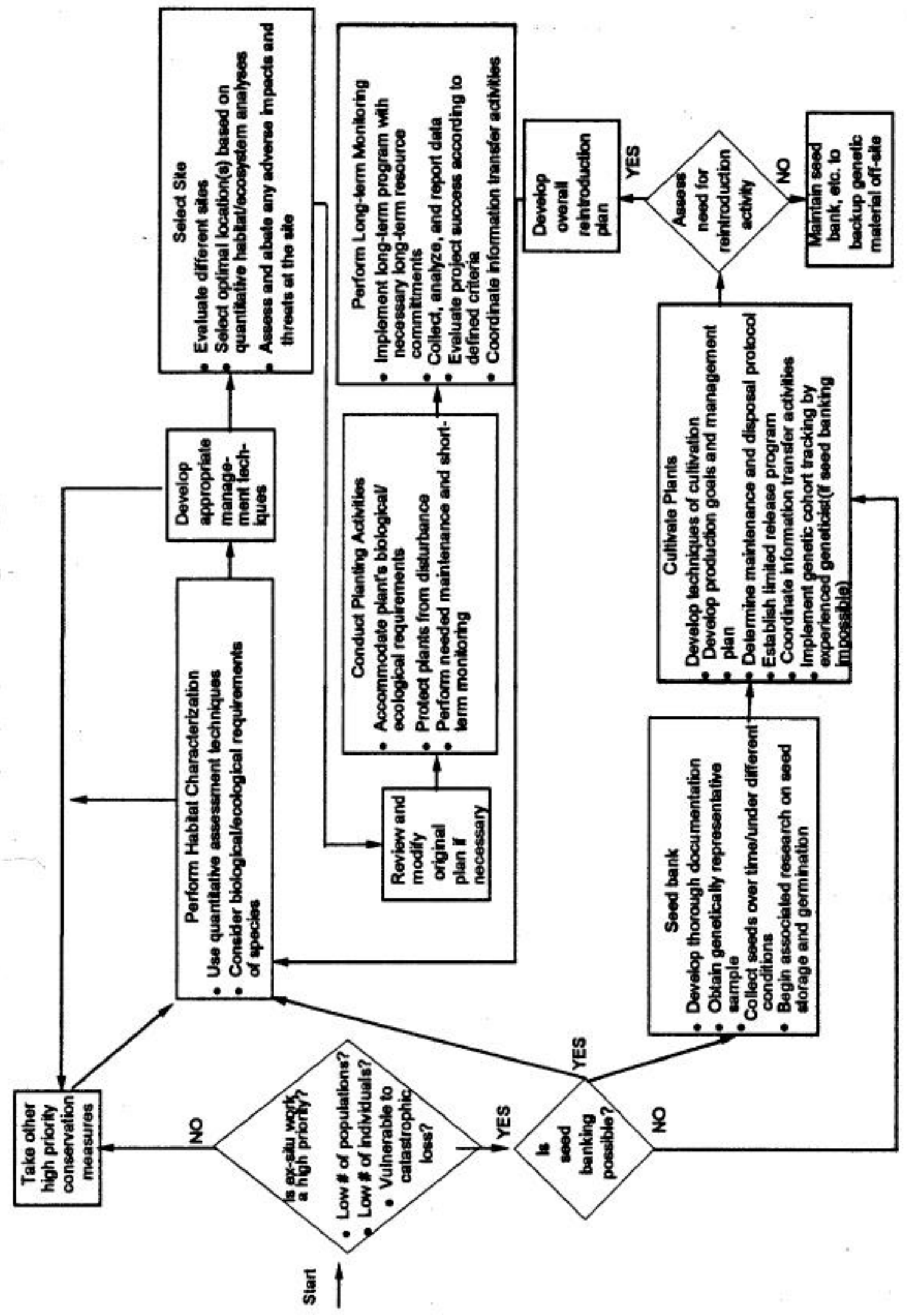

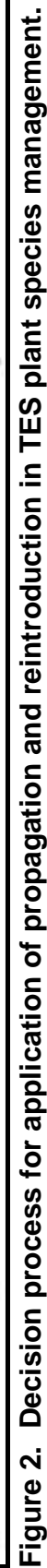


Seed Bank. The first step in the process should be to back up the genetic material of as many populations as possible in at least two off-site refugia. Getting samples of seed into a seed storage bank is preferred, if possible, because it is relatively inexpensive, does not require a lot of room, and is effective over the long term for many species. For example, the National Seed Storage Bank in Fort Collins, Colorado, provides this vital service, in cooperation with the Center for Plant Conservation (CPC). It is important to obtain a genetically representative sample of seed from as many of the known populations as possible. I deally, seed banking should occur at two or more established, reputable seed storage banks in order to obtain a more secure back-up system.

The CPC presents guidelines for collecting genetically representative samples of populations in their 1991 volume, The Genetics and Conservation of Rare Plants (F alk and Holsinger, eds.). Seed should be collected in a manner that will minimize interference with natural processes in wild populations wherever possible. Where possible, these decisions about permissible impacts should be made based on the known biology of the species and the crop at that time. The USFWS Austin Field Office, as a general rule of thumb, does not permit collection of more than 10 percent of the seed crop in any given year, and has not allowed any seed collection when a population contains fewer than 25 individuals, unless it is identified by the Service as a critical situation where there is little alternative. To obtain the needed seed with minimal interference and to maximize representative variability, it may be necessary to collect seed over several different seasons. Recent research has demonstrated genetic adaptation within plant populations to particular microsites, climatic regimes, or events; some populations may have important adaptations that are not represented in every seed crop. Because of this, the Austin Field Office has supported seed collection from several crops, if it is necessary to help minimize impacts and ensure that genetic adaptations to varying environmental conditions are represented.

In some cases seed storage is not possible, and meticulous cultivation is the only alternative. When obtaining plant material for cultivation, the same minimal impact approach should be used-trying to take seed first, then offshoots or rhizomes, cuttings, etc., and removing whole plants from the wild only as a last resort. The objective is to "back up" the genetic information from the populations efficiently and economically, with minimal impacts, using appropriate techniques determined by the biology of the species concerned. Many agencies immediately begin off-site cultivation of a few plants as a conservation strategy without providing for or documenting genetic representation in the cultivated population(s), without careful documentation of the pedigrees of the cultivated plants or populations, and without assuring long-term integrity of the collection. These 
actions may in fact be detrimental, resulting, for example, in uncertified interpopulation crosses that have lost site-specific adaptive advantages. Population geneticists have pointed out that to truly maintain the genetic representation of a natural population through cultivation alone is expensive and risky. The process requires that population samples be kept separate and reproductively isolated in cultivation, and requires genetic tracking and breeding by an experienced geneticist. When cultivation is the only alternative to long-term seed storage and seed banking, it is difficult to avoid a loss of genetic material and vigor.

A great deal of research is needed al ong with refugia activities. Agencies participating in refugia efforts should determine seed longevity, germination parameters, and appropriateness of various storage techniques such as cryogenic storage. Seed needs to be periodically tested for viability and germination. This information is important to the success of the program. If longevity in storage is low, seed may need to be replenished periodically. In cases where wild populations are no longer extant, periodic cultivation of stored seed may be necessary to maintain viable seed stocks. All seed banking activities and research (including periodic cultivation for replenishment) should be thoroughly documented. Data and information collected should be shared with others involved with recovery efforts. As expressed in the previous paragraph, serious concerns surround the cultivation of stored seed; these concerns should be addressed to the highest degree possible through careful cultivation protocol design, together with meticulous pedigree documentation of stored and cultivated seed.

Cultivation. Once genetically representative material of the vulnerable populations has been preserved, if it has been agreed that cultivated plants are needed for research, education, or ultimately for augmentation or reintroduction purposes, the next step in the process is to develop techniques of cultivation. For many species, growing plants is relatively easy, but problems arise if cultivation programs are not well-planned or documented. Suddenly the program has produced many plants, with inadequate plans for what to do with them. Often they are germinated and grown with minimal monitoring or collection of data. As a result, in the future, problems encountered in the first effort cannot be avoided and successes cannot be duplicated or "fine tuned". Pressure builds to "plant out" the cultivated material, often without adequate planning and preparation, without adequate pedigree, habitat knowledge, nor ecological background, and without ensuring that the material is of ideal age and condition. The result can be a waste of scarce agency resources and rare genetic material. 
Before propagation or planting begins, it is important to develop a cultivation management plan. This plan should identify exactly why the plants are being grown (e.g., genetic back-up, produce research material, education), set rigorous production goals that do not result in excessive production, outline maintenance and disposal protocols, and identify requirements for any experimental investigations (including design, data collection, analysis, and reporting and information transfer to others).

Release policies and procedures should also be established in this plan. There are differing philosophies among practitioners regarding the release or sharing of plant material for enthusiasts, collectors, and the horticultural trade. However, it must be remembered that commercial activity in listed species is regulated, and requires special permits. The potential for problems with genetic contamination and possible weakening either of the species or of other closely related taxa that may come in contact with it must be considered, as must the potential for the species to become a pest or interfere with natural community composition if it should escape and become established outside its natural habitat.

I mportant ethical issues surround the use of limited genetic material of vulnerable species. Unless it can contribute to the overall preservation and eventual recovery of a species in the wild, the Service will not provide permits for commercial activities with listed plant species. The Austin Field Office examines each species' situation on a case-by-case basis, but generally discourages the release of plant material of rare and vulnerable species by agencies, gardens, etc. The Austin office is supporting the development of horticultural sources in a few cases where the release of material to the horticultural trade is important to controlling collection threats in the wild, and careful evaluation has shown little threat of adverse impacts.

Program Assessment. If genetic back-up systems are in place and needed cultivation techniques have been devel oped to sustain these systems, an assessment is needed to determine whether or not further field activities are really needed and appropriate. This decision should not be made independently. The agency should determine if the actions are suitable and necessary based on the recovery plan or an overall conservation strategy developed for the species. The agency should coordinate with the USFWS and other agencies to evaluate the appropriateness of augmentation or reintroduction activities. If populations appear to be capable of recovery through habitat conservation, stabilization and restoration alone, the Service would discourage it, because such work is too expensive and labor intensive. If additional work is not needed, the process should stop here, maintaining the seed bank and whatever associated cultivation activities are necessary to maintain the back up of the genetic material and supply 
recovery research and education needs. If augmentation or reintroduction is agreed to be needed, the agency needs to conduct additional planning activities before proceeding in an experimental context in the wild.

Field Activities - Program Design and Management Planning. If a decision is made to proceed with field trials, a detailed program design and management plan should be developed and finalized through a peer review process including conservation agencies. The plan should cover all aspects of the project, including habitat characterization and management techniques, site selection, experimental design, quality assurance/quality control (QA/QC), planting procedures and maintenance, threat abatement, monitoring activities (data collection, analysis, and reporting), and detailed, objective, success criteria. Before the plan is developed, adequate funding should be committed to support the necessary, long-term level of effort.

Habitat characterization. Environmental habitat characterization is an important precursor to field planting, and can also contribute important knowledge for conservation and management activities at the installation level. Habitat characterization is a detailed, quantitative process that examines biological characteristics (community, closely associated species, etc.) as well as other critical site attributes such as soils, hydrology, and microdimate. If possible, a team approach to defining the habitat should be taken using expertise from biologists and ecologists of various subdisciplines, geologists, soil scientists, climatologists, etc.

It is important to realize that plants may require specialized situations for certain phases of their life history (such as germination sites, "nurse plants," mycorrhizae, or dispersal agents), and that some plants within a population may be genetically adapted to particular micro-conditions within a site. To obtain accurate information that really covers the possible range of variation, the habitat characterization should be done not just at a single site (which may be anomalous or borderline in quality) but at all known populations of the species. In many species and in many regions, variation in conditions from year to year also expose significant differentials between and within populations. Commonalities and differences should be noted. Techniques such as principle components analysis and factor analysis should be used to produce quantitative analytical results.

Thorough natural history studies of the species at the population level and over multiple field seasons will provide an even better habitat characterization, establishing the essential baselines and ecological frameworks within which the habitat data must be interpreted. Often, insufficient time and resources do not 
permit researchers to acquire multi-year natural history data in advance of other program phases. However, critical, quantitative examination of natural habitat should continue over time whenever possible, and the ongoing, systematic acquisition of natural history and habitat data should always be built into the long-term monitoring program. Less informed, tentative conclusions from earlier program phases should be rigorously reassessed on a periodic basis as data assemblages mature.

Habitat management techniques. Once the habitat is characterized, the degree of management necessary to maintain it in suitable condition needs to be evaluated, and management techniques developed if necessary. Restoration efforts will fail if habitat suitability is not maintained. Like site characterization, this process should be done using quantitative rather than qualitative techniques or simple observation. Some indications of likely degree of management needed and potentially effective techniques may be derived from a review of the history of land use practices on existing sites, and the relative condition of those populations. However, such observation may not reveal all the impacts and processes involved at a site and cannot be used by themselves to make management decisions. If necessary, pilot projects should be established to quickly determine appropriate management to assure the needed habitat elements, age structure, and distribution of individuals for a healthy population. The agency should use only known, demonstrated techniques for managing the habitat, providing either protection or needed disturbance regimes as determined by the biology and responses of the species of concern.

Siteselection and threat abatement. With a detailed habitat profile developed and management scenario worked out, there is a basis for proceeding with site selection. An appropriate habitat should be selected with potential for successful management. In addition to habitat and ecological requirements necessary for success, factors to consider concern logistics for installation, maintenance, and monitoring/data collection.

Threats must also be evaluated, including those specific to the site such as the potential for unauthorized collection, vandalism, and impacts from use or maintenance activities in the area. General factors considered as significant threats to the species (such as livestock, exotic species, etc.) should be evaluated. Where possible, quantitative assessment of the risks presented by these factors should be undertaken. If threats cannot be sufficiently ameliorated at a site, there is little point in proceeding. The methods and results of partial or complete threat abatement should also be carefully documented and monitored. 
Review of experimental design and preparation. Based upon the experience and information gained during habitat characterization, management evaluation, and site selection activities, the initially proposed experimental design should be reevaluated to be sure it is still feasible and appropriate. If necessary, the initial plan should be modified, in consultation with other interested, expert, and responsible parties, as noted above. Once the design and plan are validated, preparations such as producing needed plant materials, and arranging logistics, can proceed. (An element of experimental design recommended especially for a long-term project is a periodic self-assessment, allowing for regular, systematic "calibration and adjustment," and refinement of the design as information about and understanding of the subject develops, both from within the project and in the research field at large. This will maximize both the defensibility of the research and the value of the resources invested in these long-term projects.)

Planting, maintenance, and monitoring. Planting should be done or supervised by experienced field personnel and carefully trained assistants, using techniques (previously developed in refugia and cultivation research efforts) that are appropriate for the species and the environment. In many cases, plants require some care after initial planting. The previously developed experimental design and data gathering/monitoring plan should be meticulously implemented. As a protocol under the plan, problems that are encountered during the course of the project, and the solutions that are devised and implemented, should be carefully documented. This valuable information should be transferred to others working on similar problems as soon as possible. Problems should be discussed with the conservation agency cooperators and peer review experts for assistance in developing and sharing solutions whenever possible. Periodically, other agencies and peer experts should be kept informed of the progress of the project.

Conclusion. Field-based reintroduction and augmentation projects require longterm monitoring and documentation to really evaluate the project, not only in terms of success or failure, but for all of the other important knowledge that will be acquired regarding the species, and significant experience gained with such projects and research. Monitoring requirements can span a period of 20 years or more; it should cover the life spans of several generations. The useful information that can be gained from very short monitoring periods of 1 to 5 years is limited and suspect; certainly, long-term success cannot be reliably predicted or assured. If a project is poorly planned and is not conducted in an experimental context with rigorous data collection and analysis, it is likely to be useless, wasteful of rare genetic material or, worse, result in incorrect conclusions that could be disastrous for species management. Undertaking propagation, augmentation, and 
reintroduction efforts requires a commitment to quality work, and considerable time and resources. Such efforts must be carefully considered and planned.

\section{Information and Research Needs}

Participants were asked to identify research and information needs, focusing on possible activities that USACERL could support. USACERL is interested in conducting research and information transfer activities that address broad military needs. Research that is specific to a particular site or species is generally addressed at theinstallation or MACOM level. USACERL could consider supporting site-specific projects if they address issues of interest to multiple installations. USACERL is also interested in site-specific projects to demonstrate or test protocols that have been developed.

The following research and information needs were identified through the group process. In addition, Kathryn Kennedy, USFWS, offered a cogent outline of research issues and approaches. This outline follows the group's products:

\section{Inventory and Monitoring}

- Methodologies for monitoring TES plant populations

- Methodologies for vegetation mapping and del ineations, including enhancements to ITAM

- $\quad$ Techniques for monitoring the general health of plant communities within a larger ecosystems framework; techniques to identify indicators of species/ecosystem health

- $\quad$ Remote sensing techniques for identifying TES species in munition impact areas

\section{Impact Assessment}

- Studies on the effects of ground-disturbing activities (e.g., fire, tank maneuvers, etc.) on TES species and habitat (including both positive and negative impacts caused by various intensity, timing, and frequency of activities)

- Guidelines and techniques for determining the impact of landscape changes on TES species and ecosystems

\section{Biological/Ecological Requirements of TES Species}

- Biological and ecological information at the landscape, community, and species level 
- Information on species genetics/reproduction including methods for maintaining co-adapted gene complexes, determining the impact of seed selection on P\&T projects, and issues associated with inbreeding depression versus outbreeding depression (effects of mixing plants from the local area with plants from distant sources)

\section{Conservation/Protection of TES Species}

- $\quad$ Methods for determining habitat patch size and scale for protective areas based on species population and variety

- Guidelines for management of candidate species

\section{Propagation and Translocation}

- Guidelines on when P\&T can or should beused to enhancesurvival of TES plants

- Management information related to propagation and translocation including a flow chart on decision processes involved, quality control procedures, population viability models, identification of resource people, and training

- Techniques for propagating and translocating TES plants (needs to be specific to site and species)

\section{Management Guidelines}

- Management decision process diagrams and tools

- Guidelines for ecosystems management (would also include coordination of inventory and management activities for TES species found on land adjacent to military installations; provide information on the role/niche of species within ecosystem)

- Guidelines for coordinating TES plant programs with non-military and private sector organizations outside of installation boundaries

- Strategies and techniques for optimizing installation-specific carrying capacity

- Guidelines for exotic species control

- $\quad$ Strategies and techniques for maintenance/restoration of keystone species and lifeforms

- $\quad$ "Toolbox" of possible techniques for enhancing survival of TES plants (e.g., management, recovery, mitigation actions); evaluation of available tools

\section{Regulatory Compliance/Planning Support}

- Guidelines for integrated planning associated with regulatory requirements for TES species (e.g., coordination of planning for permits, experimental populations, 
NEPA, and ESA consultations; development of standardized compliance checklists; etc.)

\section{Needs Assessment}

- Regional workshops to assess specific needs and opportunities for research on TES plants

- Intra-military issue identification and resolution

- Facilitate command-level review of environmental priorities and problem areas (address needs associated with balancing TES species and mission requirements, and compliance versus conservation/protection actions, etc.)

- Methods for ranking and prioritizing TES species and habitats

\section{Information Transfer}

- Assistance in identifyingliterature, data, and sources of expertise on specificTES species and methodologies for enhancing their survival (literature searches and databases)

- Information on seed sources for native plants

- $\quad$ Guidelines and strategies to improve public perception; incentive program to recognize/reward good TES management; augment environmental awareness components in ITAM

- I I dentify and write up examples where good environmental and mission planning has avoided conflict with USFWS.

\section{Criteria for Research Priorities}

The following recommendations were presented as criteria for developing research priorities and selecting possible sites and species for further study. Research should focus on:

- Military installations that have a significant portion of range (species and communities)

- Military installations with high-intensity land use and potential conflict

- $\quad$ TES species located in ecosystems that are rare or threatened

- $\quad$ Species and/or impacts that occur on a number of installations

- Installations where TES management is affected by BRAC base dynamics

- Military installations that have missions and land use practices that enhance the occurrence and survival of TES species

- Keystone species or communities that are biologically unique or rare

- Installations that have al ready developed a good biological base. 


\section{Research Issues and Approaches for Enhancement of TES Species}

On a species-specific research basis, for a given high-priority species:

a. First ensure that back-up of the genome is in place for all populations possible (most efficient to do through seed banking if feasible, or through cultivated collections if necessary, for each population). This should be done beforevaluable genomic material is used in experimental and cultivation/restoration programs. Back it up first.

Research needed:

- Germination profile, hardseededness, stratification needs, etc

- Tolerance of species for seed banking

- Tolerance for cryogenic storage

- Viability over time.

b. Determinecritical habitat factors (for siteselection and for cultivation programs) and surveys needed, and sensitivity of the habitat.

Research needed:

- Compile habitat characterization for known populations.

- Examineplant community, topography, soils, microclimateand macroclimate, and land use history.

- Test the "critical test" hypotheses derived from these pivotal questions: (1) Is this species dependent on disturbance or intolerant of disturbance? (2) Of what types? (3) What are the management implications of its disturbance profile?

c. Examine population parameters.

Research needed:

- Examine distribution and abundance of known populations and suitable habitat in present and historical context. What is a reasonable and sustainablenumber of populations over how widean area to ensure long-term survival of the species in a functional context in its natural community.

- Exami neknown populations. What is a vigorous and healthy population like? How many individuals of what age classes? What level of reproduction relative to numbers of adults in seed production? Seedling germination? Established juvenile plants? Propagation in the seed bank in the soil? 
Conduct population viability analysis, if possible, to help determine parameters for a viable population.

d. Evaluate reasons for rarity as well as the vigor and phenology of the populations: look for intrinsic limitations using simple symptomatic tests.

Research needed:

- Are there any signs of reproductive or genetic malfunction? Is viable seed being set?

- Are pollinators available in sufficient numbers?

- Is pollen germinable?

- Do seedlings fail to thrive? - If there is evidence of genetic problems, proceed with additional genetic viability research, including molecular, only if it is necessary to illuminate apparent problems.

- How is reproduction occurring in the wild? Sexually or asexually, or both? To what degree?

- Arethereany unusual reproductivesyndromes that must beallowed for, such as unisexual plants or flowers, or heterostyly?

- Is this species' reproduction cyclical in response to any periodic event, or dependent upon any catastrophic event (i.e., seasonal occurrences, fire, flood, infrequent rains, infrequent disturbance)? Can these be determined and provided for?

e. Examine threats.

Research needed:

- What extrinsic factors may be contributing to rarity or decline? Habitat loss or habitat management regimes? Catastrophic events (natural or mancaused)? Disease or herbivory? Collection?

- Can these threats successfully be mediated to levels that will allow survival of the species as a whole?

- Select sites that provide suitable habitat, threat reduction, manageability, and data collection.

f. Select appropriate enhancement objectives for the species, using most conservative, nonartificial methods possible.

Research needed:

- Will alleviation of threats alone, with natural recovery, be sufficient?, If so, investigate threat abatement methodologies, and devel op appropriate tests. 
- What methods of conservation management of existing populations will assist natural recovery? Establish appropriate field trials for these methods.

- Will augmentation of existing populations with additional individuals (from on-site or off-site) be necessary as well, per research outlined above, based on evaluation of any intrinsic problems? If so, design augmentation research program, as outlined elsewhere in the proceedings.

- Will reintroduction of species to site known to be previously occupied significantly enhance recovery and conservation of the species?

- Will some combination of the above be needed?

g. Determine role of cultivation and propagation in achieving enhancement objectives above.

Research needed:

- How many, in what form: seed, cuttings, adult transplants

- Ensure genetically representative/variable population

- Seed production protocol if seed is needed

- Seeding techniques for the wild

- Propagation techniques if cuttings are needed

- Transplant techniques (season, age, method)

- Maintenance needs after transplanting or seeding.

h. To support various of the research needs above, design small scale pilot project in the field:

- Adequately funded and staffed

- Quantitative data gathering

- Appropriate experimental design and controls

- Appropriate data analysis

- Periodic evaluation, providing built-in review of hypotheses and methodologies, including a systematic mechanism to revise protocols as necessary to respond to new knowledge, both from within the research effort itself and from the scientific community at large.

- Appropriate objective, quantitative measures of success

- Success measured over an appropriate length of time in terms of species phenology, ecology, and life history to properly evaluate relative success. 


\section{Appendix A: List of Participants - USACERL/ USFWS Scoping Workshop on TES Research, 29 November - 2 December 1994}

Bob Anderson

Envir. \& Natural Resources Specialist

HQ TRADOC

ATBO-SE (Anderson)

Fort Monroe, VA 23651-5000

tel: 804-727-2077

fax: $804-727-2362$

J ohn E. Averett

Professor \& Chair

Department of Biology

Georgia Southern University

Statesboro, GA 30460-8042

tel: $912-681-5487$

fax: 912-681-0845

Ken Berg

National Botanist

U.S. Bureau of Land Management

1849 C Street, NW (LSB 204)

Washington, D.C. 20240

tel: 202-452-7764

fax: $202-452-7701$

Albert E. (Bert) Bivings

Natural Resources Program Manager

HQ FORSCOM

AFPI-ENE

Fort McPherson, GA 30330-6000

tel: 404-669-7659

fax: 404-669-7827
Marlin L. Bowles

Research Associate

The Morton Arboretum

Rt. 53

Lisle, IL 60532

tel: 708-719-2422

fax: 708-719-2433

Andre F. Clewell

President

Society for E cological Restoration

Rt. 7 Box 1195

Quincy, FL 32351

tel: $904-875-3868$

fax: $904-875-1848$

Rafael D. Corral

Endangered Species Biologist

Commander, USAADACENFB

Directorate of Environment

Cultural/Natural Resources Division

Fort Bliss, TX 79916-0058

tel: $915-568-6977$

fax: 915-568-6979

Anne C. Cully

Botanist

U.S. Fish and Wildlife Service

315 Houston, Suite E

Manhattan, KS 66502

tel: 913-539-3474

fax: $913-539-8567$ 
Ellen DeBruin

Botanist - Endangered Species

NM Natural Heritage Program

University of New Mexico

2500 Yale BIvd. SE

Albuquerque, NM 87131

tel: 505-277-1991

fax: $505-277-7587$

Alan Dyck

Wildlife Administrator

Fish \& Wildlife Management Branch

HQ USAG Fort Pickett

Attn: AFRC-FMP-PW

Blackstone, VA 23824

tel: $804-292-8501$

fax: $804-292-2518$

Donald Falk

Executive Director

Society for Ecological Restoration

1415 N. 6th Avenue

Tucson, AZ 85705

tel: 602-670-6893/6896

fax: $602-670-6525$

Edward Guerrant

Conservation Director

Center for Plant Conservation/

The Berry Botanic Garden

11505 S.W. Summerville

Portland, OR 97219

tel: $503-636-4112$

fax: $503-795-3370$

c/o Margie Gardner

Tracy Halward

Research Associate, Center for

E cological Mgt. of Military Lands

Colorado State University

202 Natural Resources Building

Fort Collins, CO 80523

tel: 303-491-2984

fax: $303-491-2713$ e-mail: thalward@amar.colostate.edu

Alison Hill

Ecologist

Natural Resources Assessment

\& Management Division (LL-N)

U.S. Army Construction Engineering

Research Laboratories (USACERL)

P.O. Box 9005

Champaign, IL 61826-9005

tel: $217-398-5218$

fax: $217-398-4570$

e-mail: a-hill@cecer.army.mil

Kathryn Kennedy

Botanist

U.S. Fish and Wildlife Service

Ecological Services Field Office

Hartland Bank Building

10711 Burnet Road, Suite 200

Austin, TX 78758

tel: $512-490-0057$

fax: $512-490-0974$

Robert Lichvar

Botanist, Corps of Engineers

Waterways Experiment Station

CEWES-ER-W

3909 Halls Ferry Rd.

Vicksburg, MS 39180

tel: $601-634-2983$

fax: 601-634-4016

e-mail: lichvar@elmsg.wes.army.mil

David A. Lincicome

Graduate Student/Research Assistant

Dept. of Natural Resources

\& Environmental Science

University of Illinois

W-503 Turner Hall

1102 S. Goodwin Avenue

Urbana, IL 61801

tel: $217-333-2770$

fax: 217-244-3219 
e-mail: d-lincicome@cecer.army.mil

Brian Locke

Senior Scientist

Advanced Sciences, Inc.

555 Telshor Blvd., Suite 310

Las Cruces, NM 88011-8646

tel: $505-522-7229$

fax: $505-522-7014$

Timothy K. Lowrey

Assoc. Professor/Herbarium Curator

Department of Biology

University of New Mexico

Albuquerque, NM 87131

tel: 505-277-2604

fax: 505-277-0304

Charlie McDonald

Botanist

Ecological Services

U.S. Fish and Wildlife Service

2105 Osuna NE

Albuquerque, NM 87113

tel: $505-761-4525$

fax: 505-761-4542

Gretchen S. Norman

Environmental Scientist

Cortez III Service Corporation

MTD Operations

P.O. Box L

White Sands Missile Range, NM 88002-9998

tel: $505-678-2762$

fax: $505-678-6845$

Noel B. Pavlovic

Research Plant Ecologist

National Biological Survey

Lake Michigan E col. Research Stn.

1100 N. Mineral Springs Road

Porter, IN 46304

tel: $219-926-8336$ fax: 219-929-5792

Hildy Reiser

Wildlife Biologist/Nat. Res. Mgr.

U.S. Air Force, Holloman AFB

49 CES/CEV

550 Tabosa Avenue

Holloman AFB, NM 88330-8458

tel: $505-475-3931$

fax: $505-475-7015$

Kathleen C. Rice

Conservation Horticulturist/Botanist

Desert Botanical Garden

1201 N. Galvin Parkway

Phoenix, AZ 85008

tel: $602-481-8137$

fax: $602-481-8124$

J anet L. Shipley

Botanist

Dept. of the Army - Fort Bragg

AF ZA-PW-DS

Fort Bragg, NC 28307-5000

tel: $910-432-5325$ or

910-396-2544

fax: $910-432-7776$

Robert Sivinski

Botanist

Forestry \& Resources Conservation Division

New Mexico Energy, Minerals, \&

Natural Resources Department

P.O. Box 1948

Santa Fe, NM 87504

tel: 505-827-7865

fax: $505-827-3903$

Linton L. Swindell

Natural Resources Specialist

Dept. of the Army - Fort Stewart

DPW, ENRD, Fish \& Wildlife Branch

AF ZP-DEV-W

Fort Stewart, GA 30427 
tel: $912-767-5476$

fax: $912-767-2255$

Dave Tazik

Chief, Natural Resources Division

Environmental Laboratory

U.S. Army Engineer Waterways

Experiment Station

ATTN: CEWES-EN

3909 Halls Ferry Road

Vicksburg, MS 39180-6199

tel: $601-634-2610$

fax: 601-634--3726

e-mail: tazikd@exl.wes.army.mil

Gordon Venable

Sr. Regulatory Compliance Specialist

Advanced Sciences, Inc.

477 Shoup Street, Suite 207

I daho Falls, ID 83402

tel: 208-529-2002

fax: 208-529-3918

Tom Vorac

Forester/Env. Protection Specialist

HQ AMCCOM

Attn: AMSMC-EQC

Rock I sland, IL 61299-6000

tel: 309-782-1552

fax: 309-782-1412/1457
Stephanie Weisband

Senior Project Manager/Analyst

Advanced Sciences, Inc.

1525 Wilson Blvd., Suite 1200

Arlington, VA 22209

tel: $703-243-4900$

fax: 703-524-6237

Rick White

National Plant Materials Specialist USDA Nat. Res. Conservation Service c/o NW Research-Extension Center 105 Experiment Farm Road

Colby, KS 67701

tel: $913-462-7575$

fax: $913-462-2315$ 


\section{Appendix B: Baseline References, Workbook Materials, and Technical References Provided at Scoping Workshop}

\section{Baseline References Distributed Prior to Workshop}

Hari, J an. August 1994. Literature Background and Bibliography. Policy and Research Criteria for Applications of Translocation \& Propagation in the Conservation of Threatened, Endangered, Candidate \& Sensitive Vascular Plant Species on Military Reservations. U.S. Army Construction Engineering Research Laboratories, Champaign, IL.

U.S. Department of the Army. AR 420-74 DRAFT, Chapter 11, Endangered/ Threatened Species Guidance.* U.S. Department of the Army, Washington, D.C., 21 October 1992.

\section{Workbook Materials and Handouts Distributed at Workshop}

32 CFR Part 651 (Army Reg. 200-2), Environmental Effects of Army Actions. Federal Register, Wednesday, November 16, 1988. Rules and Regulations, 53(221):4632246361.

Diner, Major David N. 1994. The Army and the Endangered Species Act: Who's endangering whom? Military Law Review. 143:161-223.

Falk, Donald A. and Peggy Olwell. 1992. Symposium Paper No. 4. Scientific and policy considerations in restoration and reintroduction of endangered species. Rhodora, 94(879):287-315.

Guerrant, Edward O., J r. 1996. Designing populations: demographic, genetic, and horticultural dimensions. In Restoring Diversity: Strategies for Reintroduction of Endangered Plants, eds. D.A. Falk, C.I. Millar, and M. Olwell, pp. 171-207. Island Press, Washington, D.C.

\footnotetext{
* AR 200-3, Natural Resources C Land, Forest and Wildlife Management, 28 February 1995, supersedes AR 420-74, 1 July 1977 and AR 210-9, 1 July 1978.
} 
McDonald, Charles B. The Endangered Species Act: Regulatory and policy implications for plant introductions. U.S. Fish and Wildlife Service, Albuquerque, NM.

The Meeting F acilitation Process. Scoping workshop on research for enhancing survival of threatened, endangered, and sensitive (TES) plant species on military lands, 29 Nov 2 Dec 94, Albuquerque, NM.

Memorandum of Understanding between U.S. Department of Agriculture, U.S. Department of Defense, U.S. Department of the Army, U.S. Department of Commerce, U.S. Department of the Interior, U.S. Department of Transportation, and U.S. Environmental Protection Agency on Implementation of theEndangered Species Act, 29 September 1994.

Memorandum of Understanding (94-SMU-058) between U.S. Department of Agriculture, U.S. Department of the Interior, and U.S. Department of Commerce on Conservation of species that are tending toward federal listing as threatened or endangered under the Endangered Species Act, 25 J anuary 1994.

Office of the Under Secretary of Defense. Memorandum dated 8 Aug 94, Subject: I mplementation of ecosystem management in the DOD. U.S. Department of Defense, Office of the Under Secretary of Defense, Washington, D.C.

Pavlik, Bruce M. 1996. Defining and measuring success. In Restoring Diversity: Strategies for Reintroduction of Endangered Plants, eds. D.A. Falk, C.I . Millar, and M. Olwell, pp. 127-155. Island Press, Washington, D.C.

PreWorkshop Survey Responses: Research Approaches, Technical Issues, Legal/ Ethical Issues. Scoping workshop on research for enhancing survival of threatened, endangered, and sensitive (TES) plant species on military lands, 29 Nov - 2 Dec 94, Albuquerque, NM.

Summary of Case Studies of Mitigation-related Plant Translocation, Relocation, and Reintroduction Projects from California. Ken Berg, Bureau of Land Management for USACERL/USF WS workshop, 29 Nov - 2 Dec 94, Albuquerque, NM. Source: Fielder, Peggy L. 1991. Mitigation-Related Transplantation, Relocation and Reintroduction Projects I nvolving Endangered and Threatened, and Rare Plant Species in California. Final Report to California Department of Fish and Game, Sacramento, California.

Teller, Major Craig E., Environmental Law Division, USALSA. J une 1993. Effective installation compliance with the Endangered Species Act. In The Army Lawyer, DA PAM 27-50-247, pp. 5-27. 
U.S. Department of the Army. Memoranda, dated 25 Feb 93 and 26 J an 93, Subject: Guidance for management of endangered/threatened species. U.S. Department of the Army, Washington, D.C.

U.S. Fish and Wildlife Service. Draft Policy Regarding Controlled Propagation of Species under the Endangered Species Act; Request for Public Comment. Preliminary draft copy. U.S. Department of the Interior, Fish and Wildlife Service, Washington, D.C.

U.S. Fish and Wildlife Service. Endangered Species Permit Contacts, U.S. Department of the Interior, Fish and Wildlife Service, Washington, D.C.

Workshop Agenda. Scoping Workshop on Research for Enhancing Survival of Threatened, Endangered, and Sensitive (TES) Plant Species on Military Lands, 29 Nov - 2 Dec 94, Albuquerque, NM.

\section{Reference Materials Available at Workshop}

50 CFR 17.11 and 17.12, Endangered and Threatened Wildlifeand Plants, August 20, 1994.

Advanced Sciences, Inc. (ASI) Brochure and fact sheets. Advanced Sciences, Inc., Albuquerque, NM.

Allen, William H. 1994. Reintroduction of endangered plants. Bioscience 44(2):65-68.

Bratton, Susan Power and Peter S. White. Rare plant management--after preservation what? Rhodora. Vol. 82, pp. 49-75.

Center for E cological Management of Military Lands. Brochure. Colorado State University, Department of Forest Sciences, Center for Ecological Management of Military Lands.

Center for Plant Conservation. Brochure and list of participating organizations. Center for Plant Conservation, St. Louis, MO.

Fahselt, D. 1988. The dangers of transplantation as a conservation technique. Natural Areas J ournal 8(4): 238-244.

Fenster, C.B. and M.R. Dudash. 1994. Genetic considerations for plant population restoration and conservation. In Restoration of Endangered Species, eds. M.L. Bowles and C.J. Whelan, pp. 34-62. Cambridge University Press, New York. 
Inventory of Rare and Endangered Plants in New Mexico, 1994, eds. Robert Sivinski and Karen Lightfoot. New Mexico Energy, Minerals and Natural Resources Department, Forestry and Resources Conservation Division.

Lugo, Ariel E. Ecosystem Management in the USDA Forest Service, International Institute of Tropical Forestry, USDA Forest Service, Rio Piedra, Puerto Rico.

Pavlik, Bruce M. 1994. Demographic monitoring and the recovery of endangered plants. In Restoration of Endangered Species, eds. M.L. Bowles and C.J . Whelan, pp. 322350. Cambridge University Press, NY.

Pavlovic, Noel B. 1994. Disturbance-dependent persistence of rare plants: anthropogenic impacts and restoration implications. In Restoration of Endangered Species, eds. M.L. Bowles and C.J . Whelan, pp. 159-193. Cambridge University Press, NY.

Restoration of Endangered Species. Conceptual Issues, Planning, and I mplementation, 1994, eds. M.L. Bowles and C.J . Whelan, Cambridge University Press, NY.

Society for Ecological Restoration. Brochure. Society for Ecological Restoration. Griffith, B., J .M. Scott, J .W. Carpenter, and C. Reed. 1989. Translocation as a species conservation tool: status and strategy. Science 245:477-480.

U.S. Army Construction Engineering Research Laboratories (USACERL). Proceedings. I nteragency Endangered Species Symposium. Washington, D.C., 26 and 28 April 1994, eds. D.J . Tazik, C. Martin, P. Pierce, and J . Ruth. 1994. USACERL Special Report EN-94/08/ADA286346.

Weller, Stephen G. 1994. The relationship of rarity to plant reproductive biology. In Restoration of Endangered Species, eds. M.L. Bowles and C.J . Whelan, pp. 90-115. Cambridge University Press, NY.

\section{Reference Materials Provided Subsequent to the Workshop}

Booth, G. [Undated]. Monitoring data and therisk of management decisions. Statistical Aspects of Monitoring, U.S. Forest Service, Intermountain Research Station, Ogden, UT.

Bowles, M.L., M.M. DeMauro, N. Pavlovic, and R. Hiebert. 1990. Effects of anthropogenic disturbances on endangered and threatened plants at the Indiana Dunes National Lakeshore. Natural Areas J ournal. 10(4):191-204. 
Bowles, M.L., W.J . Hess, M.M. DeMauro, and R. Hiebert. 1986. Endangered plant inventory and monitoring strategies at Indiana Dunes National Lakeshore. Natural Areas J ournal 6:18-26.

The Nature Conservancy. Vegetation Monitoring in a Management Context. The Nature Conservancy, Portland, OR.

Turner, D.L. [Undated]. Estimates without measures of precision are unacceptable Statistical Aspects of Monitoring, U.S. Forest Service, Intermountain Research Station, Ogden, UT. 


\section{Appendix C: Draft USFWS Policy on TES Propagation}


Federal Register: February 7, 1996 (Volume 61, Number 26, 4715).

Section: Notices

Agency: FISH AND WILDLIFE SERVICE

Title: Draft Policy Regarding Controlled Propagation of Species Listed Under the Endangered Species Act;

Request for Public Comment

Action: Draft policy; request for public comments.

FISH AND WILDLIFE SERVICE

DEPARTMENT OF THE INTERIOR

DEPARTMENT OF COMMERCE

National Oceanic and Atmospheric Administration

Draft Policy Regarding Controlled Propagation of Species Listed Under the Endangered Species Act; Request for Public Comment

AGENCIES: Fish and Wildlife Service, Interior; National Marine Fisheries Service, NOAA, Commerce.

SUMMARY: The Fish and Wildlife Service (FWS) and the National Marine Fisheries Service (NMFS), referred to jointly as the "Services", propose to issue policy that will address the role of controlled propagation in the conservation and recovery of species listed as endangered or threatened under the Endangered Species Act of 1973 (as amended) (16 U.S.C. 1531 et seq.) (ESA). The proposed policy is intended to assist the Services by providing guidance and establishing consistency with respect to activities in which the controlled propagation of a listed species may be implemented as a component of a species' recovery strategy, ensuring smooth transitions between various phases of species conservation efforts within both agencies, and ensuring prudent and effective use of limited funding resources. The proposed policy sanctions the controlled propagation of listed species when recommended in an approved recovery plan and supported by an approved genetics management plan. Controlled propagation may also be approved by 
FWS's Regional Directors, or, in the case of the NMFS, by the Assistant Administrator as necessary, to conduct recovery related research, to maintain refugia populations, and to rescue species or population segments at risk of imminent extinction or extirpation in order to prevent the loss of essential genetic viability.

DATES: Comments on this proposed policy must be received by April 8, 1996, in order to be considered in the final decision on this proposal.

ADDRESSE S: Comments and materials concerning this proposal should be sent to the Chief, Division of Endangered Species, U.S. Fish and Wildlife Service, 4401 North Fairfax Drive, Room 452, Arlington, Virginia 22203 (telephone 703/358-2171). Comments and materials received will be available for public inspection, by appointment, during normal business hours in Room 452, 4401 North Fairfax Drive, Arlington, Virginia 22203 (703/358-2105).

FOR FURTHER INFORMATION CONTACT: LaVerne Smith, Chief, Division of Endangered Species, U.S. Fish and Wildlife Service at the above address (703/358-2171), or Russell Bellmer, Chief, Endangered Species Division, National Marine Fisheries Service, 1335 East-West Highway, Silver Spring, Maryland 20910 (telephone 301/713-2322).

SUPPLEMENTARY INFORMATION:

Background

The Endangered Species Act of 1973, as amended (16 U.S.C. 1531 et seq.), specifically charges the Services with the responsibility for identification, protection, management, and recovery of species of plants and animals in danger of extinction. By implication, the ESA also promotes the protection and conservation of the genetic resources that these species represent and recognizes that the long-term viability of species depends on maintaining genetic variability within the biological species which is defined in the ESA as including "any subspecies of fish or wildlife or plants, and any distinct population segment of any species of vertebrate fish or wildlife which interbreeds when mature" (section 3(16)). Though the ESA emphasizes the restoration of listed species in their natural habitats, section 3(3) of the ESA specifically recognizes propagation as a tool available to the Services to meet their recovery responsibilities. To meet their goals of restoring endangered and threatened animals and plants, the Services are obligated to develop sound policies based on the best available scientific and commercial information. To achieve this goal the Services are soliciting review and comments from the public on the Draft I nteragency

Cooperative Policy for Controlled Propagation of Species Listed Under the Endangered Species Act of 1973 (as amended).

Draft Policy Statement 


\section{A. Purpose}

The purpose of this policy is: (1) To provide guidance and establish consistency with respect to U.S. Fish and Wildlife Service (FWS) and National Marine Fisheries Service (NMFS) activities in which the controlled propagation of a listed species, as defined in section 3(16) of the Endangered Species Act, is implemented as a component of a species' recovery strategy; (2) to ensure smooth transitions between various phases of species conservation efforts (e.g., propagation, introduction, and monitoring) within both agencies (hereafter referred to as Services when addressed jointly); and (3) to ensure prudent use of limited funding resources.

The purposes of controlled propagation under this policy include:

--Avoiding listed species, subspecies, or population extinction;

--Providing, when feasible, unlisted animals or plants as surrogates for recovery oriented scientific research including, but not restricted to, devel oping propagation methods and technology, and other actions which are expected to result in a net benefit to the listed species;

--Maintaining genetic vigor, diversity, bloodlines, and an appropriate mix of sexes and ages;

--Maintaining refugia populations for nearly extinct animals or plants on a temporary basis until threats to a listed species' habitat are alleviated, or necessary habitat modifications are completed, or when potentially catastrophic events occur (e.g., chemical spills, severe storms, fires, etc.);

--Providing individuals for establishment of new, self-sustaining populations necessary for recovery of the listed species;

--Supplementing or enhancing extant populations to facilitate recovery of the listed species;

--Holding offspring for a substantial portion of their development or through a significant or critical life-stage which cannot be supported in the wild.

\section{B. Scope}

This policy applies to all pertinent organizational elements of the Services notwithstanding those differences in administrative procedures and policies as noted. This policy pertains to all efforts funded, authorized, or carried out by the Services that are conducted to propagate threatened or endangered species by: 
--Establishing or maintaining refugia populations;

--Producing individuals for research or technol ogy development;

--Producing individuals for the supplementation of extant populations; and,

--Producing individuals for reintroduction to historical habitat.

C. Background

The controlled propagation of animals and plants is recognized in certain situations as an essential tool for the conservation and recovery of listed species. The Services have used controlled propagation to support the recovery of listed species and successfully return them to suitable habitat. The NMFS, as lead Service for the recovery of Pacific salmon, has devel oped an interim policy addressing controlled propagation of these species. This policy was published in the Federal Register on April 5, 1993 (58 F R 17573).

Though controlled propagation has a supportive role in the recovery of some listed species, the Endangered Species Act clearly states that its intent is "to provide a means whereby the ecosystems upon which endangered species and threatened species depend may be conserved." Therefore, the mandate of the Services is to recover wild populations in situ whenever possible.

The Services recognize that there are a number of genetic and ecological risks which may be associated with the controlled propagation and release of animals and plants. When considering controlled propagation as a recovery option for a listed species, an assessment of the potential benefits and risks must be undertaken and reasonable alternatives requiring less intervention objectively evaluated. If controlled propagation is to be used as a strategy in the recovery of a listed species, it must be conducted in a manner that will minimize risks to existing populations (if any), and preserve the genetic and ecological distinctiveness of the listed species. However, controlled propagation is not a substitute for addressing factors responsible for an endangered or threatened species' decline.

Controlled propagation can pose a number of genetic and ecological risks to listed species. Specific risks which must be addressed in the planning of controlled propagation programs include the following:

--Removal of natural broodstock that may result in an increased risk of extinction by reducing the abundance of wild individuals and reducing genetic variability within naturally occurring populations;

--Equipment failures, human error, disease, and other potential catastrophic events that may cause the loss of some or all of the population being held or maintained in captivity; 
--The potential for an increased level of inbreeding or other adverse genetic effects within populations that may result from the enhancement of only a portion of the gene pool;

--Potential erosion of genetic differences between populations as a result of mixed stock transfers or supplementation; and,

--Exposure to novel selection regimes in controlled environments that may diminish a listed species' natural capacity to survive and reproduce in the wild.

Potential genetic and ecological risks are also associated with introductions of captively-reared individuals to naturally occurring populations.

Possible impacts may include:

--Genetic introgression which may diminish local adaptations of the naturally occurring population;

--Increased predation, competition for food, space, mates, or other factors which may displace naturally occurring individuals, or interfere with foraging, migratory, reproductive, or other essential behaviors; and,

--Disease transfer.

An additional risk specific to naturally occurring populations of some listed species is incidental take through commercial and recreational harvest. This is particularly true when listed species occur with unlisted target species. It is therefore essential that controlled propagation programs for listed species recovery be coordinated in a manner that minimizes potentially adverse impacts to existing wild populations of listed species, and that controlled propagation programs be conducted by the Services in a manner that avoids additional listing actions.

D. Definitions

The following definitions apply:

Controlled Environment

A controlled environment is one specifically manipulated by humans for the purpose of producing or rearing progeny of the species in question, and of a design intended to prevent unplanned escape or entry of plants, animals, or reproductive products.

Intercross and I ntercross Progeny

The term "intercross" is applicable to all crosses between individuals of different species, subspecies, or populations. The following description is excerpted from the Services' 
proposed Policy on the Treatment of I ntercrosses, Intercross Progeny to Include Hybrids, and Proposed Definitions.

The degree of genetic mixing possible from intercrosses spans a broad continuum. At one extreme are cases in which a small number of individuals of a species display evidence of introgression. Genetic material originating from another entity may remain as evidence of long past and/or infrequent matings with that other entity but may have little or no effect on the morphology and behavior of the organism. At the other extreme are individuals that exhibit morphology that is intermediate between that of the parent types, nuclear DNA showing strong affinities with both parent types, some degree of functional sterility, and/or an inability to "breed true." Somewhere along this continuum there may be individuals that possess DNA from past intercrosses but in most other ways are representative of a single parental stock.

\section{Controlled Propagation}

The mating, transfer of gametes or embryos, development of offspring, and grow-out of animals, if reproduction is sexual, or other development of offspring, including grow-out if reproduction is asexual, when intentionally confined or directly intended by human intervention.

--Propagation of plants by humans from seeds, spores, callus tissue, divisions, cuttings or other plant tissue in a controlled environment or when intentionally confined.

--Defined in the context of this policy, controlled propagation refers to the production of individuals, generally within a managed environment for the purpose of future supplementation or augmentation of an extant population(s), or reintroduction to the wild (with the exception of the establishment of an experimental population, which is excluded from this policy).

Rescue/Salvage

Refers to extreme conditions wherein a species or population segment at risk of extinction is brought into a controlled environment (e.g., refugia) on a temporary or permanent basis as dictated by the situation.

Recovery Priority System

The system whereby the Services assign priorities to listed species and to recovery tasks. Recovery priority is based on the degree of threat, recovery potential, taxonomic distinctness, and presence of an actual or imminent conflict between the species' conservation and development or other economic activities. (48 FR 43098, Endangered and Threatened Species Listing and Recovery Priority Guidelines, September 21, 1983.) 


\section{E. Policy}

This policy is intended to address primarily those activities involving gamete transfer and subsequent development and grow-out of offspring in laboratory, botanical facility, zoo, hatchery, aquaria, or similarly controlled environments. This policy also encompasses activities related to or preceding controlled propagation activities such as:

--Obtaining and rearing offspring for research;

--Procuring broodstock for future controlled propagation and supplementation efforts; or,

--Holding offspring for a substantial portion of their development or through a significant or critical life-stage which cannot be supported in the wild.

This policy is not intended to address temporary removal and holding of individuals unless such actions intentionally involve reproduction in the interim, or are the result of an action deemed necessary to the survival of the listed species or a specific population (such circumstances are addressed under rescue and/or salvage). This policy is not intended to address short-term holding or captive rearing of individuals obtained for later reintroduction, supplementation, or translocation efforts when controlled propagation does not take place or is not intended during the period of captive maintenance. Actions involving cryopreservation or other preservation of biological materials, if not intended for subsequent use in the controlled propagation of listed species, are exempt from this policy.

Among the goals of this policy common to both Services are coordinating recovery actions specific to controlled propagation activities; maximizing benefits to the listed species from controlled propagation efforts; assuring that appropriate recovery measures other than controlled propagation are fully considered and that other existing recovery priorities within Service regions and nationwide are consi dered in decisions concerning the implementation or conduct of controlled propagation activities; and, ensuring prudent use of limited funds.

It is the policy of the Services that the controlled propagation of threatened and endangered species:

1. Will be used as a recovery strategy only when other measures employed to maintain or improve a listed species' status in the wild have failed, are determined to be likely to fail, are shown to be ineffective in overcoming extant factors limiting recovery, or would be insufficient to ensure/achieve full recovery. Every effort should be made to accomplish conservation measures that enable a listed species to recover in the wild, with or without intervention (e.g., translocation), prior to implementing controlled propagation for reintroduction or supplementation. 
Controlled propagation programs must be coordinated with conservation actions and other recovery measures, as appropriate or specified in recovery plans, that will contribute to, or otherwise support, the provision of secure and suitable habitat. Specifically, controlled propagation programs intended for reintroduction or supplementation (as opposed to the support of research and technology development) must be coordinated with habitat management, restoration, and other species' recovery efforts. Controlled propagation programs and habitat conservation actions will be reviewed by the appropriate Service at least annually, to insure that the efforts of the parties involved in the recovery of the listed species maintain adequate integration and coordination.

2. Will be based on the specific recommendations of recovery strategies identified through approved recovery plans. The recovery plan, in addressing controlled propagation, should clearly identify the necessity and role of this activity as a recovery strategy; the lead agency

responsible for a particular controlled propagation effort including the role of FWS or NMFS facilities, personnel, and resources, or those of non-Service cooperators as appropriate (e.g., Center for Plant Conservation (CPC), American Association of Zool ogical Parks and Aquaria (AZA); and, the estimated cost and duration of controlled propagation efforts.

3. Will specifically consider the potential ecological and genetic effects on wild populations of the removal of individuals for controlled propagation purposes and the potential effects of such introductions on the receiving population and other resident species [risk assessment] (e.g., Endangered Species Act--section 7, Endangered Species Act section 10, NEPA).

4. Will be based on sound scientific principles to conserve genetic variation and species integrity. Intercrossing will not be considered for use in controlled propagation programs unless (1) recommended by an approved recovery plan, (2) supported in an approved genetic management plan (which may or may not be part of an approved recovery plan), (3) implemented in a scientifically controlled and approved manner, and (4) undertaken to compensate for a loss of genetic viability in listed taxa that have been genetically isolated in the wild as a result of human activity. Use of intercross individuals for species conservation will require Director's/Assistant Administrator's approval.

5. Will be preceded by the development of a genetics management plan based on accepted scientific principles and procedures. This plan will: Include all necessary consultations and permits; use or be comparable to existing standards (e.g., AZA Species Survival Program studbooks and protocols for animals, or CPC guidelines for plant species); insure that

the genetic makeup of propagated individuals is similar to that of freeranging populations and that propagated individuals are behaviorally and physiologically suitable for release [1] and, specifically address the issue of disposal of individuals found to be: 
(a) Unfit for introduction to the wild

(b) Unfit to serve as broodstock

(c) Surpl us to the needs of research; [2] or

(d) surplus to the recovery needs for the species (e.g., to preclude genetic and ecological swamping); [3]

Programs involving the controlled propagation of individuals of listed species for research purposes and not intended for reintroduction to the wild are exempt from the requirement to develop a genetics management plan. Examples of exempt actions indude research involving the determination of germination rates in plants and spawning success rates in fishes and mussels.

6. Will be conducted in a manner that minimizes potential introduction or spread of diseases and parasites into controlled or suitable habitat.

7. Will be conducted in a manner that will prevent the escape or introduction of captive stock outside their historic range.

8. Will, when feasible, be conducted at more than one location in order to reduce the potential for catastrophic loss at a single facility.

9. Will be coordinated as appropriate with organizations and investigators both within and outside the Services. The Services will cooperate with other Federal, State, Tribal, and local governments.

10. Will be conducted in a manner consistent with meeting the information needs of the Services and other institutions including AZA Species Survival Program and the International U nion for the Conservation of Nature's I nternational Species I nformation System as appropriate. In the case of listed species for which traditional studbooks or registrations are not practical, records of eggs and larvae, or other life-stages will be maintained. Plant propagation programs and recordkeeping will be coordinated as appropriate with the CPC.

11. Will, with limited exceptions, be implemented only after a commitment to funding is secured following approval of final recovery plans and genetics management plans.

12. Will, prior to releases of propagated individuals, require development of a controlled propagation/reintroduction plan. This document may be produced separately or in combination with a recovery plan. However, the specific elements of the controlled propagation/ reintroduction plan must be clearly identifiable. Controlled propagation/reintroduction plans will identify measurable objectives and milestones for the 
proposed propagation/reintroduction effort. The controlled propagation/reintroduction plan should be based on strategies identified in the approved recovery plan, and it is strongly recommended that it include protocols for health management, disease-free certification, monitoring and evaluation of genetic, demographic, life-history, phenotypic, and behavioral characteristics, data collection, recordkeeping, and reporting. On implementation of controlled propagation, annual evaluations must be made to assess project objectives, evaluate progress, and consider new scientific information and the status of any ongoing habitat conservation efforts. This annual evaluation will be provided to the Director/Assistant Administrator by the Regional Director with lead recovery responsibility.

13. Will be conducted in accordance with the regulations implementing the Endangered Species Act, Marine Mammal Protection Act, Animal Welfare Act, Lacey Act, Fish and Wildlife Act of 1956, and Departmental and Service procedures relative to the National Environmental Policy Act.

\section{F. Exceptions}

Few exceptions to the above policy guidelines will be considered and will require specific Regional Director/Assistant Administrator's approval. The following circumstances have been anticipated and are considered potential exceptions to the general policy guidelines.

1. In those instances where a listed species has an ephemeral reproductive stage or very short (1-2 year) life span that necessitates controlled propagation for the listed species' maintenance in refugia or for purposes of required research, exceptions may be granted by the Regional Director/Assistant Administrator.

2. In the absence of an approved recovery plan, and only in cases of a defensible immediate need, information or recommendations contained in recovery outlines or draft recovery plans may be used to identify controlled propagation as a necessary recovery measure for listed species in critical peril. Under such circumstances initiation of controlled propagation activities will require Regional Director's/Assistant Administrator's approval.

3. Programs in which candidate or proposed species are being held in refugia, used for research, or under controlled propagation and which are subsequently listed, are granted temporary exception to the requirements of this policy and activities may be continued at their present level unless directed otherwise by the Regional Director/ Assistant Administrator. No change in program activities will be made without approval of the Regional Director/Assistant Administrator and until such time as the requirements of this policy are met. Conformance to this policy for candidate and proposed species which become listed subsequent to the implementation of this policy is required within 12 months following listing. 
4. Any additional exceptions for unforeseen circumstances which are not specifically addressed by this policy will require the approval of the Director/Assistant Administrator.

\section{G. Cooperators}

The Services recognize the need for partnerships with other Federal agencies, States, Tribes, local governments, and private entities in the recovery of listed species. In this regard the Services will seek to develop partnerships with qualified cooperators for the purpose of propagating listed, proposed, and candidate species (as authorized under Sections 6 and 2(a)(5) of the Endangered Species Act). Guidance for this activity is as follows:

1. The Regional Directors/Assistant Administrator will explore opportunities for accomplishing controlled propagation and any associated research tasks with other Federal cooperators, FWS/NMFS facilities, State agencies, Tribes, zoological parks, aquaria, botanical gardens, academia, and other qualified parties. Cooperators will be selected on the basis of scientific merits, technical capability, willingness to adhere to the Services' policies, guidance, and protocols, and cost-effectiveness (e.g., willingness of non-agency cooperators to assume or share costs). State and private cooperators will be required to submit, either independently or in concert with the appropriate lead agency (FWS or NMFS), a genetics management plan for new species propagation efforts (as specified in E-5). Likewise, a controlled propagation/reintroduction plan will also be required of cooperators as and when appropriate (as specified in E-12).

2. The Regional Director/Assistant Administrator of the appropriate listed species lead agency will be responsible for assigning staff to oversee programs conducted by all cooperators to ensure adherence to necessary protocols and permit conditions and to coordinate annual reporting requirements.

3. The listed species' lead Region will be responsible for funding maintenance in refugia, controlled propagation research, and controlled propagation/reintroduction efforts unless this responsibility is assumed by a cooperating facility.

4. The Regional Director/Assistant Administrator will be responsible for ensuring Cooperator's compliance with this policy.

H. Responsibilities

This policy shall be implemented in accordance with the following guidelines:

1. Regional Directors/Assistant Administrator are responsible for recovery of listed species for which they have lead. Recovery actions for which Regional Directors/Assistant 
Administrator have authority include establishment of refugia, initiation of necessary research or technology development, and implementation of controlled propagation programs and/or propagation research for listed species. When determining species priority for inclusion in controlled propagation programs, considerations should include the foll owing:

(a) Whether or not a listed species' recovery plan outline, draft recovery plan, or final recovery plan, identifies controlled propagation as an appropriate recovery strategy and what priority this task is assigned within the overall recovery strategy.

(b) The potential a species' overall recovery program, including controlled propagation, has to enhance the conservation of other listed or candidate species.

(c) The availability and willingness of non-agency cooperators to assume the lead or to contribute to recovery activities including cost sharing.

(d) Exceptions to the general guidance of this policy may be made if a critically diminished listed species is threatened by imminent extinction or population extirpation due to temporary or uncontrollable causes, and therefore, in the Regional Director's/Assistant Administrator's judgment, warrants partial or total removal from the wild for purposes of rescue/salvage, the establishment of refugia, initiation of research, or controlled propagation.

2. In the event that the current recovery plan fails to identify the establishment of refugia, initiation of propagation research, or controlled propagation as recovery tasks, the recovery plan will be updated or revised as appropriate. Recovery plans in preparation will be amended to reflect the changed status of the listed species and provide justifications as necessary.

3. Within 6 months of the effective date of this policy, the responsible Services' Regional Directors/Assistant Administrator will identify all listed species for which they have the lead recovery responsibility that are: (1) Being held in refugia; (2) involved in pre-propagation research; (3) undergoing controlled propagation; and, (4) if so, at what level and for what recovery purposes (e.g., augmentation of extant populations, establishment of new populations). The status of each species with regard to conformity with this policy will also be reported to the appropriate Regional and Washington D.C. offices.

4. Continuation of those programs not in conformity 12 months following implementation of this policy, shall require Director's/ Assistant Administrator's concurrence. The Regional Director shall provide his/her recommendation to the Service Director/Assistant Administrator.

I. Annual Reporting Requirements 
Annual reports will be prepared by the responsible Regional authority and submitted to the Director/Assistant Administrator not later than October 31. Reports will contain the following information for each species being maintained in refugia, in pre-propagation research, and under propagation:

--Recovery priority number;

--Policy criteria that are not met (if any);

--A description of the controlled propagation program, including the objectives and status;

--List of cooperators;

--Expenditures for the past fiscal year; and,

--Prospects for and obstacles to achieving research, controlled propagation, or reintroduction objectives.

Both FWS and NMFS agree to exchange programmatic information regarding controlled propagation of species of mutual interest on request, and that access to such information will include but not be limited to, budgetary information if required.

\section{J. Authorities}

Endangered Species Act of 1973, as amended; Marine Mammal Protection Act of 1972, as amended; Animal Welfare Act; Lacey Act; Fish and Wildlife Act of 1956; and National Environmental Policy Act.

\section{K. Supersessions}

All previously issued documents regarding this subject shall be revised, as necessary, to be consistent with this policy.

Footnotes:

(1) Determination of biological "suitability" may include, but should not necessarily be limited to, analysis of geomorphological similarities of habitat, genetic similarity, phenotypic characteristics, stock histories, habitat use, and other ecological, biological, and behavioral indicators.

(2) Protocols should identify disposition of individuals that die during holding, research, or propagation. Specimens can be valuable sources of tissue for genetic research. Disposition of remains in biological collections should also be considered. 
(3) The Services recognize that reproduction among organisms maintained in a controlled environment may occur under a variety of circumstances that may not be necessarily predictable or desirable. Reproduction of individuals under such circumstances may not be desirable and culling or disposal of surplus offspring or seeds may be necessary. Therefore, controlled propagation activities should not be initiated without the inclusion of these provisions, the securing of required take permits, and other authorizations as necessary.

Public Comments Solicited

The Services intend that any final decision on this draft policy on controlled propagation of listed species be as accurate and as effective as possible and that it take advantage of information and recommendations from all interested parties. Therefore, comments and suggestions from the public, other concerned governmental agencies, the scientific community, industry, or any other interested party concerning this draft policy are hereby solicited.

The final decision on this draft policy will take into consideration the comments and any additional information received by the Services, and such communications may lead to a decision that differs from this draft. The Services' decision will be published for public information.

Author/E ditor: The editors of this draft policy are David Harrelson of the Fish and Wildlife Service's Division of Endangered Species, Mail Stop 452 ARLSQ, 1849 C Street, NW, Washington, DC 20240 (703/358-2171), and Marta Nammack of the National Marine Fisheries Service's Protected Species Management Division, 1335 E ast-West Highway, Silver Spring, Maryland 20910 (301/713-2322).

Authority: The authority for this proposed action is the Endangered Species Act of 1973, as amended (16 U.S.C. 1531 et seq.)

Dated: February 1, 1996.

J ohn G. Rogers,

Acting Director, Fish and Wildlife Service.

Dated: February 1, 1996.

Nancy F oster,

Deputy Assistant Administrator for Fisheries, National Marine Fisheries Service.

[FR Doc. 96-2638 Filed 2-6-96; 8:45 am] 
BILLING CODE 4310-55-P 


\title{
Appendix D: The Endangered Species Act - Regulatory and Policy Implications for Plant Introductions
}

\author{
THE ENDANGERED SPECIES ACT: REGULATORY AND POLICY \\ IMPLICATIONS FOR PLANT INTRODUCTIONS \\ Charles B. McDonald, U.S. Fish and Wildlife Service \\ Albuquerque, NM
}

The U.S. Fish and Wildlife Service (USFWS) is the principal Federal agency responsible for implementing the Endangered Species Act of 1973 (ESA), as amended (Table D1). In that role the USFWS enacts regulations and establishes policies intended to carry out the purposes of the ESA in a consistent and responsible way. Because plant introductions, reintroductions, and population augmentations are only a small part of the overall USFWS endangered species program, they are the subject of relatively few USFWS regulations and policies. Nevertheless, the few existing regulations and policies concerning these activities provide a framework for carrying out introductions, reintroductions, and population augmentations when needed to support the purposes of the ESA.

Regulations have the force of law and are binding on all who come under the jurisdiction of the issuing government, in this case the U.S. Government. The USFWS has the authority to create regulations that implement the purposes of the ESA. These regulations, and all other Federal regulations, are established through a process called rulemaking. In this process, a proposed regulation is published in the Federal Register* and public comment is invited. After an appropriate comment period, all comments are considered and either a final regulation is published in its original or altered form, or the proposal is withdrawn. Final

\footnotetext{
* The Federal Register is a daily publication intended to inform the public of actions of the executive branch affecting them, including regulations. All Federal agencies publish in the Federal Register proposed rules, final rules, and notices, which cover the programs under their authority. The Office of the Federal Register is an agency of the National Archives and Records Administration.
} 
regulations amend the Code of F ederal Regulations (CFR) ${ }^{*}$ and have the force of law.

The rulemaking process is followed when adding species to the Federal list of endangered and threatened wildlife and plants (the lists are found in the Code of Federal Regulations at title 50, part 17, sections 11 and 12, which may be abbreviated 50 CFR 17.11 and 17.12), as well as when establishing procedures that direct the conservation of species under the ESA (Table D2).

Policies, unlike regulations, are only binding on the establishing group, so technically only the USFWS is required to follow USFWS policies, director's orders, handbooks, guidelines, procedures manuals, etc.

\section{U.S. Fish and Wildlife Service Regulations Relating to Endangered Plant Introductions, Reintroductions, and Population Augmentations}

USFWS regulations relating to endangered and threatened plant introductions, reintroductions, or population augmentations are intended to interpret and implement the ESA prohibitions against certain activities with endangered and threatened species. As will become evident from this discussion, the ESA gives the USFWS only limited regulatory authority over individuals who wish to conduct introductions, reintroductions, or populations augmentations with endangered and threatened plants.

\section{Prohibitions and Permits Under the ESA}

Prohibited activities with endangered and threatened plants are described in section 9(a)2 of the ESA, in 50 CFR 17.61 and 17.71. It is unlawful under the ESA for any person subject to the jurisdiction of the U nited States to import or export endangered plants from the United States, or engage in commercial interstate transport or sale. It is further prohibited to damage, destroy, or remove endangered plants from areas under Federal jurisdiction, or damage, destroy, or remove them from any area in knowing violation of a state law or regulation, ind uding state criminal trespass law. The ESA contains only prohibitions for endangered plants, but states the prohibitions may be extended to threatened plants through

\footnotetext{
The CFR is a codification of the general and permanent rules published in the Federal Register by the executive departments and agencies of the Federal Government. The Code is divided into 50 titles which represent broad areas subject to Federal regulation. Each title is divided into chapters which usually bear the name of the issuing agency. Each chapter is further subdivided into parts covering specific regulatory areas. Regulations created by the USFWS are found at Title 50-Wildlife and Fisheries, Chapters I and IV.
} 
regulation. Regulations describing prohibited activities for threatened plants are given in 50 CFR 17.71, and are the same as for endangered plants except the regulations have not been updated to include the 1988 ESA amendments, which make it a violation to maliciously damage or destroy endangered plants on areas under Federal jurisdiction, or to damage, destroy, or remove them from any area in knowing violation of a state law or regulation, including state criminal trespass law.

The USFWS may issue permits to undertake certain activities that are prohibited under the ESA or Federal regulation. The authority for granting permits to undertake conservation activities that would otherwise be prohibited is at section 10(a)(1)(A) of the ESA.

Permits have two principal purposes. First, they let the USFWS set terms and conditions under which a permit is valid. The USFWS, for instance, could stipulate in a permit that any endangered plants collected from Federal land for a taxonomic study could only be used for that purpose. If an endangered plant is being collected for an introduction project, the USFWS could describe in the permit the methods, locality, and other details of the project. The second purpose of permits is to provide a record-keeping mechanism for activities with various species. Such record-keeping might, for instance, be used to determine the commercial demand for certain artificially propagated cacti, which might in turn help indicate the likelihood of illegal field collecting.

Permits are issued only to allow otherwise prohibited activities, and a careful reading of the prohibitive activities for plants indicates several circumstances where no permit is required. No permit is required to collect endangered plants on private land as long as no state law is violated. No permit is required to simply possess, cultivate, or propagate endangered plants as long as no interstate commercial activity is involved. These two provisions differ from the similar provisions for endangered animals. For animals, taking is prohibited anywhere within the United States (private land included), and endangered animals cannot be possessed (either dead or alive) without a permit, except for those animals possessed prior to their being added to the Federal endangered species list.

Under the present set of ESA prohibitions, endangered plant permits cannot function as a record-keeping mechanism for tracking plant propagation and introduction, reintroduction, or augmentation activities because of the large number of instances when no permit is required. Further, permits cannot be used to direct introduction, reintroduction, or augmentation projects when the original propagation stock comes from private lands because no permit is required to collect or possess these plants. TheESA establishes no mechanism for the USF WS to 
function as a national record-keeper or coordinator for endangered and threatened plant introduction, reintroduction, or augmentation projects. It is hoped agencies, groups, and individuals conducting such projects will inform the USFWS and coordinate their work with the USFWS and other interested parties, but presently, there is no legal requirement to do so in many instances.

\section{Experimental Population Designations Under the Endangered Species Act}

The ESA and USFWS policy permit introduction of endangered species into unoccupied habitats. However, many proposals to do so have been fervently resisted because the USFWS could not assure other F ederal agencies, state or local governments, and private landowners that transplanted populations would not limit their future land management options. Introduced or reintroduced plants or animals have full protection under the ESA, including the taking prohibitions of section 9 and the Federal interagency consultation requirements of section 7. To help alleviate the resistance to introductions, the ESA was amended in 1982 to include the possible designation of an introduced population as "experimental" (section 10(j)).

"Experimental populations" must be wholly separate geographically from nonexperimental populations of the same species and are to be designated either "essential" or "non-essential." An "essential " experimental population is one whose loss would likely appreciably reduce the likelihood of the species' surviving in the wild. All other experimental populations are designated non-essential. Congress expected that most experimental populations would be designated nonessential.

The USFWS's intention to establish an experimental population must be formally announced through publication of proposed and final regulations in the Federal Register. An experimental population proposal must identify the boundaries of the experimental population area; indicate whether the population is essential; describe management restrictions, protective measures, or other management concerns for that population; and describe the periodic review process for evaluating the introduction's success and its effect on the species' conservation and recovery (50 CFR 17.81).

Most experimental population designations also contain "special rules" that permit greater management flexibility than the prohibitions of the ESA would ordinarily allow. For instance, a special rule might remove ESA protection from individuals of the endangered species that leave the experimental population area, or 
fisherman might be allowed to catch and release endangered fish of an experimental population without violating the ESA's takings provisions.

When considering whether to designate an introduced population as experimental, the USFWS must first determine if such designation is needed. If no local or other opposition exists to introducing or reintroducing a population, experimental population designation is unnecessary. Experimental populations have been designated for the red wolf, southern sea otter, blackfooted ferret, Colorado squawfish, and several other animals, but none have been designated for endangered or threatened plants despite a number of introduction projects. These plant projects have, in general, encountered little public opposition or even public attention. Reasons for this include: (1) most plant introductions are done within a relatively small area, often only a few acres, (2) plants usually stay within the introduction area, and (3) endangered plants are not protected on private land, so no ESA violation would occur if a cooperating landowner or subsequent landowner destroyed an introduced population. Despite present lack of use, experimental population designation remains available as a management tool for plant introductions.

\section{U.S. Fish and Wildlife Service Policies Relating to Endangered Plant Introductions, Reintroductions, and Population Augmentations}

These policies apply only to species that are federally listed as endangered or threatened. They do not apply to species that are candidates for Federal listing or to other rare or restricted species, although the principles involved can apply to these species as well.

\section{The Historic Range Policy}

The first USF WS policy relating to introductions was enunciated in an agency memorandum dated J une 25, 1981 (U.S. Fish and Wildlife Service 1981). The policy states, “... Endangered and Threatened species will not be relocated or transplanted outside their historical range without specific case-by-case approval from the Director." Historical range is the, "known general distribution of the species or subspecies as reported in the current scientific literature" (50 CFR 17.11 and 17.12). This policy is intended to help carry out a major purpose of the ESA, which is ". . .to provide a means whereby the ecosystems upon which endangered species and threatened species depend may be conserved. . ." (ESA, section 2(b)). Under this purpose, the goal is to rehabilitate ecosystems so they can support 
endangered species rather than to simply move endangered species away from ecosystems that are imperiled.

In addition to conforming to the purposes of the ESA, there are biological reasons for not introducing species outside their known historic range. Two reasons were enunciated in a USFWS memorandum dated 9 J uly 1982 (U.S. Fish and Wildlife Service 1982):

1. Doubtful survival of transplanted populations. The historical (natural) range limits of a species are determined by the interaction of physical and biotic factors in its environment, including such influences as extreme temperature, competition with other species, susceptibility to disease under varying habitat conditions, precise substrate composition, and so forth. These interactions may be subtle and may occur only sporadically or cyclically at long intervals. When a given species is absent from what superficially appears to be suitable habitat near its historical (natural) range (i.e., within limits of dispersal for the species), it may generally be assumed that its absence reflects some natural quality of the habitat that precludes the species' long-term survival. Biological information is often lacking as to species' microenvironmental requirements. Transplants into habitats resembling but outside endangered and threatened species' historic ranges are thus unlikely to hold much potential for the species' survival over the long run, although initial establishment may be possible.

2. Potential alteration of gene pools. The occurrence of a species (or subspecies, or distinct population) in its present form is the product of a long evolutionary process involving close adaptation to particular habitat conditions. Introduction of representatives of a species into nonhistorical range inevitably subjects them to new selection pressures and may result in significant genetic change, so that eventually the protected transplanted population, if it survives, may not in fact be the same organism we were attempting to conserve. Even more drastic would be the introduction of a listed species (or subspecies or distinct population) into the range of a closely related taxon with which hybridization could occur. In this case we would run the risk of significantly altering the gene pools of both taxa.

This policy and the just stated operational assumptions of the USFWS have guided the agency in conflicts over development of occupied endangered species habitat. In instances of conflict, the usual preferred solution put forth by developers is to simply translocate species to "safe" habitat and allow devel opment to proceed. Such proposals might even be accompanied by proposals to "enhance" the species through propagation and introduction of more individuals than would be moved in the first place. When possible, the USFWS has resisted such proposals because 
attempts at this kind of "conservation" have usually failed due to inadequate biological understanding and the fact that they represent trading known suitable habitat for habitat of unknown quality.

Adherence to the policy of not introducing endangered species outside their historical range is extended by regulation to any state agency that has a cooperative agreement with the USFWS under section 6 of the ESA (50 CFR 17.61(c)(4)(iii)). By this regulation, qualified employees or agents of state conservation agencies may without a permit collect endangered plants from areas under Federal jurisdiction provided the collecting is not anticipated to result in the introduction of the species into an area beyond its historic range.

\section{The Captive Propagation Policy}

The policy titled "Captive Propagation/Artificial Propagation of Native Threatened and Endangered Species" is at this writing still in draft form in preparation for inclusion in the Fish and Wildlife Service Manual, which contains the standing and continuing directives of the USFWS (USFWS 1993a). The policy, when finalized, may differ somewhat from what is presented here; however, many sound principles are incorporated in the draft so only minor modifications are expected. The policy pertains to propagation programs for producing individuals for research, establishing and maintaining refugia populations, eventual introduction or reintroduction into the wild, or augmentation of existing populations. Animal propagation programs provided the initial impetus for this policy because of the significant resource commitments that such programs often require. However, most of the guidance in the policy is equally applicable to plant propagation programs. The draft policy reads:

Captive propagation of animals and artificial propagation of plants are recognized in certain situations as essential tools for the conservation and recovery of species, subspecies, or populations. The Service has used this tool to enhance the recovery of several species and successfully return them to the wild. However, to ensure prudent use of limited funds, the long-term resource benefits must be critically assessed and evaluated relative to alternative conservation measures and other recovery priorities nationwide. Therefore, it is the policy of the U.S. Fish and Wildlife Service that captive propagation or artificial propagation of native threatened and endangered species, subspecies, or populations:

1. Will be conducted in accordance with the regulations implementing the Endangered Species Act, the Animal Welfare Act, and the Departmental and Service procedures relative to the National Environmental Policy Act; 
2. Will be based on the specific recommendations of recovery strategies identified through approved recovery plans and in accordance with the recovery task priority system. The recovery plan should clearly identify; (a) the role of propagation as a recovery strategy, (b) the role of Service facilities in propagation efforts as appropriate, (c) the role of Service cooperators and partners in recovery strategies involving propagation (e.g., Center for Plant Conservation, American Association of Zoological Parks and Aquaria), (d) the estimated cost of propagation efforts, including an analysis of expected capital and operation expenditures, (e) estimate of the number of individuals (FTEs) and training which will be required for implementing propagation/maintenance, and (f) an estimate of task duration;

3. Will be used as a recovery strategy only when other measures employed to maintain or improve a species', subspecies', or populations's status in the wild have failed, are determined to be likely to fail, or would be insufficient to ensure/achieve full recovery. Every effort should be made to accomplish conservation measures that enable a species, subspecies, or population to recover naturally in the wild, with or without human manipulation (e.g., translocation) prior to contemplating captive/artificial propagation for reintroduction or augmentation. Propagation programs will not be employed in lieu of habitat conservation or other measures that would stimulate natural recovery in the wild. Propagation programs intended for reintroduction/augmentation should be closely coordinated with habitat management efforts and both propagation programs and habitat conservation efforts should be periodically reviewed;

4. Will be implemented only after appropriate consideration of the potential effort on wild populations of the removal of individuals for propagation purposes (e.g., following a population viability analysis and/or risk assessment in the instance of severely depleted populations). In those instances where individuals propagated in captivity are to be introduced to suitable habitat, or are to be used to augment an existing population, consideration of the potential effects of such introductions on the receiving population and other resident species will be evaluated;

5. Will be based on sound genetic principles to preserve the genetic variability and integrity of wild populations of the species, subspecies, or population involved. Intercrosses will not be considered for use in propagation programs unless absolutely necessary to preserve unique genetic material of species critically close to extinction. Use of intercross individuals for species conservation will require written justification and Director's approval. Propagation should not be initiated without the completion of an approved genetics management plan. Such a plan should be comparable to existing stands (e.g., American Association of Zoological Parks and Aquaria, Species Survival Program, Center for Plant Conservation guidelines) and insure the genetic 
makeup of propagated individuals is similar to that of wild populations. The genetic management plan will include all necessary consultations and permits, including those required by States. The genetic management plan, in addition to other elements (e.g., maintenance of genetic variability), should specifically address the issue of disposal of individuals found to be; unfit for introduction to the wild, unfit to serve as broodstock, surplus to the needs of research*, or surplus to the recovery needs for the species (e.g., to preclude genetic swamping). Exceptions to these general guidelines may be granted at the Director's discretion when the species in question has an ephemeral or very short (1-2 year) life span which necessitates propagation for the purposes of maintenance in refugia or for purposes or required research;

6. Will be conducted in a manner to produce individuals that are behaviorally and physiologically suitable for release to the wild;

7. Will be conducted in a manner that minimizes potential introduction or spread of disease and parasites of concern into captive or wild environments;

8. Will be conducted in a manner which will prevent the escape of captive stock outside their historical range;

9. Will, when feasible, be conducted at more than one location in order to reduce the potential for catastrophic loss at a single facility;

10. Will be coordinated, as appropriate, with organizations and investigators both within and outside the Service. The Service will make efforts to cooperate with other Federal, State, Tribal, and local governments;

11. Will be conducted in cooperation with the Wildlife Conservation Management committee of the American Association of Zoological Parks and Aquaria (AAZPA) in maintaining studbooks and registration of animals with the Species Survival Program (SSP) and the International Union for the Conservation of Nature's (IUCN's) International Species I nformation System (ISIS) as appropriate. Plant propagation programs will be coordinated with the Center for Plant Conservation or other appropriate groups or investigators;

12. The policy and guidelines contained herein will be subject to exceptions on a species-by-species or case-by-case basis only when biologically supported and approved by the Director.

\footnotetext{
* Captive propagation research and production for introduction purposes generally should not be conducted simultaneously though it may be desirable in some instances. The primary objective of captive propagation research is to conduct studies which will provide for future propagation success in establishing and maintaining refugia populations and producing individuals for release into the wild.
} 
Three major points are emphasized in this policy. The first and most important is that the USFWS must use considerable restraint in employing propagation for conservation of endangered and threatened species. Propagation for introduction should be a final rather than an initial option, and is totally inappropriate if done in lieu of protecting the habitat needed to support existing or introduced populations. The final two points provide guidance on how to assure a high likelihood of success for propagation propjets determined to be essential. These points involve the requirements (1) to carefully plan and coordinate projects prior to initiation, and (2) to employ genetic and biological principles in their execution.

\section{Recovery Plans as Policy Documents}

The ESA (section 4(f)) requires the USFWS to devel op plans (referred to as recovery plans) for the conservation and survival of endangered and threatened species. Recovery plans represent the official position of the USFWS on the goals for achieving species' recovery and the tasks required for reaching those goals. Recovery plans are to be updated regularly and revised as needed to reflect new findings and changes in the species' status. A public comment period is required prior to approval of any new or revised recovery plan (ESA, section 4(f)(4)).

Recovery plans are written in three parts. The first part provides background information discussing, to the extent known, the species' taxonomy, distribution, abundance, ecology, threats and past conservation efforts. The second part describes the objectives and criteria for achieving recovery and provides an outline of tasks to accomplish the objectives. The third part gives a schedule for implementing the recovery tasks; it assigns priorities, durations, costs, and responsible parties for the recovery task. Recovery plans identify all parties the USFWS anticipates will be involved in recovery. Parties other than USFWS are identified to aid planning and to help those parties justify seeking and expending funds for recovery tasks.

Introduction, reintroduction, population augmentation tasks are identified in species' recovery plans if anticipated as necessary to prevent extinction or accomplish full recovery. As indicated in items 2 and 3 of the previous draft policy, propagation for introduction, reintroduction, or population augmentation is to be initiated only if it has been identified as necessary in an approved recovery plan and only if other higher priority recovery tasks to protect the species' habitat have failed or appear likely to fail.

Approximately $25 \%$ of the USFWS plant recovery plans identify introduction or reintroduction as a needed part of the recovery program, thus indicating the 
importance the USFWS places on this recovery activity for many species (F alk and Olwell 1992). Although the need for introductions or reintroductions is identified in the plans, the details of these programs are seldom described. It is anticipated the contents of this volume will provide much of the information needed for USFWS personnel and others to plan and execute successful introduction, reintroduction, and population augmentation programs.

\section{Summary}

1. The ESA allows individuals to possess endangered and threatened plants and to collect them from private land without a permit. Therefore, permits to undertake prohibited activities with endangered and threatened plants do not provide the USFWS a reliable mechanism for tracking or supervising non-F ederal endangered plant introduction projects.

2. The possibility of designating "experimental" status for introduced or reintroduced populations of endangered or threatened species was included in the ESA to reduce public resistance to endangered species introductions. Thus far no introduced plant populations have been given "experimental" status because the few such projects have lacked public controversy.

3. USFWS policy requires that the agency introduce endangered and threatened species only within their historic ranges and only after habitat conservation efforts have failed, appear likely to fail, or would be insufficient to accomplish full recovery.

4. A draft USFWS policy establishes the biological and procedural framework for the propagation of endangered species for introduction, reintroduction, and population augmentation projects. The policy emphasizes such projects should be initiated only after it is determined habitat conservation actions alone will be inadequate to recover the species. The policy also emphasizes the need for full consideration of genetic and biological principles in conducting propagation projects.

5. Introduction, reintroduction, or population augmentation tasks are described in USFWS recovery plans when they are determined to be needed to conserve a species or accomplish its full recovery. Few recovery plans, however, describe specific details for implementing these tasks. 


\section{References}

Falk, Donald A., and Peggy Olwell. 1992. Scientific and policy considerations in restoration and reintroduction of endangered species. Rhodora 94:287-315.

U.S. Congress. 1988. Endangered Species Act of 1973, as amended through the 100th Congress. U.S. Government Printing Office, Washington, D.C. 45 pp.

U.S. Fish and Wildlife Service 1981. Memorandum. Subject: Reintroduction of endangered and threatened species. U.S. Department of Interior, Fish and Wildlife Service, Office of Endangered Species, Washington, D.C. 1 p.

. 1982. Memorandum. Subject: Fish and Wildlife Service policy on transplanting listed endangered and threatened species. U.S. Department of Interior, Fish and Wildlife Service, Office of Endangered Species, Washington, D.C. $2 \mathrm{pp}$.

. 1993a. Draft policy: Captive propagation/artificial propagation of native threatened and endangered species. U.S. Department of Interior, Fish and Wildlife Service, Division of Endangered Species, Washington, D.C. 8 pp.

. 1993b. Code of Federal Regulations, Title 50- Wildlife and Fisheries, Chapters I and IV. Office of the Federal Register, National Archives and Records Administration, Washington, D.C. 
Table D1. An index to some topics in the Endangered Species Act of 1973, as amended.

\begin{tabular}{|c|c|}
\hline $\begin{array}{l}\text { Sections and } \\
\text { Subsections } \\
\text { of the Act }\end{array}$ & Subjects Covered \\
\hline 2 & Findings, purposes, and policies \\
\hline 2(b) & Purpose of the Act \\
\hline 3 & Definitions \\
\hline 4 & Determinations of species as endangered or threatened \\
\hline $4(a)(1)$ & Factors for determining endangered or threatened status \\
\hline $4(\mathrm{a})(3)$ & Requirement to designate critical habitat \\
\hline $4(b)(3)$ & Petitions to list, delist, or revise critical habitat \\
\hline $4(b)(7)$ & Emergency listing \\
\hline $4(d)$ & Authority to create special rules for threatened species \\
\hline $4(f)$ & Recovery plans \\
\hline $4(f)(4)$ & Requirement for public review of draft recovery plans \\
\hline 5 & Land acquisition \\
\hline 6 & Cooperation with the States \\
\hline $6(c)(2)$ & Cooperative agreements for States with plant conservation programs \\
\hline 7 & Interagency cooperation \\
\hline 8 & International cooperation \\
\hline 9 & Prohibited acts \\
\hline $9(\mathrm{a})(2)$ & Prohibited acts for plants \\
\hline 10 & Exceptions \\
\hline $10(a)(1)(A)$ & Permits for research or conservation activities \\
\hline $10(j)$ & Experimental populations \\
\hline 11 & Penalties and enforcement \\
\hline
\end{tabular}


Table D2. An index to some ESA regulations in Title $\mathbf{5 0}$ of the Code of Federal Regulations.

\begin{tabular}{|c|c|}
\hline Part & Subject Covered \\
\hline 17.12 & List of endangered and threatened plants \\
\hline 17.61 & Prohibitions for endangered plants \\
\hline $17.61(\mathrm{c})(4)$ & $\begin{array}{l}\text { Exceptions to endangered plant collecting prohibitions for employees or agents } \\
\text { of State conservation agencies with a Section } 6 \text { cooperative agreement }\end{array}$ \\
\hline 17.62 & Permit procedures for endangered plants \\
\hline 17.71 & Prohibitions for threatened plants \\
\hline $17.71(b)$ & $\begin{array}{l}\text { Exceptions to threatened plant collecting prohibitions for employees or agents of } \\
\text { State conservation agencies with a Section } 6 \text { cooperative agreement }\end{array}$ \\
\hline 17.72 & Permit procedures for threatened plants \\
\hline 17.81 & Listing experimental populations \\
\hline 17.86 & Special rules for plant experimental populations (reserved, but not yet used) \\
\hline 17.96 & Critical habitats for plant species - legal boundaries, constituent elements, and maps \\
\hline 23.23 & $\begin{array}{l}\text { List of species protected under the Convention on International Trade in } \\
\text { Endangered Species of Wild Fauna and Flora (CITES) }\end{array}$ \\
\hline 81 & Procedures for cooperation with States under Section 6 \\
\hline 402 & Procedures for Federal interagency cooperation under Section 7 \\
\hline 424 & $\begin{array}{l}\text { Procedures for revising the endangered and threatened species lists and } \\
\text { designating critical habitat under Section } 4\end{array}$ \\
\hline 424.11 & Factors for listing, delisting, or reclassifying species \\
\hline 424.12 & Criteria for designating critical habitat \\
\hline 424.14 & Petitions \\
\hline 424.15 & Authority to publish lists of candidates species in the Federal Register \\
\hline 424.17 & Time limits and required actions for procedures under Section 4 \\
\hline 424.20 & Emergency rules \\
\hline
\end{tabular}




\title{
Appendix E: Regulatory Overview and Commentary on Chapter 11, AR 420-74: DRAFT; "Endangered/Threatened Species Guidance"
}

\author{
Prepared for the Scoping Workshop on Research for Enhancing Survival of Threatened, \\ Endangered, and Sensitive (TES) Plant Species on Military Lands \\ Albuquerque, NM, 29 November - 2 December 1994
}

Gordon Venable, J .D., Sr. Regulatory Compliance Specialist, Advanced Sciences, Inc.

Introduction. This presentation was devel oped as a "walk-through" of the draft regulations, focusing on broad compliance strategy in response to clear signals of evolving high priorities for TES protection in the context of new, strong policy statements favoring ecosystem/community/habitat management and conservation of biological diversity. These comments do not focus on any class or type of TES management or enhancement strategy, technique or application; the appropriate use of each such tool or approach must be considered on a case-by-case basis within the entire matrix of regulatory requirements and species-specific, site-specific, and action-specific conditions. Therefore, the broadest understanding of the regulations considered below is vitally important to the achievement of scientifically and legally defensible TES species management decisions.

Because of the potential controversies surrounding the finalization and implementation of the proposed regulations, it is especially important to note that the opinions expressed herein, although developed under contract to USACERL, are not necessarily those of the Army nor any branch of the United States Government. These opinions are solely those of the preparer. Further, the reader is entitled to understand the preparer's approach in devel oping these comments. The preparer strove to offer a consistently conservative interpretation to the draft regulatory language. That is, his view attempts to minimize the risk of noncompliance, applying statutory and other policy underpinnings (legislative history, case law, comparable legislative materials) as primary guidance to his regulatory interpretation, while still recognizing the priorities of "real world" management concerns

\footnotetext{
* AR 200-3, Natural Resources C Land, Forest and Wildlife Management, 28 February 1995, supersedes AR 420-74, 1 July 1977 and AR 210-9, 1 July 1978.
} 
and the need for long-term cost-effective compliance. This is in contrast (in the preparer's view) to the "minimal compliance" approach that accepts a higher probability of violation in favor of other competing objectives (such as short-term cost-effectiveness or profitability), and which assigns little or no inherent or interpretive value to the underlying public policy (statutory language, leading case law and legislative history) driving the regulatory compliance.

One of the foundations for the preparer's choice of approach in this particular case was the Army's promulgation of draft regulation AR 420-74, containing this draft Chapter 11, as interim policy guidance in early 1993 (see G.C. Brown and J .W. Welk, DAEN and USAMC transmittal memoranda, 26 J anuary and 25 February 1993, respectively). In the preparer's experience, this was an agency action unmistakably establishing proactive environmental policy changes and priorities, a clear signal that the underlying public policies expressed in the environmental statutes germane to AR 420-74 had achieved significant inherent and interpretive value in planning and implementing future Army environmental regulatory compliance strategies. It is important to recognize that draft Chapter 11 does not stand alone, but constitutes an integral component of an extensive reframing of the Army environmental regulation system; taken together and read as a whole, it is even more evident that a comprehensive reworking of environmental policy has been documented in these interim policies, soon (it is rumored) to be implemented as final regulations.

The preparer also would offer an additional general caution. Chapter 11, while generally focused on the Endangered Species Act (ESA), also incorporates policy and compliance directives arising under the National Environmental Policy Act (NEPA). The coherent design of Chapter 11, while not emphatic in this respect, is nonetheless extremely clear in its integration of NEPA compliance with ESA compliance, intent on achieving overall operational efficiency and cost-effective, short- and long-term compliance, together with improved decision support and documentation.

The format of the prepared materials bel ow also requires a brief explanation. Numerous drafts of the proposed regulations appear to exist, including a sequence of internal official review draft versions and unofficial intermediates. The vintage of the materials used for this presentation is believed to be the most recent or very nearly so, but could not be absolutely verified through the source at USACERL. Therefore, to assure that the preparer's comments are read together with the exact materials which elicited those comments, the preparer has interspersed his comments, in a different font, into the body of the draft regulatory material.

\section{1-1. Scope - Army policy on listed species}

a. Balancing mission requirements. The Army is committed to being a national leader in conserving listed species. DA personnel at all levels must ensure that they carry out mission requirements in harmony with the 
requirements of the Endangered Species Act (ESA) of 1973, sections 1531 to 1544, title 16, United States Code (16 U.S.C. 1531- 1544). Mission requirements do not justify actions violating theESA. All Army land uses, including military training, testing, timber harvesting, recreation, and grazing, aresubject to ESA requirements for the protection of listed species and critical habitat. The key to successfully balancing mission requirements and the conservation of listed species is long-term planning and effective management to prevent conflicts between these competing interests.

This first subsection addresses policy and procedure; it expresses (i) general policy objectives favoring protection of listed species and critical habitat, (ii) unrestricted recognition of the ESA's statutory applicability to all Army land uses, (iii) clear, specific standards of agency conduct, and (iv) broad guidance for long-term planning and management.

b. Cooperation and informal consultation with regulatory agencies. In fulfilling its conservation responsibilities under the ESA, the Army will work closely and cooperatively with the Federal agencies charged with enforcement of the act: the U.S. Fish and Wildlife Service (USFWS) and the National Marine Fisheries Service (NMFS). In planning projects and activities, installations should engage in informal consultation with the USFWS or NMFS at the earliest opportunity to ensure that proposed actions that may affect listed species or critical habitat are consistent with the requirements of the ESA. Installations will routinely seek informal USFWS or NMFS review of installation plans. If there is any question whether an Army action may affect a listed species or critical habitat, DA personnel should informally consult with the NMFS or USFWS to determine the need for formal consultation. Working closely and cooperatively with the USFWS and NMFS through informal consultation to develop mutually satisfactory courses of action is in the Army's best interest.

The second subsection reinforces the first with general and specific procedural mandates to establish close, cooperative, informal, long-term working relationships with NMFS and USFWS, the ESA regulatory agencies.

C. Biological diversity.

(1) It is an Army goal to systematically conserve biological diversity on Army lands within the context of its mission. Natural ecosystems can best be maintained by protecting the biological diversity of naturally occurring organisms and the ecological processes that they perform and with which they interact. The Army also recognizes the importance of habitat management, the key to effective conservation of 
biological diversity, in the protection of listed, proposed, and candidate species. Conserving native species in numbers and distributions that provide a high likelihood of continued existence is a crucial element of biological diversity. Conserving and restoring biological diversity minimizes the number of species that must be protected as threatened and endangered.

(2) To the greatest extent practicable, installation commanders and Army natural resource planners and managers at all levels will devel op and implement policies and strategies toassist, in cooperation with other landowners, to achieve the foll owing objectives:

(a) Maintenance of viable populations of the nation's native plants and animals throughout their geographic range.

(b) Maintenance of natural genetic variability within and among populations of native species.

(c) Maintenance of functioning representative examples of the full spectrum of ecosystems, biological communities, habitats, and their ecological processes.

(d) Implementation of management solutions which integrate human activities with the conservation of biological diversity.

(e) Increased scientific understanding of biological diversity and conservation.

(f) Public awareness and understanding of biological diversity.

(g) Encouragement of private sector development and application of innovative approaches to the conservation of biological diversity.

Subsection 11-1c is very important in establishing the framework for interpretation of Chapter 11 as a whole. It is particularly significant in terms of regulatory construction. This subsection sets out substantive rather than mere procedural standards for agency conduct, and by focussing on conservation of biological diversity, sets substantive policy at a level well beyond minimal ESA compliance. In preparing any compliance-sensitive action, plan or document under this Chapter, careful reference back to a thorough checklist derived from this subsection, or from a current implementation plan developed for this subsection, would be a prudent quality assurance/regulatory assurance (QA/RA) measure.

\section{1-2. Summary of Primary Endangered Species Act Requirements}

The ESA imposes five primary requirements upon the Army.

a. Requirement to conservelisted species. Section 7(a)(1) of the ESA requires the Army to carry out programs for the conservation of listed species. "Conservation", as defined by the ESA, means the use of all methods and 
procedures that are necessary to bring any listed species to the point where protections provided pursuant to the ESA are no longer necessary. Therefore, the Army has a responsibility to take affirmative measures to increase, as well as to avoid actions likely to jeopardize, listed species. This chapter is theArmy's primary means of implementing theESA requirement to conserve listed species.

Subsection 11-2a reinforces the Army commitment to a strong, affirmative, actionforcing interpretation of the ESA $\S 7(a)(1)$ mandate of conservation, emphasizing improvement in the status of protected species and habitats. Should be read together with $\$ 11-1$, especially $\$ 11-1 c$.

b. Requirement not to "jeopardize" listed species. Section 7(a)(2) of the ESA requires the Army to ensure that any action authorized, funded, or carried out by it is not likely to jeopardize the continued existence of any listed species or result in the destruction or adverse modification of critical habitat. "J eopardize" means to engage in an action that would be expected, directly or indirectly, to reduce appreciably the likelihood of the survival and recovery of a listed species by reducing its reproduction, numbers, or distribution. Irrespective of any opinion, action, or inaction by the USFWS or NMFS, the Army is ultimately responsible for ensuring that its actions do not jeopardize listed species or result in the destruction or adverse modification of critical habitat.

This provision strengthens proactive Army policy by asserting an agency standard of independent Army responsibility not to jeopardize listed species, regardless of regulatory inaction or insufficient action. The clear reading of this subsection is that Army decision-makers should not look to the regulators for excuses for actions contrary to ESA $\S 7$ and Army policy in this chapter.

c. Requirement to "consult" and "confer."

(1) Section 7(a) of theESA requires formal consultation with the USFWS or NMFS whenever the Army anticipates taking any action or is engaging in on-going action that may affect, beneficially or adversely, a listed species or critical habitat. Formal consultation, however, is not required if it is determined by the Army, with the written concurrence of the USFWS or NMFS, that the action is not likely to adversely affect any listed species or critical habitat. Early entry into informal consultation with the USFWS is key to resolving potential problems and establishing the foundation to address issues in a proactive and positive manner and is the preferred method of consultation. Additionally, the Army must confer with the USFWS or NMFS whenever an action is likely to jeopardize any species proposed for listing as threatened or endangered under the ESA 
(proposed species) or to result in the destruction or adverse modification of proposed critical habitat. Informal consultation with the USFWS or NMFS is always appropriate to clarify an action command's ESA responsibilities. Consultation and conference procedures are discussed in para 11-7.

(2) The NMFS has jurisdiction over most marine species. (See section 23a, part 222, title 50, Code of Federal Regulations (50 CFR 222.23(a)) and 50 CFR 227.4 for a listing of species within NMFS jurisdiction.) The USFWS has jurisdiction over all other species.

(3) "Action" is broadly defined in 50 CFR 402.02 to include: measures to conserve listed species or critical habitat; promulgation of plans and regulations; granting of licenses, contracts, leases, easements, rightsof-way, and permits; construction projects; etc.

Subsection 11-2c provides broad guidance about ESA §7 interagency processes whenever listed or proposed species, or listed or proposed critical habitat, may be affected by a proposed action. This provision should be read together with $\S 11-1 \mathrm{~b}$.

d. Requirement to conduct a biological assessment. Section 7(c) of the ESA and the implementing regulations (50 CFR 400.18) require the Army to conduct biological assessments for major construction and other activities having similar physical impacts on the environment if:

(1) the impacts will significantly affect the quality of the human environment as referred to in National Environmental Policy Act of 1969 (NEPA) and

(2) any listed species or critical habitat is present in the area directly or indirectly affected by the action (action area).

Subsection 11-2d explicitly opens the discussion of NEPA compliance by listing two trigger conditions for a Biological Assessment. However, subsections 11-2b and $c$ also trigger ESA actions by consideration of proposed Army actions, and this same NEPA standard (action may have significant impact) will generally be applicable to those actions under $\S 11-2 b$ and $c$. See also $\S 11-4 b$ and $\S 11-5 a(5)$. Also, the two enumerated criteria are NOT separate and independent for the purposes of NEPA analysis; the presence and potential vulnerability of a federally listed species or critical habitat, state listed species or habitat, or, probably, federal or state proposed species or habitat, in an "action area" will probably be sufficient to trigger the NEPA "significant impact" criterion, listed as $\S 11-2 \mathrm{~d}(1)$. This subsection should be read together with \$11-4b, §11-5a(5), §11-6f, §11-7d(1) and other NEPA-related sections, in their regulatory context; NEPA processes should be considered very early whenever TES species or protected habitat are even potentially present and affected. 
e. Requirement not to "take" listed fish and wildlife species or to remove or destroy listed plant species. Under section 9 of the ESA, "take" means to "harass, harm, pursue, hunt, shoot, wound, kill, trap, capture, or collect, or attempt to engage in any such conduct" with respect to listed fish and wildlife. It includes significant habitat modification or degradation that kills or injures wildlife by significantly impairing essential behavioral patterns, including breeding, feeding, or sheltering. Section 9 further makes it unlawful to remove and reduce to possession any listed plant from areas under federal jurisdiction or to maliciously damage or destroy any listed plant in such areas.

This subsection summarizes the ESA $\S 9$ civil and criminal prohibitions applicable to all persons, federal agency employees and civilians. Two points important to Army operations are emphasized, (i) habitat modification or degradation leading to $\S 9$ "takings", and (ii) removal or possession of listed plants from areas under federal jurisdiction, or malicious damage or destruction of listed plants. These reminders do not stand alone in these regulations; in particular, the concept of "malice" should be understood in the broader legal and regulatory context. Often, "malice" is naively conceived as necessarily implying deliberate, highly specific intent. However, neglect and inexcusable ignorance are sometimes also predicate conditions for a judicial finding of malice. In this context, the specific requirements for installation-level UCMJ regulation and criminal enforcement (\$11-3c), comprehensive TES inventories (§11$11)$, awareness programs, $(\S 11-10)$, warning signs (\$11-16), and the general requirements for ESMPs and ESMGs (\$11-5 and $\$ 11-6)$, comprehensive applicability of and compliance with the ESA ( $\$ 11-1 \mathrm{a})$ and biodiversity management $(\S 11-1 \mathrm{c})$, taken together, all militate for highly informed operating conditions measured against Army regulatory standards under which neglect and ignorance will be very difficult to explain or raise as a defense.

\section{1-3. Compliance with the Endangered Species Act}

a. DA personnel who violate the provisions of the ESA or implementing USFWS/NMFS regulations are subject to both civil and criminal penalties. Criminal violations are punishable by a fine up to $\$ 50,000$ and imprisonment of up to one year for each violation. The law imposes civil and criminal penalties for the knowing failure totake required action (such as willful failure to consult with the USFWS or NMFS when legally required) and for the commission of prohibited acts (such as "taking" a listed species). DA personnel are not immune from prosecution. Actions in violation of the ESA or of implementing USFWS/NMFS regulations are not within the scope of the official duties and responsibilities of DA personnel. 
b. Failure to comply with the ESA can result in halting or delaying ongoing or proposed projects and activities. Proponents of Army actions will coordinate with the installation's natural resources staff early in the planning stage of projects and activities to identify potential conflicts with the conservation of listed and proposed species. The installation engineer and theenvironmental directorate, whereapplicable, will integrateendangered species management and installation planning functions to avoid conflicts with ESA requirements.

c. Installations will enforce the protective measures specified in Endangered Species Management Plans (ESMPS) (para 11-5 and 11-6) by the issuance of regulations punishable under the Uniform Code of Military J ustice. Installations will designate and train law enforcement personnel to enforce these regulations.

§11-3 articulates strong compliance policy and an internal enforcement mandate.

\section{1-4. Candidate and state-listed species}

a. Candidate species. Species that are candidates for federal listing as threatened or endangered are not protected under the ESA. Because candidate species may be listed in the future, installations will consider them in making decisions that may affect them. Installations will avoid taking actions that result in the need tolist candidate species as threatened or endangered. Installations are encouraged to develop ESMPs for candidate species and to participate in conservation agreements with the USFWS. Affirmative action to conserve candidate species can preclude the need to list such species. At a minimum, installations will document the distribution of candidate species on the installation and monitor their listing status. Early planning and coordination with the USFWS or NMFS will avoid conflicts with mission requirements and speed development of an ESMP if the species is formally proposed for listing.

The simple conclusion one might draw from the first sentence of this subsection, that candidate species are not protected under the ESA, could lead to serious vulnerability. The thoughtful and extremely important directives in the remainder of the subsection should not be neglected due to a perceived loophole in the ESA blanket of protection for candidate species. See also $\$ 11-5 b(1)$. Keep in mind that USFWS, suffering from severe resource shortages, has been substantially in arrears on final listing packages for hundreds of species. Resultant litigation has placed many of these on court ordered schedules for final processing; similar but highly focused litigation should be anticipated as a significant project- or delay-threatening risk if proposed agency actions could adversely affect candidate species and inadequate protective actions are evident. Such litigation would probably seek 
injunctive relief against the Army, and possibly against USFWS, imposing delays until one or more processes were completed: (i) an expedited ESA listing process, and/or (ii) an ESA biological assessment/opinion process, and/or (iii) completion of appropriate NEPA review, and/or (iv) appropriate protective measures enforceably incorporated in the project plan. Although this subsection does not mention the NEPA issue with respect to protection of and consideration of impacts upon candidate species, these avenues of agency vulnerability should not be forgotten. In the context of this comment, the minimum requirement in this subsection to document TES species distribution is a good example of a low-profile requirement with latent liabilities; failure to comply could constitute significant if not compelling evidence that apparent compliance with other TES species management requirements is suspect, and deserves a judicial "hard look", for example in regard to the proposed species ESMP requirement in $\$ 11-5 b(1)$. This installation ESMP requirement for "proposed" species at $\$ 11-5 b(1)$ would seem to substantially exceed the limited requirements in this section, and may supersede the mere "encouragement" provision in this subsection, potentially raising an internal consistency issue regarding this draft regulation.

b. Statelisted species. Army installations must be sensitive to those species listed as endangered or threatened under statelaw, but not federally listed. State, but not federal, listed species are not protected under the ESA. Whenever feasible, installations should cooperate with state authorities in efforts to conserve these species. There is no requirement for ESMPs for state-listed species. Installations, however, will identify statelisted species in the installation's cooperative plan and set forth agreed conservation measures. Additionally, NEPA normally requires an environmental assessment for activities affecting state-listed species. AR 200-2, para 5-3q.

Again, the potential for ESA or NEPA litigation cannot be overlooked; for example, serious impacts to state listed or candidate species or state sensitive habitats might in some cases generate changes in federal status as well. Additionally, compliance planning that intersects either of these subsections under \$11-4 must consider the general directives under $\$ 11-1 \mathrm{a}, \mathrm{b}$ and $\mathrm{c}$. At the least, a significant presumption may arise that federal candidate and state listed/candidate species are likely indicators of habitats or communities at risk. Such a presumption should be viewed as a QA "hold point", requiring appropriate and affirmative inquiry to prove or disprove this presumption, rather than automatically assuming that it is false until decided otherwise by an outside expert biologist, a federal judge, etc. 


\section{1-5. Endangered Species Management Plan (ESMP) and Guidelines (E SMG)}

§\$11-5 and 11-6 contain relatively thorough, detailed requirements related to ESMPs and ESMGs, including important NEPA interactions and requirements. The following comments on these sections are limited to a few primary points; thorough compliance with the ESMP and ESMG requirements should not be considered inconsequential due to lack of specific attention in these remarks. Bottom line: thorough, conservative compliance with the ESMP and ESMG processes is the heart of Chapter 11.

a. General requirement.

(1) Installations will prepare ESMPs for listed and proposed species and critical habitat present on the installation, including areas used by tenant organizations. Installation ESMPs are the Army's primary means of ensuring ESA compliance and balancing mission requirements. Army endangered species management will givefirst priority to the preparation and resourcing of installation ESMPS, including associated inventories. HQDA and MACOMs will assist installations in obtaining adequate funding and support to effectively devel op and implement ESMPs (refer to paragraph 2-3). Installation commanders will approve ESMPs, as required by this regulation, within one year after the discovery of a listed/proposed species or the proposal for listing a species or proposal for designation of critical habitat, whichever occurs first.

(2) In addition to installation ESMPs, MACOMs will consider preparing a MACOM ESMG for listed and proposed species present on more than one subordinate installation when a species has or could have a significant impact on the installations' ability to support mission requirements. The MACOM will also consider whether limited resources could more effectively be directed toward preparation and resourcing of installation ESMPs. If prepared, the MACOM ESMG will contain guidance to be used by installations in preparing ESMPS (para c below). If the MACOM determines that a MACOM ESMGs are not warranted, the MACOM will, however, issue sufficient written guidance to ensure: unity of effort, a shared research and development program, and the efficient use of MACOM resources.

(3) Where a listed species or proposed species involves more than one MACOM and has the potential to significantly affect Army training or readiness, MACOMs may request that HQDA prepare HQDA ESMGs instead of or in addition to a MACOM ESMGs. MACOMs should forward requests to HQDA, ACSIM, ATTN: DAIM-ED, 600 Army Pentagon, Washington, DC 20310-0600.

(4) HQDA will consider preparing HQDA ESMGs for listed and proposed species present on installations of more than one MACOM 
when it is determined that a species has or could have a significant impact on Army mission requirements. HQDA will also consider whether limited resources could more effectively be directed toward preparation and resourcing of installation ESMPs. If HQDA determines that an HQDA ESMG is not warranted, HQDA will, however, issue sufficient written guidance to ensure: unity of effort, a shared research and development program, and the efficient use of Army resources.

(5) All proposed ESMPs and ESMGs are subject to the requirements of NEPA, in addition to the consultation requirements of $\S 7$ of theESA.

This sub-subsection contains a valuable but easily overlooked reminder of the wide regulatory matrix through which the ESMP or ESMG must pass. While out of the scope of this commentary, it is imperative to keep in mind that these entries into the NEPA universe will have "ripples" throughout the local NEPA constellations; on an installation-by-installation basis, at least, to avoid NEPA deficiencies, the EAs and EISs prepared for other actions must all recognize and incorporate the NEPA processes for that installation's ESMPs and ESMGs. This should in fact facilitate subsequent NEPA processes for new missions and projects by providing established NEPA coverage readily incorporated by reference. However, if an unfamiliar NEPA document preparer should overlook this opportunity, an all-too-frequent occurrence, the resulting NEPA document is vulnerable.

b. Installation ESMPs.

(1) Installations will prepareE SMPs for each listed and proposed species and critical habitat on the installation. They may combine ESMPS, provided the combined plans satisfy the substantive requirements in (3) and (4) below. If feasible, combined ESMPs addressing several species and focusing on management of the supporting ecosystem is encouraged.

(2) Upon approval by the installation commander, the ESMP will be made part of the installation's Integrated Natural Resources Management Plan and the cooperative plan (see paragraph 11-6a) as required by the Sikes Act.

(3) Installation ESMPs will prescribe area specific measures necessary to meet the installations' conservation goals for the subject species and critical habitats. ESMPS will be consistent with MACOM or HQDA ESMGs as applicable, or other MACOM or HQDA guidance on the subject species, unless USFWS or NMFS biological opinions require otherwise. In the latter case, installations will report inconsistencies between MACOM or HQDA guidance and USFWS or NMFS opinions, through MACOM channels, to HQDA, ATTN: DAIM-ED in coordination with The J udge Advocate General (TJ AG, DAJ A-EL). DAIM-ED will expeditiously review such reports and 
determine if HQDA level action is necessary. Installations will not approve ESMPs until this HQDA review is completed.

Before proceeding with $\$ 11-5 b(4)$, the importance $\mathrm{C}$ and the dangers $\mathrm{C}$ of the compliance checklist strategy it contains at \$11-5b(4)(g) must be strongly emphasized. The proposed checklist will be an integral element in the ESMP. A sound checklist, prepared in advance and finalized through reconciliation with the "as built" approved ESMP, can provide the clearest guidance for those tasked with development of the ESMP. It will thus become the best possible auditing tool, whose terms are most likely to be mutually understood between the programmatic staff and the auditors. Uniform practices and overall efficiency both gain, as does consistent, measurable compliance, under favorable management circumstances. From a different perspective, such an auditing tool also becomes the most effective deterrent against noncompliance because it becomes the environmental litigant's best objective yardstick against which to measure the agency's conduct. The development of an annotated checklist for each ESMP tier (installation, MACOM and HQ), should be based upon standardized quality assurance practices, and should provide a uniform, comparable document for all installations, recognizing that certain facilities, missions, and species will have extremely different specific requirements; ultimately, the standardized annotated checklist should systematically assemble and annotate many of the requirements throughout Chapter 11, not just \$11-5 and \$11-6, matching requirements and guidance with successful compliance strategies and techniques. The development process for the standardized annotated ESMP checklist, and the species-specific checklists eventually emerging from the process, offers an extremely valuable opportunity to coordinate with the regulatory agencies, USFWS and NMFS, to achieve a mutually ratified ESMP development and compliance auditing program. See \$11-6a(1), requiring such informal consultation on the installation-level speciesspecific ESMP development process. Finally, the standardized annotated ESMP checklists must be sufficiently comprehensive to include NEPA compliance as well C see $\$ 11-6 f$.

(4) Preparation of ESMPs requires a systematic, step-by-step approach. The species' population size (current and goal), habitat (current and potential), and training and other mission requirements (present and future) must be identified. Detailed evaluation of these factors and their interrelated impacts are required as a first step in the development of ESMPS. Thelength and detail of installation ESMPS are dependent upon the complexity of the management problems associated with the species and its habitat. At a minimum, installation ESMPs will include:

(a) documented survey and inventory information (including maps, written descriptions, GIS data base, etc.) on the species, 
including habitat distribution and the location and size of the installation population;

(b) the installation's conservation goals for the subject species and critical habitat, established in consultation with the USFWS or NMFS;

(c) objective, measurable criteria which, when met, would meet the installation's conservation goals for thelisted species and critical habitat and milestones for achieving the goals;

(d) area specificmanagement prescriptions and actions necessary to meet the installation's conservation goals for the species and critical habitat;

(e) the means to include, as appropriate, ESMP provisions into the installations Integrated Training Area Management (ITAM) program;

(f) an on-going inventory and monitoring plan;

(g) estimates of the time, cost, and personnel needed to carry out those measures needed to achieve the conservation goals; and

(h) a checklist for use by those assessing installation compliance with the ESMP (para 11-6g). The checklist should identify actions, tasks, and steps required to effectively implement the ESMP over its projected life; the objective milestones for achieving conservation goals; and the primary conservation measures specified in the ESMP. Checklists are intended to be the primary tool used in assessing installation compliance with ESMPs. A well-designed checklist will serve as a stand-alone guidefor those conducting theassessment. Noparticular format is required, however, checklists should include a brief narrative explanation for each point on the checklist and a cross-reference to the pertinent ESMP provision.

c. MACOM ESMGs. Thelength and detail of MACOM ESMGs are dependent upon the complexity of the management problems associated with the species and its habitat. At a minimum, MACOM ESMGs will contain guidance to subordinate installations necessary for effective MACOM-wide management of the listed species and critical habitat, avoidance of duplication of effort, uniformity of management practices wherever feasible, efficient use of MACOM resources, and appropriate MACOM coordination and oversight.

d. HQDA ESMGs. The length and detail of HQDA ESMGs are dependent upon the complexity of the management problems associated with the species and its habitat. At a minimum, HQDA ESMGs will contain guidance to Army installations necessary for effective Army-wide management of the listed species and critical habitat, avoidance of 
duplication of effort, uniformity of management practices wherever feasible, efficient use of Army resources, and appropriate HQDA coordination and oversight.

\section{1-6. Preparation and approval of ESMPs and ESMGs}

a. Installation level.

(1) The installation engineer (or environmental directorate where applicable), in coordination with the testing or training directorate and the installation environmental law specialist, is responsible for preparing installation ESMPs. Installations will establish working teams to draft ESMPs. Each team will be comprised of, at a minimum, natural resources personnel, testers or trainers, and the environmental law specialist. The installation engineer will identify and arrange for other installation personnel to advise the team on funding and contracting matters. The team is responsible for complying with NEPA and ESA procedural requirements, including conference and consultation with the USF WS or NMFS, coordination with appropriate state agencies. (State concurrence to the Cooperative Plan is necessary under the Sikes Act (see (5) below)), and preparation of NEPA documentation. The team will informally consult with and receive input from the USFWS or NMFS throughout the ESMP development process. On smaller installations, and government owned contractor operated facilities, where there are inadequate resources to establish a team (e.g., no TJ AG office or natural resources personnel), the responsible installation engineer will coordinate with the MACOM staff for the necessary support.

(2) The installation engineer or environmental director will brief the Environmental Quality Control Committee (EQCC) (see section 2-5 and AR 200-1) on each proposed ESMP and supporting NEPA documentation.

(3) The installation TJ AG will render a written legal opinion stating whether the approval of the ESMP and supporting NEPA documentation will bein accordance with NEPA, ESA, and regulatory requirements before the ESMP is forwarded to the installation commander for approval.

These first three subsections constitute the bulk of the work in developing and validating the installation ESMP, analogous to the other ESMP tiers. Considering the requirements and tasks needed to meet the needs of ESMP preparers and reviewers under these subsections, a thoroughly annotated, standardized checklist for each ESMP tier (there will be great overlap between tiers), designed to be customized for each species or other management level (habitat, community, multi-facility common 
ecosystem) while retaining comparability and inter-auditability, will quickly prove to be the most efficient tool for development and approval of each ESMP.

(4) An ESMP is not effective until it and the supporting NEPA documentation are approved and signed by the installation commander.

(5) Upon approval of the ESMP by the installation commander, the installation engineer will obtain final, formal agreement from the USFWS or NMFS and the state wildlife agency to include the ESMP as part of the cooperative plan (informal agreement should be obtained during the development process). Theinstallation engineer, in coordination with the testing or training directorate, will integrate the ESMP's provisions into ITAM planning and resourcing (para 1112). Installations will revise the installation Real Property Master Plan (RPMP) according to AR 210-20. Installations will forward a copy of the approved ESMP to HQDA, ATTN: DAIM-ED and the MACOM engineer (or staff environmental officer whereappropriate).

(6) The MACOM engineer or MACOM environmental director will review installation ESMPS to monitor compliance with this regulation, identify funding and personnel requirements, and to identify problems that could significantly impact on future mission requirements. Every effort will be made by MACOMs to resolve identified problems and issues. The MACOM will report problems that cannot be resolved to the Office of the Director of E nvironmental Programs (DAIM-ED). The MACOMs will retain copies of ESMPS and will make them available to other installations that could benefit from the completed work.

b. MACOM level. If prepared, the MACOM engineer (or MACOM environmental director), in coordination with the MACOM Deputy Chief of Staff for Operations and Plans (DCSOPS) and the TJ AG, is responsible for the preparation of MACOM ESMGs. MACOMs will establish working teams comprised of, at a minimum, natural resources personnel, military trainers or testers, and an environmental attorney to prepare ESMGs. The team is responsible for complying with NEPA and ESA procedural requirements, including conference and consultation with the USFWS or NMFS and preparation of NEPA documentation. The TJ AG will render a written legal opinion stating whether the approval of a MACOM ESMGs and supporting NEPA documentation will be in accordance with NEPA, ESA, and regulatory requirements. ESMGs will not become effective until approved and signed by the MACOM chief of staff. MACOMs will forward a copy of MACOM ESMGs to HQDA, ATTN: DAIM-ED and to affected subordinate installations. 
c. HQDA level. HQDA, (DAIM-ED), in coordination with DCSOPS (DAMOTRS) and the TJ AG (DAJ A-EL)), is responsible for preparation of HQDA ESMGs. The Director of Environmental Programs will approve HQDA ESMGs. As necessary, the Director of E nvironmental Programs may direct the formation of teams to develop HQDA ESMGs. The teams, at a minimum, will have DAIM-ED, DCSOPS, and DAJ A-EL representation. The teams will operate under the operational control and direction of the Director of Environmental Programs. The team (or, if none is formed, DAIM-ED, in coordination with DAJ A-EL), will consult with the USFWS or NMFS as required by the ESA and prepare supporting NEPA documentation.

d. Coordination outsi de HQDA. Other federal, state, and private lands are important to the survival and recovery of endangered species. Effective conservation will normally depend upon a comprehensiveeffort throughout the species' range. To assist in this effort, installations with listed or proposed species should encourage and support local, regional, and rangewide cooperative agreements for the conservation of these species with other federal, state, and private landowners; conservation organizations; and the USFWS or NMFS. Additionally, these installations will take the lead in promoting conservation efforts on non-Army lands surrounding installations to preclude having to sustain and recover listed species populations entirely on Army lands. Army proponents of ESMPs and ESMGs at all levels should establish and participate in joint task forces with other Department of Defense (DoD) entities to devel op common plans, share information and resources, and avoid duplication of efforts.

It is worth noting here that the integrated design of Chapter 11 ultimately returns to overall conservation and biological diversity considerations.

e. Annual review of ESMPs and ESMGs. Proponents will review their ESMPS or ESMGs annually and update them as required to meet conservation goals. Installations should conduct the annual review of ESMPs concurrently with preparation of the annual installation engineer's or environmental director's ESMP compliance report required by (g) below. Except for minor changes, installations will prepare and approve revisions in the same manner as the ESMPs themselves. Minor changes may be approved by the installation engineer or environmental director, where applicable, after: coordination with the TJ AG and training or testing directorate; informal consultation with the USFWS or NMFS; and coordination with the appropriate state agency. Minor changes include only those changes that will have no effect (considered together with all previous minor changes to the current ESMP), beneficial or adverse, on 
listed or proposed species or critical habitat. The cooperative plan will be amended to reflect minor changes at least every two years.

f. NEPA compliance

(1) NEPA, implemented by AR 200-2, applies to actions taken in managing listed and proposed species and critical habitats. Consultation under section 7 of the ESA does not replace compliance with NEPA requirements. In preparing and staffing ESMPs, proponents must ensure that they satisfy NEPA requirements. Proponents will normally prepare environmental assessments for activities, including developing ESMPS and ESMGs, that affect federal or state listed or proposed species, or critical or proposed critical habitat (para 5-2q, AR 200-2). NEPA requires an environmental impact statement if an ESMP or ESMGs will significantly affect a listed or proposed species, critical habitat or proposed critical habitat, or the human environment (See para 6-2, AR 200-2). To avoid unnecessary delay, proponents should provide complete NEPA documentation for early inclusion with recommendations or reports on ESMPs and ESMGs.

(2) Consultation, conference, and biological assessment procedures under section 7 of the ESA should be consolidated with NEPA procedures to the maximum extent feasible. Simultaneous compliance with NEPA and ESA procedures minimizes duplication of effort and avoi ds delay. Proponents may combine ESA and NEPA documentation to reduce paperwork (such as the biological assessment and environmental assessment) so long as the requirements of both statutes are met. Generally, an installation should determine the effect of a proposed action on listed species or critical habitat in accordance with ESA section 7 before completing NEPA documentation. Proponents will not avoid consultation with the USFWS or NMFS to facilitate completion of NEPA documentation.

An extremely important section, with pervasive ramifications for compliance efforts for all other requirements under this Chapter, throughout draft AR 420-74, and the NEPA implementation regulations at AR 200-2, currently being revised. The importance of careful, in-depth planning with respect to this section cannot be adequately emphasized.

g. Monitoring compliancewith and effectiveness of ESMPs. Installations will use the following means to monitor compliance with and the effectiveness of ESMPS. Those conducting assessments will, at a minimum, use the checklist contained in each ESMP (para 11-5b(4)(h)).

(1) Assessments. Installations will ensure that external and internal environmental audits, conducted according to para 12-8, AR 200-1, 
thoroughly assess compliance with, progress under, and the effectiveness of ESMPs. Prior to commencing assessments, the installation engineer or environmental director will provide assessment teams with ESMP checklists and explain their use and purpose.

Note the reappearance of the ESMP checklist in a pivotal role; imagine the difficulties associated with auditing based upon nonstandardized ESMP checklists. EPA's longtime failure to standardize document format and contents for CERCLA (Superfund) documentation (RI/FS, RODs, etc) led to several major critiques of that agency by GAO, the courts, Congress, and others.

(2) Annual review.

(a) During the fourth quarter of each calendar year, theinstallation engineer or environmental director will make a written report to the installation commander. The report will be reviewed by the installation TJ AG and the EQCC before it is sent to the installation commander.

(b) The report specified in (a) above shall include information on: the status of listed and proposed species and their habitats on the installation, progress toward completion of any incomplete ESMPS, progress toward installation conservation goals, actions taken to implement ESMPs, contacts with theUSFWS or NMFS, ESA violations, problem areas, compliance with MACOM and HQDA guidance, changes to ESMPs, and any other information necessary for reviewers to make an independent assessment of installation compliance with and the effectiveness of ESMPs in balancing conservation with other mission requirements. If the report concludes that the installation is not in full compliance with the ESMP or the ESMP is not effective in meeting installation goals, thereport will enumeratethe deficiencies and contain recommendations for resolving the deficiencies.

(c) Installation commanders will approve and sign annual ESMP reports. Installations will forward approved reports to the MACOM for review and approval. Reports must be received by the MACOM by 31 December.

(d) If an installation is not in full compliance with an ESMP, the ESMP is not effective in meeting the installation's goals, or another endangered species management problem is indicated, the MACOM will coordinate with HQDA (DAI M-ED), and other organizations, as necessary, to devel op an effective solution.

\section{1-7. F ormal consultation and conference procedures}


§11-7 sets out detailed compliance guidance, with substantial references cited for further regulatory guidance. Careful compliance with the formal requirements under this section should not lead to neglect of the wider mandate under this chapter to establish long-term, cooperative and informal relations with the regulatory agencies.

a. Requirements.

(1) Formal consultation.

(a) F ormal consultation under section 7(a)(2) of the ESA is a formal procedure that takes place between the USFWS or NMFS and another federal agency. (Seefig. 11-1). 50 CF R part 402 sets out detailed consultation procedures. The process begins with a written request to the USFWS or NMFS to initiate formal consultation. The process results in the issuance of a biological opinion by the USFWS or NMFS to the agency. Written requests for consultation must contain the information required by 50 CFR 402.14(c), including the biological assessment, if prepared, and other relevant materials, such as environmental impact statement or environmental assessment.

(b) Installations must review all activities at the earliest opportunity to determine whether any action may affect listed species or critical habitat. This review must be conducted on an on-going basis by all action proponents, commanders, installation engineers, and environmental directorates. The installation commander is ultimately responsible for ensuring that this requirement is met. "Action" includes virtually all activities (see glossary). If the installation decides that a proposed action "may affect" a listed species or critical habitat, it must formally consult with the NMFS or USFWS. If, however, the installation decides that an action is not likely to adversely affect the listed species or its habitat, and the USFWS or NMFS concurs in writing, formal consultation is not required. Without the written concurrence of the USFWS or NMFS, consultation is mandatory.

(2) Conference. Installations must confer with the USFWS or NMFS on any action that is likely to jeopardize the continued existence of any proposed species or result in the destruction or adverse modification of proposed critical habitat. Conference procedures are designed to help the action proponent in identifying and resolving potential conflicts before the species is listed or critical habitat is designated. Upon listing of a species or designation of critical habitat, installations must review proposed actions to determine if formal consultation is necessary even if a conference has occurred. The conference process usually consists of informal discussions resulting in advisory recommendations from the USFWS or NMFS. The 
proponent may request, however, that the conference be conducted as a formal consultation. If the USFWS or NMFS consents, formal conference is conducted according to the procedures for formal consultation. If conducted formally, the USFWS or NMFS may adopt the opinion issued at the conclusion of the conference as the biological opinion when the species is listed or critical habitat is designated (e(4) below). Installations may use informal consultation and/or a biological assessment to decide if a conference is required. A biological assessment is not required for proposed species. $50 \mathrm{CFR}$ part 402.10 sets out detailed conference procedures.

(3) Commitment of resources pending completion of formal consultation. For proposed actions that may require formal consultation, action proponents will make no irreversible or irretrievable commitment of resources that will forecl osetheformulation or implementation of any reasonable and prudent alternative before completion of formal consultation or the written concurrence of USFWS or NMFS that it is not required.

(4) Conducting consultation and conference. Except for ESMPs (Seepara 11-6(a)(1) above), consultation (formal and informal) and conference with the USFWS or NMFS on installation actions will be conducted by the installation engineer or environmental directorate, in coordination with the training or testing directorate, and the environmental law specialist. Technical assistance will be available from MACOMs and HQDA (DAIM-ED and DAJ A-EL).

b. Notice of initiation of formal consultation.

(1) Installations will coordinate with the MACOM in conducting biological assessments and informal consultation preliminary to initiating formal consultation. Before initiating formal consultation, installations will forward through MACOM channels a summary of the proposed action and all of the documents they intend to submit to the USFWS or NMFS (e.g., biological assessment, biological evaluation) to HQDA (DAIM-ED). DAIM-ED, in coordination with DAJ A-EL, will review proposals for formal consultation and supporting documents and provide comments.

(2) MACOMs will coordinate with DAIM-ED before initiating formal consultation on MACOM ESMGs.

C. The "may affect" determination.

(1) Informal consultation with the USFWS or NMFS and a biological assessment or biological evaluation will be used in assessing whether an action may affect a listed species or critical habitat. The presence of a listed species in the area directly or indirectly affected by the action (action area) will normally result in a "may affect" 
determination. When a listed species or critical habitat is present in the action area, a "no affect" determination should be made only if the USFWS or NMFS concurs through informal consultation. Installations will document USFWS or NMFS concurrence. A "may affect" determination does not necessarily mean that the installation will receive a jeopardy biological opinion.

(2) Installations should engagein informal consultation with the USFWS or NMFS at the earliest opportunity to assess the effects of Army actions and decide the need for formal consultation. Even when the installation makes a "may affect" determination, continued informal consultation may be productive. Modifications agreed to through informal consultation may avoid the need for formal consultation.

(3) A biological assessment is required for major construction proposals or other activities that may have an impact on the environment where a listed species or critical habitat is present in the action area ( $d$ below). Even if not legally required, a biological assessment is a good way to assess the impact of an action on listed or proposed species and critical habitat and present the Army's scientific case supporting its determination. Installations should prepare a biological assessment for all actions that may result in formal consultation. If a biological assessment is not required, installations should prepare a written biological evaluation at a minimum documenting its determination of the effect or no effect of an action on listed species and critical habitat. Biological evaluations should set forth the biologically supportable rationale for the installation's determination.

(4) It is the responsibility of the Army to provide the USFWS or NMFS with the most current and the best scientific and commercial data available during the consultation process. If reasonably available data are not provided for formulation of a biological opinion, the USFWS or NMFS can request that the agency obtain available data, that more studies or surveys be undertaken at the Army's expense, or that the Army await the results of relevant non-Army studies.

(5) Biological assessments should include the following information:

(a) The results of an on-site inspection of the action area to discover if listed or proposed species are present or occur seasonally.

(b) The views of recognized experts on the subject species and its habitat.

(c) A review of the literature and other information on the species and its habitat.

(d) An analysis of the effects of the action on the species and habitat, including consideration of cumulative effects, and the results of any related studies. "Cumulative effects" under the 
ESA include those future, nonfederal (state, local, or private) activities that are reasonably certain to occur in the action area.

(e) Coordination/mitigation measures that will reduce/eliminate adverse impacts to listed or proposed species.

(f) A determination of whether the action is "likely to adversely affect" or "not likely to adversely affect" listed species.

(g) For proposed species, a determination of whether the action "is likely to jeopardize" or "is not likely to jeopardize" the continued existence of proposed species.

(h) A determination of whether the action is likely to result in the destruction or adverse modification of a critical habitat or a proposed critical habitat.

(i) An analysis of alternative actions considered by the action proponent.

d. Major activities.

(1) For major construction activities or other activities having similar physical impacts on the environment, where the impacts will significantly affect the quality of the human environment as referred to in NEPA, theESA requires installations to request concurrence on a submitted list of proposed and listed species and proposed and designated critical habitat that may be present in the action area or to request such a list from the USFWS or NMFS. The USFWS and NMFS have 30 days in which to concur with the submitted list or provide the requested list.

(2) If a listed species or critical habitat may be present in the action area, installations must begin a biological assessment within 90 days of receipt of the list to avoid having to reverify the species list with the USFWS or NMFS before commencing the biological assessment. Installations must complete the biological assessment with a determination of effect within 180 days unless a different period is agreed to by the USFWS or NMFS.

(3) If the installation determines that a listed species or its habitat does not occur or have the potential to occur in the action area and the USFWS or NMFS concurs in the determination, a biological assessment is not required and the consultation process ends.

(4) If a proposed species or proposed critical habitat occurs or has the potential to occur in the action area, the installation must confer with the USFWS or NMFS if the action is likely to jeopardize the continued existence of any proposed species or result in the destruction or adverse modification of proposed critical habitat $(\mathrm{a}(2)$ above). A biological assessment, however, is not required if only proposed species or habitat are present, unless the listing or designation becomes final. While not required, installations are 
encouraged to complete biological assessments for proposed species and habitats.

(5) Once the biological assessment process begins, the installation may not enter into any contract for construction or begin construction before it completes the biological assessment and, if required, formal consultation.

(6) Installations must submit the completed biological assessment to the USFWS or NMFS for review. The USFWS or NMFS must provide a written response within 30 days, concurring or nonconcurring in the findings of the biological assessment. Installations have the option of initiating formal consultation concurrently with thesubmission of the assessment.

e. Biological opinion.

(1) Theresult of formal consultation is a biological opinion of theUSFWS or NMFS on whether the proposed action is likely to result in jeopardy to the continued existence of the species and/or will result in destruction or adverse modification of critical habitat.

(2) A jeopardy biological opinion includes reasonable and prudent alternatives, if any are available. Reasonable and prudent alternatives are actions identified during formal consultation that will avoid jeopardy to listed species or destruction of critical habitat. Thealternatives must be consistent with the purpose of the proposed action and capable of implementation by the installation. Proposed actions cannot proceed after a jeopardy or adverse modification biological opinion except in accordance with any reasonable and prudent alternative contained therein. Installations will coordinate with the USFWS or NMFS during formal consultation to assist with the development of reasonable and prudent alternatives.

(3) Biological opinions will contain an incidental take statement if the USFWS or NMFS concludes that the agency action (or the implementation of any reasonable and prudent alternatives) and the anticipated incidental takeitself, if any, will not violatesection 7(a)(2) of theESA. Incidental take refers to takings that result from, but are not the purpose of, carrying out an otherwise lawful activity conducted by the action agency. If the USFWS or NMFS anticipates take, the statement will include nondiscretionary reasonable and prudent measures that the installation must undertake to minimize incidental take. If the installation proceeds in compliance with the terms and conditions of the incidental take statement, then a resulting incidental take is not a violation of section 9 of the ESA.

(4) The USFWS or NMFS may issue a conference report in response to a request for a formal conference regarding a proposed species or proposed critical habitat. In such cases, the USFWS or NMFS may 
adopt the conference report as the biological opinion when the proposed species is listed or critical habitat is designated, if the project and the status of the species or habitat have not changed in the interim.

(5) With the biological opinion, the USFWS or NMFS may provide discretionary conservation recommendations, with a request for notification of their accomplishment. Installations will carry out such recommendations unless the installation determines, in coordination with HQDA (DAIM-ED) that the conservation recommendations are not feasible. If found not feasible, installations will notify the USFWS or NMFS of the decision and the reasons.

(6) If the USFWS or NMFS issues a jeopardy or adverse modification biological opinion, the installation must notify, through MACOM channels, HQDA DAIM-ED and DAJ A-EL within five days and forward copies of the opinion. Unless changed through further consultation with the USFWS or NMFS, the installation will comply with the reasonableand prudent alternatives and thereasonableand prudent measures (with the related terms and conditions) in the biological opinion. Theinstallation must notify theUSFWS or NMFS of its final decision on the action.

f. Reinitiation of formal consultation. Formal consultation must be reinitiated under the following circumstances:

(1) the amount or extent of taking specified in the incidental take statement is exceeded;

(2) new information reveals effects of the action that may affect listed species or critical habitat in a way or to an extent not previously considered;

(3) the identified action is subsequently modified in a way that causes an effect to a listed species or critical habitat that was not considered in the biological opinion; or

(4) a new species is listed or critical habitat is designated that the action may affect.

\section{1-8. Recovery plans and proposed designation of critical habitat}

a. Recovery plans devel oped by the USFWS and NMFS guide the USF WS and NMFS in consultations with other agencies under section 7 of the ESA. The Army should actively participate in the devel opment of recovery plans, whenever possible, to ensure that the USFWS or NMFS and the recovery teams appointed by the USFWS or NMFS know and consider Army interests. For listed species present on Army installations, the Army should make a request to the USFWS or N MFS to provide for Army representation on recovery teams. For recovery plans affecting only one MACOM, except 
as provided in b below, the MACOM will coordinate Army participation in the development process and the submission of formal comments to the draft recovery plan. For recovery plans affecting more than one MACOM, HQDA (DAIM-ED) will coordinateArmy participation and official comment. Installations and MACOMs will coordinate with DAIM-ED before officially commenting on draft recovery plans.

b. In cases where DAIM-ED determines that a proposed recovery plan may significantly affect Army interests, it will coordinate Army participation in the development process and the submission of formal comments to the draft recovery plan.

c. The USFWS and NMFS must consider economic and other relevant impacts, such as impacts on military training and testing, in designating critical habitat. Potentially affected installations should work closely with USFWS and NMFS during the designation process to ensure that these services understand mission requirements and minimize mission impacts. Installations will coordinate formal comments on proposed designation of critical habitat with MACOM and DAIM-ED.

As recommended in this section, early and thorough participation in Recovery Plan development is highly advantageous to the Army, both in terms of achieving informed and balanced regulatory agency decisions, and in terms of establishing long-term credibility with those regulators. This interaction on Recovery Plans should be integrated with ESMP development and associated NEPA processes wherever possible.

11-9. Notice of ESA violations. Installations will immediately report, by telephone or electronic means, through MACOM channels to HQDA (DAIM-ED and DAJ A-EL), any violation or suspected violation of the ESA. A written report will be made within seven days. Violations include failure to formally consult or preparea biological assessment as required by theESA, taking of listed species, etc. Written reports will include:

(1) a detailed factual summary of the violation(s) or suspected violation(s);

(2) copies of any relevant correspondence from the USFWS or NMFS; and

(3) a summary of any command actions taken in response to the violation(s) or suspected violation(s).

Installations will coordinate with theMACOM and HQDA (DAI M-ED and DAJ A-E $L$ in taking final action to correct any endangered species management problems contributing to the ESA violation(s). 
11-10. Awareness training program. On installations with listed species or critical habitat, training and testing directorates, in coordination with the installation engineer (or environmental directorate where appropriate), will establish a mandatory, ongoing training program for personnel who may have contact with listed species or their habitats. Testing directorates are responsible for ensuring that users of test ranges receive appropriate awareness training. Specific requirements for training and implementation are to be identified in the ESMP. The training will, at a minimum, cover the following topics:

(1) identification of listed species and markings that identify restricted areas;

(2) actions necessary to avoid injury to listed species and their habitat;

(3) the pertinent requirements of the ESA and applicable regulations;

(4) the importance of protecting listed species and biological diversity; and

(5) the Army policy that mission accomplishment must be consistent with the conservation of listed species and critical habitats (para 11-1a).

Installations are encouraged to use films, videos, posters, and other training aids as part of these programs. Installations should involve the USFWS or NMFS regional and field offices in the development and implementation of training programs.

The lack of mention of candidate and state sensitive species in this section suggests multiple authors and some consistency problems with this draft regulation. Awareness programs should probably cover this wider assemblage of species under the same rationale expressed in $\$ 11-4$ and $\$ 11-5 a$.

11-11. Inventory of plants and wildlife. Identifying and documenting the location of listed, proposed, and candidate species on an installation is crucial to effectively balancing mission and conservation requirements. Failure to properly inventory listed and proposed species can lead to violation of the ESA and costly disruption of military operations and construction activities upon discovery of such species. Installations will conduct initial, thorough inventories of plants, fish, wildlife, and habitat types on installation lands, using scientifically accepted methodology. I nstallations will conduct a 100 percent inventory of suitable habitat for listed, proposed, and category 1 candidate species that may occur on the installation. Prior to conducting inventories, installations will coordinate with the USFWS and 
NMFS for guidance on appropriate field survey methodology and individuals and organizations qualified to conduct surveys. Inventories are to be conducted at least every ten years, or sooner, if required by ESMPs. Records of inventory data will be maintained permanently.

The importance of this section is discussed in comments under various sections elsewhere.

\section{1-12. Integrated Training Area Management (ITAM) Program}

a. ITAM is the primary Army program for balancing land use for military training and testing with natural resources conservation requirements, including the protection of listed species and critical habitats. The program provides the technical foundation to integrate these competing requirements. Effective implementation of ITAM requires close coordination and cooperation between the installation engineer (or environmental directoratewhereappropriate) and the training/ testing directorate.

b. If ITAM is implemented on theinstallation, upon approval of an installation ESMP, the installation engineer, in coordination with the training/testing directorate, will integratethe ESMP's protective and conservation measures into ITAM planning and resourcing. Thetraining/testing directoratewill consider ITAM generated data in scheduling and authorizing training/testing activities.

11-13. F unding. Endangered species management projects are funded through environmental channels and are included in the RCS1383 reporting process. The reporting and funding guidance for these projects is issued by HQDA (DAIM-ED).

11-14. Reintroduction and introduction of listed, proposed, and candidate species The Army will support the reintroduction and introduction of federal and state listed, proposed, and candidate species on Army lands unless reintroduction/introduction will have a significant impact on the present or future ability of the Army to meet its mission requirements. Proposals for reintroduction/introduction on Army lands will not be approved or disapproved without a thorough assessment, of the impact of reintroduction/introduction on the environment and mission requirements and the potential benefits 
of reintroduction/introduction. The latter assessment may be integrated with required NEPA documentation. Prior to approving or disapproving proposals for reintroduction/ introduction, installations must coordinate with the MACOM and HQDA (DAIM-ED).

11-15. Water rights. Installations with listed, proposed, or candidate aquatic species will determine the ownership of water rights necessary for the survival and recovery of these species. To the extent feasible, installation ESMPs will provide for the protection of water rights necessary to meet these needs. Water rights necessary to sustain aquatic species are commonly governed by the state. Installations should not rely solely on federal water rights to protect aquatic species. Where state water rights are necessary to meet installation conservation goals for listed, proposed, and candidate species, installation commanders should consider asserting water rights for their protection. All water rights issues will be coordinated with the environmental law specialist.

11-16. Warning signs. Warning signs for listed, proposed, and candidate species and their habitat will conform to the following specifications. Signs will be constructed of durable material, ten inches square (oriented as a diamond), yellow or white in color, and of the design in fig 11-2. The graphic depicting the species, the lettering "E ndangered Species Site" and the species name will be printed in black. The lettering "Do Not Disturb" and "Restricted Activity" will be printed in red. All lettering will be3/8 inches in height. 


\section{USACERL DISTRIBUTION}

Chief of Engineers

ATTN: CEHEC-IM-LH (2)

ATTN: CEHEC-IM-LP (2)

ATTN: CECC-R

ATTN: CERD-L

ATTN: CERD-M (2)

ACS(IM)

ATTN: DAIM-ED-R 20310

Army Training Support Center (2) ATTN: ATIC-CTS 23602-5166

ODASN(E\&l) 20350

ODCSOPS

ATTN: DAMO-TRO 20310-0400 ATTN: DAMO-TRS

DA-Env. Programs Directorate ATTN: NGB-ILE-EC 22204-1382 ATTN: NGB-ARE-C

HQ, USAF

ATTN: CEVP 20330-1260

HQ US Army, Pacific

ATTN: APEN-E 96858-5100

HQ USARCOM 30331-5099

ATTN: AFRC-ENP-NC

ATTN: AFRC-ENS-E

HQ AFCEE/ECR 78235-5363

HQ, AF Operations Support Div. ATTN: AF/X00A 20330-1480

HQ, Marine Corps 20380

HQ, USAG, Fort Pickett 23824 ATTN: AFRC-FMP-PW

Engineer Waterways Experiment Stn. ATTN: CEWES-ER-W 39180

Military Traffic Command ATTN: MTPAL-FE

USAADACENFB 79916-0058 ATTN: Cultural/Natural Resources

USARMC (ISA)

ATTN: AMXEN-M

ATTN: AMXEN-U (2)

USAMCCOM 61299-6000 ATTN: AMSMC-EQC

USAMEDCOM 79234-6020 ATTN: MCFA-E

USDA Nat. Res. Cons. Service Colby, KS 67701
U.S. Army Space and Strategic Def. Cmd. ATTN: CSSD-EN-V 35807-3801

U.S. Army Engineering \& Support Ctr. ATTN: CEHNC-ED-S 35816-1822

U.S. Env. Protection Agency 20460

U.S. Fish and Wildlife Service Fort Snelling, MN 55111-4056

Anchorage, AK 99505

Denver, CO 80225

Hadley, MA 01035-9589

Portland, OR 97323-4181

Manhattan, KS 66503

Atlanta, GA 30345

Austin, TX 86858-5100

Washington, DC 20240 (2)

Albuquerque, NM

ATTN: Ecological Services 87113

ATTN: Off. of Endangered Sp 87103

USFS

Corvallis, OR 97331

Flagstaff, AZ 86011 (2)

Fort Collins, CO 80526-2098

USMA 10996-1592

ATTN: MAEN-ED

HQ FORSCOM

ATTN: AFPI-ENE 30330-6000

ATTN: AFOP-TE

HQ TRADOC

ATTN: ATBO-FN 23651-5000

ATTN: ATBO-SE 23651

ODUSD (ES) 22202

OASD Policy Division 22202

Holloman AFB, NM 88330-8458 ATTN: 49 CES/CEV

Fort Bragg, NC 28307-5000 ATTN: AFZA-PW-DS

Fort Lee, VA 23801-1705 ATTN: ATSZ-LSE

Fort Stewart, GA 30427 ATTN: AFZP-DEV-W ATTN: STEWS-NRES-E

Yuma Proving Ground 85365-9107 ATTN: STEYP-ES-C

Military District of Washington ATTN: ANEN-ES 20319-5050

USAEC
White Sands Missile Range 88002
ATTN: SFIM-AEC-ECM ATTN: SFIM-AEC-ECN (2) ATTN: SFIM-AEC-EC

U.S. Bureau of Land Management 20240

SERDP Program Office 22203 (2)

Defense Tech Info Center 22304 ATTN: DTIC-O (2)

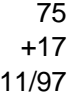

$11 / 97$ 